Florida International University FIU Digital Commons

$11-14-2017$

\title{
Effect of Ultrasonic Treatment on the
} microstructure and mechanical properties of Al6061 and composite

Ana S. Exime

Florida International University, aexim001@fiu.edu

DOI: $10.25148 /$ etd.FIDC004032

Follow this and additional works at: https:// digitalcommons.fiu.edu/etd

Part of the Engineering Mechanics Commons, Mechanical Engineering Commons, Mechanics of Materials Commons, and the Metallurgy Commons

\section{Recommended Citation}

Exime, Ana S., "Effect of Ultrasonic Treatment on the microstructure and mechanical properties of Al6061 and composite" (2017). FIU Electronic Theses and Dissertations. 3534.

https://digitalcommons.fiu.edu/etd/3534 


\section{FLORIDA INTERNATIONAL UNIVERSITY}

Miami, Florida

\section{EFFECT OF ULTRASONIC TREATMENT ON THE MICROSTRUCTURE AND MECHANICAL PROPERTIES OF AL 6061 ALLOY AND COMPOSITES}

A thesis submitted in partial fulfillment of the requirements for the degree of

MASTER OF SCIENCE

in

MATERIALS SCIENCE AND ENGINEERING

by

Ana Exime 
To: Dean John L. Volakis

College of Engineering and Computing

This thesis, written by Ana Exime, and entitled Effect of Ultrasonic Treatment on the Microstructure and Mechanical Properties of Al 6061 and Composites, having been approved in respect to style and intellectual content, is referred to you for judgment.

We have read this thesis and recommend that it be approved.

Norman Munroe

Benjamin Boesl

Arvind Agarwal, Major Professor

Date of Defense: November 14, 2017

The thesis of Ana Exime is approved.

Dean John L. Volakis College of Engineering and Computing

Andrés G. Gil

Vice President for Research and Economic Development and Dean of the University Graduate School

Florida International University, 2017 


\section{DEDICATION}

I dedicate this thesis to my family. My mom Nancy, my dad David, my brother David, my sister Karla and my two nephews Victor and Anabella, without your love and support accomplish this goal would be impossible. All of you are my inspiration to be better every day. 


\section{ACKNOWLEDGMENTS}

I would like to thank my advisors, Dr. Arvind Agarwal and Dr. Benjamin Boesl for their patience, support, and guidance. I'll always be thankful to you for giving me the opportunity to work with you. I would also like to thank my committee member Dr. Norman Munroe for his helpful suggestions.

I would like to extend my thanks to all PFL members. Special thanks to Jenniffer Bustillos, Dr. Cheng Zhang, Melania Antillon, Luiza da Fontura and Pranjal Nautiyal for all your guidance, help, support and friendship during the preparation of this thesis. For this past year and a half working in the PFL group, all of you have become more than coworkers for me, and I am so glad that I had the opportunity to meet all of you.

Most importantly, I'd like to thank my family and friends that support me since the first day I came to FIU. I'm thankful to my parents for always supporting me and encouraging me to follow my dreams. My brother David and my sister Karla, who motivated me to pursue my master's degree. I would also like to thank to Nohelis Montano, Mauricio Trigo, Viviana Ojeda y Alberto Pernas our friendship has kept us together for years since we were in Venezuela, thanks for been here for me when I needed help and support. 


\author{
ABSTRACT OF THE THESIS \\ EFFECT OF ULTRASONIC TREATMENT ON THE MICROSTRUCTURE AND \\ MECHANICAL PROPERTIES OF AL 6061 ALLOY AND COMPOSITES \\ by \\ Ana Exime \\ Florida International University, 2017 \\ Miami, Florida \\ Professor Arvind Agarwal, Co-Major Professor \\ Professor Benjamin Boesl, Co-Major Professor
}

In this study, the effect of ultrasonic treatment (UST) parameters such as amplitude, sonication time, and melt temperature on microstructure and microhardness of Al 6061 alloy is evaluated. The effect of UST on the dispersion of tungsten disulfide $\left(\mathrm{WS}_{2}\right)$ and carbon nanotubes (CNT) as reinforcement particles in Al 6061 during casting is also studied. The cast Al 6061 with UST demonstrated 32\% grain size reduction and 8\% increase in the microhardness for optimum processing conditions. The cavitation process induced by UST is responsible for the refinement in microstructure and increase of hardness by enhancing the degassing and nucleation process. UST treated $6061 \mathrm{Al}$ alloy demonstrated Hall-Petch relationship for all processing conditions. The UST process also aids in excellent dispersion of $\mathrm{WS}_{2}$ and $\mathrm{CNT}$ as reinforcement particles. UST treated $\mathrm{WS}_{2}$ and CNT reinforced Al 6061 composites displayed improved wear resistance as compared to samples without cavitation. 


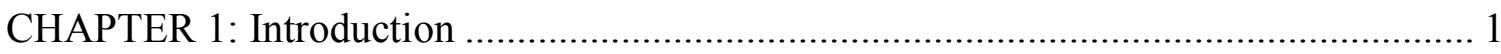

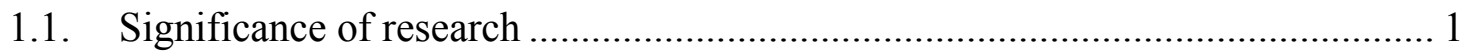

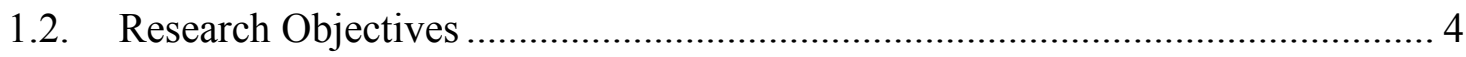

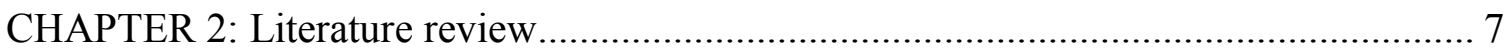

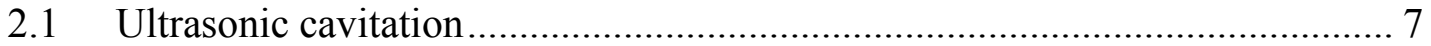

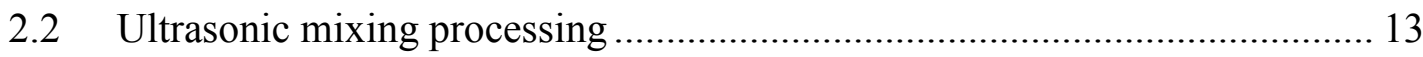

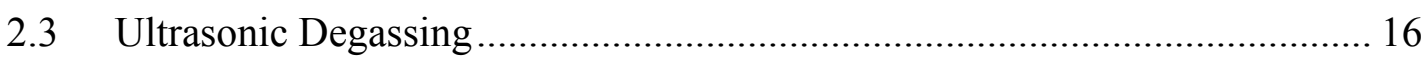

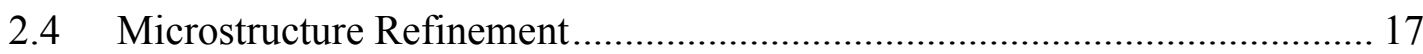

2.5 Addition and dispersion of reinforcements particles to Aluminum, .............. 22

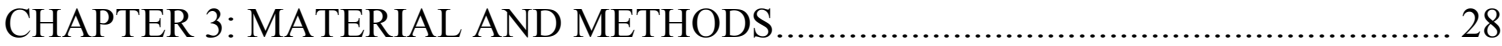

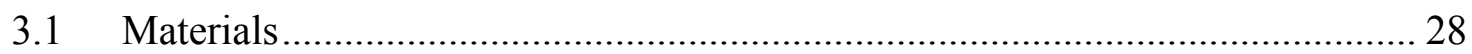

3.2 Experimental Set-up \& Procedure ............................................................ 30

3.3 Structural and Microstructural Characterization ………………………….... 34

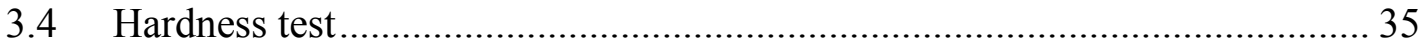

3.5 Evaluation of Tribological Behavior ....................................................... 35

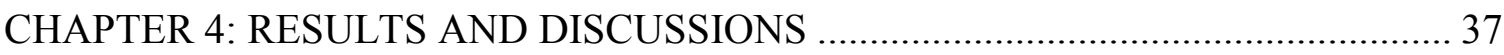

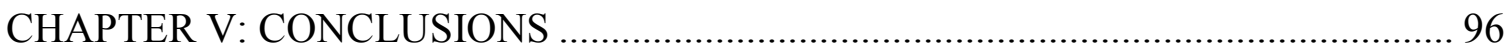

CHAPTER VI: RECOMMENDATIONS AND FUTURE WORK ………………….....98

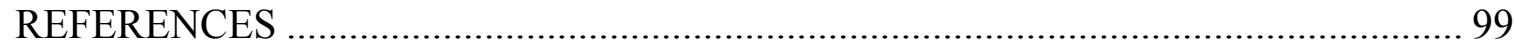




\section{LIST OF TABLES}

TABLE

PAGE

Table 2. 1 Ultrasonic treatment and outcomes of different metals.............................. 12

Table 2. 2 MMC manufactured by the addition of UST to the casting process. .............. 26

Table 3. 1 Chemical composition of Aluminum 6061 alloy ........................ 28

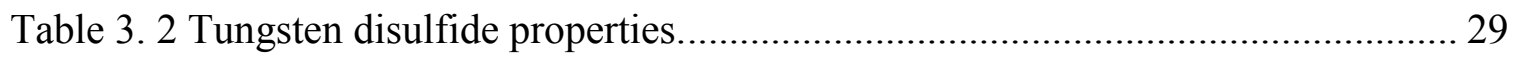

Table 3. 3 Processing Parameters for Ultrasonic Treatment of Al 6061 alloy ................ 32

Table 4. 1 Variation of ultrasound intensity and sound pressure with UST parameters.. 37

Table 4. 2 Porosity measurements as a function of UST parameters ............................ 40

Table 4. 3 Complied results of grain size measurements as a function of UST parameters (Time, amplitude and temperature).

Table 4. 4 Complied results of micro hardness as a function of UST parameters (Time, amplitude and temperature)

Table 4. 5 Porosity measurements of Al-1wt. \% $\mathrm{WS}_{2}$ as a function of ultrasonic treatment

Table 4. 6 Grain size measurements of Al-1wt. \% $\mathrm{WS}_{2}$ as a function of ultrasonic treatment 69

Table 4. 7 Micro hardness of Al-1wt. \% $\mathrm{WS}_{2}$ as a function of ultrasonic treatment ........ 76

Table 4. 8 Porosity measurements of Al-0.15wt. \% CNT as a function of ultrasonic treatment 83

Table 4. 9 Grain size measurements of Al-0.15wt. \% CNT as a function of ultrasonic treatment 85

Table 4. 10 Micro hardness of Al-0.15wt. \% CNT as a function of ultrasonic treatment 90 


\section{LIST OF FIGURES}

\section{FIGURE}

Figure 2. 1 Schematic presentation of acoustic cavitation yielding energy release

Figure 2. 2 Schematic of ultrasonic equipment. (1) Ultrasonic power Supply, (2)

Converter, (3) Waveguide, (4) Sonotrode.

Figure 2. 3 Schematic of ultrasonic degassing. (1) Formation of cavities, (2) growth of cavities due to the diffusion of $\mathrm{H} 2$ from the melt, (3) the migration of large cavities to the surface of the melt.

Figure 2. 4 (1) Resulting microstructure without UST, (2) Representation of added nuclei sites in the microstructure, (3) Resulting microstructure after introduction of UST in the melt

Figure 2. 5 (A) Microstructure of pure metal, (B) microstructure of an alloy and (C) microstructure of a metal after UST . 21

Figure 2. 6 Schematic diagram showing strength as a function of grain size 22

Figure 2. 7 Schematic of the dispersion of particles by the addition of UST to the casting process .

Figure 3. 1 SEM Images of the reinforcements: (A) Low magnification image of asreceived $\mathrm{WS}_{2}$ and (B) High magnification image of as-received CNTs

Figure 3. 2 (A) Schematic of the set-up, (B) real set-up. 31

Figure 3. 3 Schematic of sample preparation and UST for manufacture of MMC 33

Figure 4. 1 Porosity measurements as a function of sonication time for $700^{\circ} \mathrm{C}$ and $750^{\circ} \mathrm{C}$ melting temperature, (A) 20 micron sonication amplitude, (B) 13 micron sonication amplitude.

Figure 4. 2 X-ray diffraction patterns. (A) Al6061 $750^{\circ} \mathrm{C}$ melting temperature no UST, (B) $750^{\circ} \mathrm{C}$ melting temperature with UST

Figure 4. 3 X-ray diffraction patterns. (A) Al6061 $700^{\circ} \mathrm{C}$ melting temperature no UST, (B) $700^{\circ} \mathrm{C}$ melting temperature with UST 
Figure 4. 4 Optical images of the microstructure of Al6061 melting temperature of $750^{\circ} \mathrm{C}$, amplitude of UST $13 \mu \mathrm{m}$, (A) 0 seconds, (B) 5 seconds, (C) 30 seconds, (D) 45 Seconds

Figure 4. 5 Optical images of the microstructure of Al6061 melting temperature of $750^{\circ} \mathrm{C}$, amplitude of UST $20 \mu \mathrm{m}$, (A) 0 seconds, (B) 5 seconds, (C) 30 seconds, (D) 45 Seconds

Figure 4. 6 Optical images of the microstructure of Al6061 melting temperature of $700^{\circ} \mathrm{C}$, amplitude of UST $13 \mu \mathrm{m}$, (A) 0 seconds, (B) 5 seconds, (C) 30 seconds, (D) 45 Seconds.

Figure 4. 7 Optical images of the microstructure of Al6061 melting temperature of $700^{\circ} \mathrm{C}$

Figure 4. 8 Comparison in the microstructure of cast at $700^{\circ} \mathrm{C} \mathrm{A16061} \mathrm{with} \mathrm{and}$ without UST by sections.

Figure 4. 9 Grain size distribution Al6061 $750^{\circ} \mathrm{C}$ melting temperature, 13 micron sonication amplitude as a function of sonication time, (A) 0 seconds UST, (B) 5 seconds UST, (C) 30 seconds UST, (D) 45 seconds UST.

Figure 4. 10 Grain size measurement for cast $\mathrm{A} 16061,750^{\circ} \mathrm{C}$ melting temperature 13 micron amplitude as a function of sonication time.

Figure 4. 11 Grain size distribution Al6061 $750^{\circ} \mathrm{C}$ melting temperature, 20 micron sonication amplitude as a function of sonication time, (A) 0 seconds UST, (B) 5 seconds UST, (C) 30 seconds UST, (D) 45 seconds UST.

Figure 4. 12 Grain size measurement for cast A16061, $750^{\circ} \mathrm{C}$ melting temperature 20 micron amplitude as a function of sonication time.

Figure 4. 13 Grain size distribution $\mathrm{A} 16061700^{\circ} \mathrm{C}$ melting temperature, 13 micron sonication amplitude as a function of sonication time, (A) 0 seconds UST, (B) 5 seconds UST, (C) 30 seconds UST, (D) 45 seconds UST.

Figure 4. 14 Grain size measurement for cast A16061, $700^{\circ} \mathrm{C}$ melting temperature 13 micron amplitude as a function of sonication time.

Figure 4. 15 Grain size distribution Al6061 $700^{\circ} \mathrm{C}$ melting temperature, 20 micron sonication amplitude as a function of sonication time, (A) 0 seconds UST, (B) 5 seconds UST, (C) 30 seconds UST, (D) 45 seconds UST 55

Figure 4. 16 Grain size measurement for cast A16061, $700^{\circ} \mathrm{C}$ melting temperature 20 micron amplitude as a function of sonication time. 
Figure 4. 17 Grain size measurements as a function of UST parameters (Time, amplitude and temperature)

Figure 4. 18 SEM of fracture surface of Al 6061 with $20 \mu \mathrm{m}$ UST amplitude,(A) $750{ }^{\circ} \mathrm{C}$ melting temperature without UST (B) $750{ }^{\circ} \mathrm{C}$ melting temperature with 45 Seconds UST, (C) $700{ }^{\circ} \mathrm{C}$ melting temperature without UST (D) $700^{\circ} \mathrm{C}$ melting temperature with 45 Seconds UST.

Figure 4. 19 SEM \& EDS of fracture surface of Al $6061750{ }^{\circ} \mathrm{C}$ melting temperature without UST.

Figure 4. 20 Micro hardness as a function of UST parameters (Time, amplitude and temperature).

Figure 4. 21 Hall-Petch relationship at $700{ }^{\circ} \mathrm{C}$ melting temperature for $13 \mu \mathrm{m}$ and $20 \mu \mathrm{m}$ sonication amplitude.

Figure 4. 22 Hall-Petch relationship at $750{ }^{\circ} \mathrm{C}$ melting temperature for $13 \mu \mathrm{m}$ and $20 \mu \mathrm{m}$ sonication amplitude.

Figure 4. $23 \mathrm{X}$-ray diffraction patterns. (A) Al-1wt. \% WS 2 with and without UST, (B) slow scan Al-1wt. \% WS 2 without UST, (C) Al-1wt. \% $\mathrm{WS}_{2}$ with UST.

Figure 4. 24 Optical microstructure, (A) Al6061 with UST, (b) Al-1wt. \% $\mathrm{WS}_{2}$ without UST, (C) Al-1wt. \%WS 2 with UST.

Figure 4. 25 Comparison of grain size measurements of Al 6061 with UST and Al-1wt. $\% \mathrm{WS}_{2}$ with and without UST.

Figure 4. 26 Backscattering and SEM of Al-1wt. \% WS 2 fracture surface without UST

Figure 4. 27 Backscattering and SEM of Al-1wt. \% WS 2 fracture surface with UST .... 73

Figure 4. 28 SEM images of fracture surface of Al-1wt. \% WS, (A) Without UST, (B) With UST.

Figure 4. 29 EDS mapping of fracture surface Al-1wt. \% $\mathrm{WS}_{2}$ without UST 74

Figure 4. 30 EDS spectrum of Al-1wt. \% $\mathrm{WS}_{2}$ without UST. 74

Figure 4. 31 EDS mapping of fracture surface Al-1wt. \% WS $\mathrm{W}_{2}$ with UST.................... 75

Figure 4. 32 EDS spectrum of Al-1wt. \% WS 2 with UST .......................................... 75

Figure 4. 33 Comparison of microhardness of Al 6061 with UST and Al-1wt. \% WS with and without UST. 
Figure 4. 34 3D optical profiles of wear track of cast $\mathrm{A} 16061$ at $700^{\circ} \mathrm{C}$

Figure 4. 35 3D optical profiles of wear tracks of Al-1wt. \% $\mathrm{WS}_{2}$ with and without UST

Figure 4. 36 Coefficient of friction for Al-1wt. \% $\mathrm{WS}_{2}$ with and without UST 80

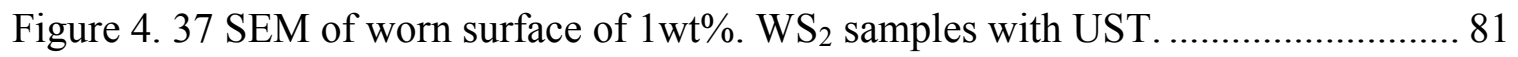

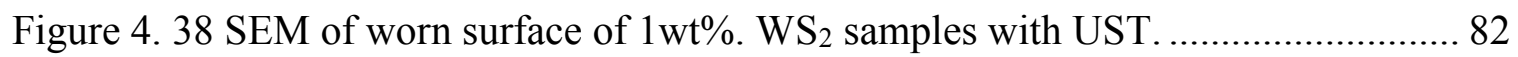

Figure 4. 39 SEM of worn surface of $1 \mathrm{wt} \%$. WS 2 samples without UST...................... 82

Figure 4. 40 Optical microstructure, (A) Al6061 with UST, (b) Al-015wt. \% CNT without UST, (C) Al-0.15wt. \%CNT with UST. 84

Figure 4. 41 Comparison of grain size measurements of Al 6061 with UST and Al0.15 wt. \% CNT with and without UST. 86

Figure 4. 42 Backscattering and SEM of Al-0.15wt. \% CNT fracture surface without UST 87

Figure 4. 43 EDS mapping of fracture surface Al-0.15wt. \% CNT without UST........... 88

Figure 4. 44 EDS spectrum of Al-0.15wt. \% CNT without UST ................................. 88

Figure 4. 45 Backscattering and SEM of Al-0.15wt. \% CNT fracture surface with UST

Figure 4. 46 Comparison of microhardness of Al 6061 with UST and Al-0.15wt. \% CNT with and without UST.

Figure 4. 47 3D optical profiles of wear tracks of Al-.015wt. \% CNT with and without UST

Figure 4. 48 Coefficient of friction for Al-0.15wt. \% CNT with and without UST 93

Figure 4. 49 SEM of worn surface of Al-0.15 wt. \% CNT (A) with UST, (B) without UST. 


\section{CHAPTER 1: Introduction}

The main objective of this study is to understand the effects of ultrasonic treatment and its parameters (i.e. amplitude, sonication time, and temperature of the melt) on the resultant microstructure of Al 6061 alloy. This research will focus on performing a parametric study of the ultrasonic treatment process to obtain optimal processing conditions for highest hardness and finest grain size in Al 6061 alloy. The second objective is the dispersion of micron size particles in Al 6061 alloy using ultrasonic treatment to obtain metal matrix composites (MMC). The uniform dispersion of micron size particles in the metal matrix by casting method is still a major challenge [1]. In the present work, the introduction of ultrasonic treatment to the casting process of pure Al6061 and its composites has two major goals:

(i) improvement of the mechanical properties of the material by introducing cavitation mechanisms, and

(ii) providing a uniform distribution of micro particles for the development of metal matrix composites.

Tungsten disulfide $\left(\mathrm{WS}_{2}\right)$ and Carbon nanotubes (CNT), are known to serve as a solidlubricant with excellent wear resistance in MMC. Thus, $\mathrm{WS}_{2}$ and CNT are selected as additive to $6061 \mathrm{Al}$ alloy via ultrasonic cavitation.

\subsection{Significance of research}

A16061 is one of the most widely used aluminum alloys in industrial and structural applications due to its physical and mechanical properties [2, 3]. Advantageous properties 
of Al6061 such as low density, excellent wear resistance and corrosion resistance makes it suitable for aircraft and aerospace components, automobile and military industries [4-7]. However, the fact that the strength of aluminum is much lower than other metals such as steel limits its applications [5]. In order to overcome this limitation, grain refinement is one of the basic method to improve the mechanical properties. This correlation is mathematically expressed by Hall Petch's relationship as shown in equation 1

$$
H=H_{O}+K_{h} D^{-1 / 2}
$$

where $\mathrm{H}$ is the hardness of the material, $\mathrm{Ho}$ is the resistances for dislocation movement, $\mathrm{K}_{\mathrm{h}}$ is the strengthening coefficient and D is grain size in the microstructure [8]. In order to improve the hardness and yield strength of A16061, thermal, chemical and mechanical methods have been implemented during the casting process [9-12]. Chemical method, is a widely used technique which consists of the addition of grain size refiners (impurities) to the melt. However, the use of grain size refiners is limited to some alloys, and its addition could result in the contamination of the melt. These impurities will decreases the performance of the cast metal [13-15]. To overcome these challenges, thermal and mechanical methods have been introduced to the casting processes. These methods could include control of the cooling rate, mechanical/magnetic stirring and ultrasonic treatments [9-12].

The addition of ultrasonic treatment (UST) to the casting process has proven to result in the elimination of columnar dendritic structures, which are detrimental to the mechanical properties of the material $[2,11]$. Dendritic structures act as stress concentrations and can be considered defects in the microstructure. UST promote the formation of globular grains, the grain refinement and uniform distribution of grains in the microstructure. 
One of the major contributions of the present work is the enhancement of mechanical properties of Al6061 by understanding the effects of the UST parameters (i.e. amplitude, sonication time, melt temperature) on the resultant microstructure and the dispersion of micro particles during solidification. A few studies have briefly investigated the effects of UST on Al6061 [16, 17]. However, parametric studies on the influence of UST parameters on the casting process of A16061 have never been studied and reported in the literature.

The introduction of particles in the micron and nano scale to the aluminum matrix, such as Aluminum oxide $\left(\mathrm{Al}_{2} \mathrm{O}_{3}\right)$, Silicon carbide $(\mathrm{SiC})$, Boron Carbide $\left(\mathrm{B}_{4} \mathrm{C}\right)$ and Carbon nanotubes CNT [18-22], have demonstrated significant potential to develop composites with low density, enhanced mechanical strength and remarkable wear and abrasion resistances [20]. As a result, their processing has been extensively studied for aerospace, automobile and military defense applications [23]. Currently, processing techniques to manufacture aluminum matrix composites include the casting of the metal matrix and the subsequent introduction of micron and nano particles into the melt, followed by vigorous stirring for effective dispersion. However, the agglomeration of micro and nano sized particles due to their high surface energy presents a challenge to the conventional casting methods [18]. Thus, the introduction of ultrasonic cavitation provides a great alternative for the dispersion of fine particles in the molten metal. Several studies have reported that vibration-induced cavitation in the melt would be beneficial in the development of metal matrix composites $[23,24]$. The strong energy released during the ultrasonic cavitation is capable of dispersing micro particle agglomerations during the casting of composites, which subsequently improves the wettability between the reinforcement and the matrix $[17,23,24]$. 
Tungsten disulphide $\left(\mathrm{WS}_{2}\right)$, a two dimensional layered material has exhibited a great potential as a reinforcement in aluminum alloy to serve as solid lubricant with enhanced wear resistance. Previous work by our group has demonstrated that the addition of 2 vol. $\%$ of $\mathrm{WS}_{2}$ in the aluminum matrix would result in $54 \%$ enhanced wear resistance as compared with pure aluminum [25]. This is attributed to the formation of tribochemical film in the worn surface and weak van der Waals interactions [25]. The main processing method for these composites is done via the powder metallurgy route [26, 27]. However, the defects generated during powder metallurgy processing are detrimental to the mechanical and tribological properties of the resulting composite [20].

Carbon Nanotubes (CNT) exhibit properties such as high elastic modulus and tensile strength and high thermal and electrical conductivity which makes them ideal to be used as reinforcement for MMC. However, the dispersion of CNTs is always a challenge due to the Van der Waals forces and poor wettability of CNT with metals [21]. In the previous work by Yan et al., aluminum alloy (A356) with CNTs was fabricated by high intensity ultrasonic processing, resulting in an increase in the microhardness, ultimate tensile strength and yield strength by, $27.8 \%, 17 \%$, and $29.2 \%$ respectively, as compared with the cast sample without CNTs [22]. Therefore, the introduction of UST will allow the uniform dispersion of the aforementioned particles in the metal matrix, minimizing excessive defects during casting.

\section{2. $\quad$ Research Objectives}

The overall objectives of this work are to improve the mechanical properties of Al6061 by the introduction of ultrasonic treatment during casting process and the implementation of ultrasonic treatment as a dispersion technique for the development of composites. 
The following reveals the approaches taken to meet the objective:

- Parametric studies are carried out in order to determine the influence of ultrasonic processing parameters on the microstructure and mechanical properties of 6061 aluminum. This is achieved by studying:

- Variation in the ultrasonic amplitude: Amplitude has a direct relationship with the intensity of cavitation. The intensity of the cavitation will determine the amount of cavities collapsing during the cavitation process creating nuclei sites. Therefore, any change on amplitude will decrease or increase the amount of nuclei sites created, affecting the refinement of the microstructure.

○ Variation of duration of ultrasonic treatment: Ultrasonic treatment duration will determinate for how long the cavitation will be induced in the melt. Increasing the duration of the UST process will result in a larger amount of cavities collapsed, generating more nuclei sites for solidification.

- Variation in the temperature of the melt during ultrasonic treatment: Temperature of the melt has an effect on the intensity of cavitation. The speed of sound travels faster in viscous and solid media. Therefore, at temperatures closer to melting point of the material will result in higher speed of sound. Speed of sound has a direct relationship with the intensity of cavitation. Therefore, any change on the speed of sound will decrease or increase the intensity of cavitation.

The processing parameters are labeled "optimum" for the conditions resulting in finest grain size, highest hardness and least porosity. Optimal processing parameters for 
ultrasonic treatment were used to achieve the second objective of this study, which is the Effective dispersion of reinforcement particles during the casting of 6061 aluminum for the creation of metal matrix composites.

The organization of this thesis is as following. Chapter 2 will present a review of Al6061 alloy, ultrasonic treatment on molten metals, influences of variation of processing parameters and addition of micro particles. Chapter 3 discusses the materials and experimental methods used to study the influences of ultrasonic treatment on the microstructure of Al6061. Addition of micro particles for the creation of composites will also be described. Chapter 4 presents the experimental results and the discussion of the underlying science of the ultrasonic treatment. Chapter 5 presents the major conclusion of this work. Chapter 6 suggests recommendations for the further research in this area. 


\section{CHAPTER 2: Literature review}

This chapter will present a literature review of: (i) the fundamentals and physics of ultrasonic treatment, and (ii) previous studies of ultrasonic treatment of molten metals and manufacturing of metal matrix composites.

\subsection{Ultrasonic cavitation}

The first study on the application of mechanical vibrations and ultrasonic vibrations in the molten metals started in the 1870 s, by Chernov [28]. His research introduces the concept of dynamic solidification, which improves the quality of cast metals by inducing vibrations during the solidification process. Since then, extensive research has been done based on the dynamic solidification as a result of the addition of ultrasonic vibrations into molten metal [29].

The introduction of ultrasonic vibrations to the casting process, also known as ultrasonic treatment (UST), induces acoustic waves $(17-20 \mathrm{kHz})$ to the molten metals. The acoustic waves promote the compression and expansion of micro-bubbles, resulting in acoustic cavitation [30]. The acoustic cavitation is believed to be beneficial to the grain refinement by introducing a higher nucleation rate, reducing the porosity and aiding in the homogenization of the melt $[31,32]$. The ramification of UST on enhancing the mechanical properties of the cast metal relies on the parameters such as melt temperature, amplitude and frequency of the wave, sonication time and power of the treatment $[33,34]$. Ultrasonic treatment is also known to enhance the wettability between the metal matrix and the reinforced micro particles allowing to create a more uniform distribution of micro particles [35]. Hence, UST - induced dispersion has a great potential of replacing the conventional 
powder metallurgy route of synthesizing metal matrix micro composites that involve inevitable defects during sintering process.

\subsubsection{Acoustic cavitation in liquid metals}

The cavitation in liquid metals has been studied by several researchers for the past years. First experimental study was performed on transparent media to understand the cavitation mechanisms in liquids. Observed cavitation mechanisms served to create possible analogies for non-transparent liquids like molten aluminum [13]. Acoustic spectrum of different liquid environments such as water, glycerin and molten aluminum have been reported in the literature [36]. Tzanakis et al. reported the acoustic spectrum of molten aluminum as being comparable with water, establishing that both of them share the same dynamic and fluid behavior [37]. In a similar manner, Eskin et al. in 2005 and Xu et

al. in 1998 demonstrated behavior of acoustic spectrum of water and molten aluminum respectively $[38,39]$.

Acoustic waves are generated by the introduction of high frequency vibrations inside the molten metal. The propagation of such waves causes an increase in pressure inside the molten metal, also known as sound pressure. The acoustic cavitation appears once the sound pressure exceeds the cavitation threshold in the molten metal. The cavitation process consists an intense cyclic formation, growth and collapse of microcavities inside molten metal. $[13,27,40]$. The cavitation threshold $\left(P_{A}\right)$ is a measure of the cavitation capability of the melt and can be estimated by measuring the sound spectrum and intensity. It is mathematically expressed as:

$$
P_{A}=\sqrt{\frac{2 W_{a} \rho_{o} c_{o}}{S}}
$$


Where $\mathrm{W}_{\mathrm{a}}$ is the acoustic power, $\rho_{o} c_{o}$ refers to the acoustic impedance of the precavitation liquid, and $\mathrm{S}$ is the sonotrode face area.

During the cavitation process, the cavities collapse after 2 - 3 cycles, generating nuclei of degassing and solidification as well as new bubbles to continue the cavitation process as shown in Figure 2.1. In the process of bubbles collapsing, the release of energy generates a local increases of temperature up to $1000{ }^{\circ} \mathrm{C}$ and pressures of $10.000 \mathrm{MPa}$ [41]. Three types of cavities are present in the melt during the cavitation process: (i) cavities that are full of gas and will only oscillate with the frequency applied, (ii) cavities that grow due to the diffusion of $\mathrm{H}_{2}$ gas dissolved in the melt, and (iii) cavities that are not fully filled of gas. Cavities of type (iii) will contribute to the cavitation process, collapsing after a compression and expansion cycle due to the effect of the acoustic waves [42].

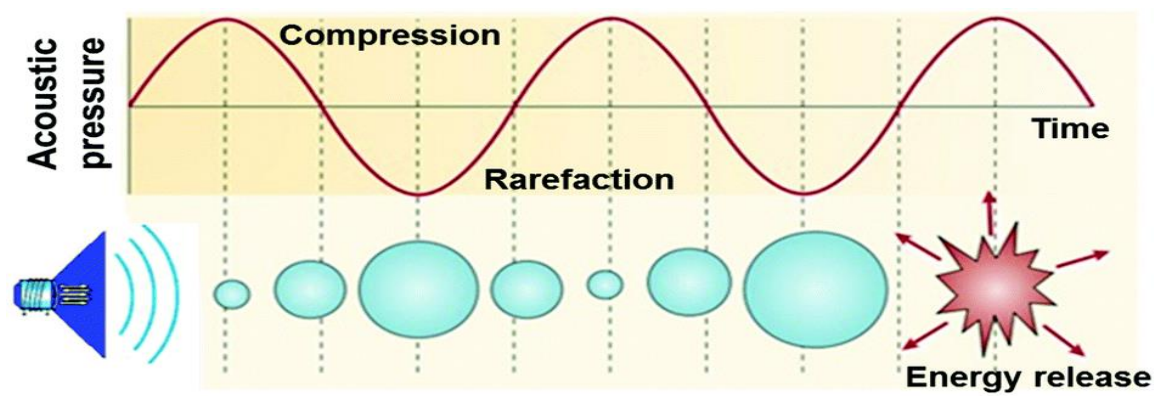

Figure 2. 1 Schematic presentation of acoustic cavitation yielding energy release [41]

\subsubsection{Mechanism of acoustic cavitation and propagation of acoustic waves.}

The cavitation process in a molten metal is related to the wave propagation, length and intensity of the acoustic waves. The wave propagation is affected by the characteristics of the media where they are traveling: temperature, viscosity and density. Acoustic waves propagated in longitudinal direction make the liquid phase experience alternative regions of compression and expansion. 
The length $(\lambda)$ and intensity $(I)$ of the acoustic wave can be estimated from equations (3) and (4) respectively

$I=\frac{1}{2} \rho c(2 \pi f A)^{2}$

$\lambda=c / f$

Where, $\rho$ is the density of the liquid metal, c represents the velocity of the wave propagating, $f$ is the frequency, and $\mathrm{A}$ is the amplitude. Intensity $(I)$ and wave length $(\lambda)$ depend on the density of the melt and the velocity of the wave propagating which are affected by the temperature of the melt. This behavior is expressed by the following expressions:

$C=4730-0.16\left(T-T_{m}\right)$

$\rho_{(T)}=\rho_{(m)}-k\left(T-T_{m}\right)$

Where, $\mathrm{T}$ is the processing temperature, $T_{m}$ the melting point of the material, similarly in Equation (6), $\rho_{(m)}$ is the density at the melting point and $k$ is the thermal conductivity of the material.

In addition, losses in oscillation energy will be experienced by the ultrasonic waves during their propagation through the melt. The intensity and the amplitude of an ultrasonic wave decreases exponentially with the propagation distance and this relationship can be related by equation (7) and (8) respectively:

$I=I_{0} e^{-2 k x}$

Eq. (7)

$A=A_{0} e^{-k x}$ 
Where, $I_{0}$ and $A_{0}$ are the initial values of intensity and amplitude of the sonication source, $\mathrm{k}$ is the thermal conductivity of the melt, and $\mathrm{x}$ is the distance from the sonication source. These mathematical relationships allow a clear comparison of the influence of UST parameters such as temperature, amplitude and sonication time on the resulting cavitation in the molten metal, which in turn will affect the microstructure. An increase in the amplitude of the UST creates larger number of collapsing micro-bubbles and subsequently, more numbers of solidification nuclei and refined grains.

\subsubsection{Effect of ultrasonic cavitation on mechanical properties}

Is well know that the acoustic cavitation developed by UST is beneficial to the mechanical properties of the material. Previous studies demonstrated that ultrasonic cavitation in molten metals result in grain refinement, reduction of columnar grain structures, homogenization of the microstructure and reduction in the porosity $[17,18]$

The effects of UST on the enhanced mechanical properties are twofold:

(i) The numerous cavities formed due to the agitation from UST can serve as nucleation sites for solidification. Nucleation sites prevent the formation of dendritic structures which are detrimental to the mechanical properties [13, 43].

(ii) The excess amount of nucleation sites result in a refined microstructure with smaller grains after solidification.

Aluminum and magnesium alloys are the most studied materials for metallurgical application of UST due to the multiple industrial applications of these materials [17, 44]. Chen et al. reported significant (65\%) grain refinement in magnesium alloy after applying 
UST for 600 seconds during the casting process [44]. In a separate study, Eskin et al. reported $50 \%$ grain size reduction and the formation of non-dendritic structures in aluminum- silicon alloy by introduction of UST to the casting process [45]. Matsuda et al. and Jian et al. also grain refinement fragmentation of columnar structures and homogenization of the microstructures in aluminum alloys with the addition of UST [46, 47]. Table 2.1 summarizes effect of ultrasonic treatment on aluminum and magnesium alloys.

Table 2. 1 Ultrasonic treatment and outcomes of different metals.

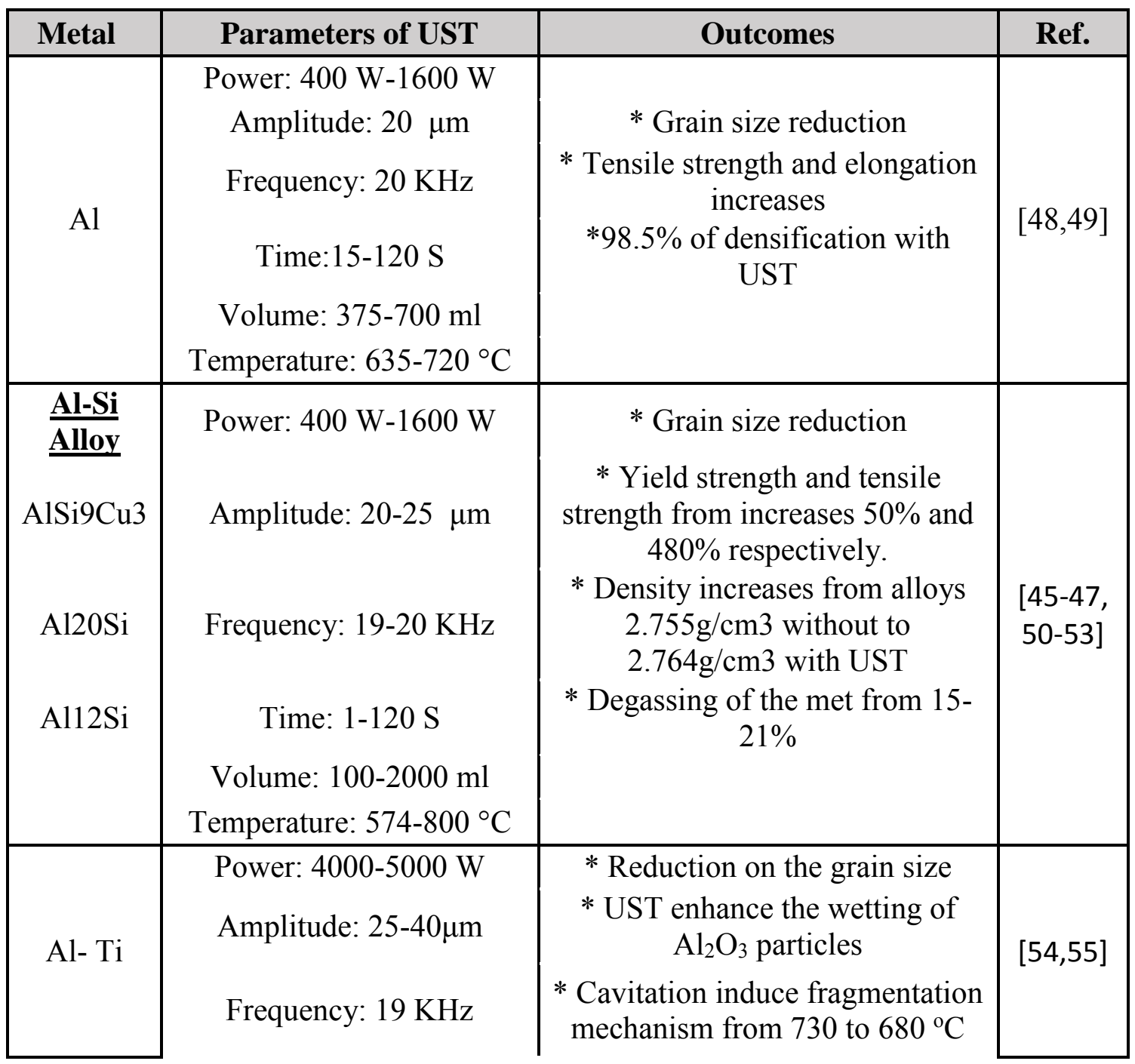




\begin{tabular}{|c|c|c|c|}
\hline & $\begin{array}{c}\text { Time: } \mathrm{N} / \mathrm{S} \\
\text { Volume: } 520 \mathrm{ml} \\
\text { Temperature: } 690-810^{\circ} \mathrm{C}\end{array}$ & & \\
\hline $\begin{array}{l}\text { Al-Mg } \\
\text { Alloys }\end{array}$ & $\begin{array}{c}\text { Power: } 100-360 \mathrm{~W} \\
\text { Amplitude: } \mathrm{N} / \mathrm{S} \mu \mathrm{m} \\
\text { Frequency: } 20 \mathrm{KHz} \\
\text { Time: } 10-300 \mathrm{~S} \\
\text { Volume: } 520 \mathrm{ml} \\
\text { Temperature: } 640-850{ }^{\circ} \mathrm{C}\end{array}$ & $\begin{array}{c}* \text { Average grain sizes were } \\
\text { refined by UST. Reduction of } \\
\text { grain size of approximated } 15 \% \\
* \text { Hardness of } 117 \pm 3.2 \text { HV with } \\
30 \mathrm{~S} \text { of UST }\end{array}$ & {$[56,57]$} \\
\hline $\begin{array}{c}\mathrm{Mg} \\
\text { Alloys }\end{array}$ & $\begin{array}{l}\text { Power: } 600-1000 \mathrm{~W} \\
\text { Amplitude: } \mathrm{N} / \mathrm{S} \mu \mathrm{m} \\
\text { Frequency: } 20 \mathrm{KHz} \\
\text { Time: } 30-600 \mathrm{~S} \\
\text { Volume: } 430-3000 \mathrm{ml} \\
\text { Temperature: } 650-680^{\circ} \mathrm{C}\end{array}$ & $\begin{array}{c}* \text { Average grain sizes were } \\
\text { refined by UST. } \\
* \text { Dendritic fragmentation. } \\
* \text { Equivalent diameter of } \mathrm{Mg} \\
\text { phases decreases from } 125 \text { to } 98 \\
\text { nm with UST } \\
\text { * Tensile strength and elongation } \\
\text { increases from } 30 \% \text { and } 67 \% \\
\text { respectively }\end{array}$ & $\begin{array}{c}{[44,58-} \\
60]\end{array}$ \\
\hline
\end{tabular}

\subsection{Ultrasonic mixing processing}

Ultrasonic processing in the molten metals consists introduction of ultrasonic waves, usually with frequencies below the human range of hearing. Ultrasound sources, also called transducers were initially designed for low temperature applications up to $480^{\circ} \mathrm{C}$. At the moment, several companies such as Reltec (Russia), Alfalina (Russia) and Sonic Vibracell (USA), manufacture transducers for high temperature applications between $675^{\circ} \mathrm{C}-775^{\circ} \mathrm{C}$. However, these transducers are limited to their applications, as they require the addition of a cooling system for the transducer and small range of 
frequency to work [13]. The efficiency of ultrasonic mixing processing is related to the characteristic of the ultrasound equipment used.

\subsubsection{Ultrasonic equipment}

The ultrasonic equipment is usually conformed by an ultrasonic power supply that converts the voltage into electrical energy (converter). This alternating voltage is applied to piezoelectric systems within the converter, generating vibrations due to the change of polarity. This longitudinal vibrations are passed to the probe to be amplified and consequently transmitted to the melt [61], as shown in figure 2.2 .

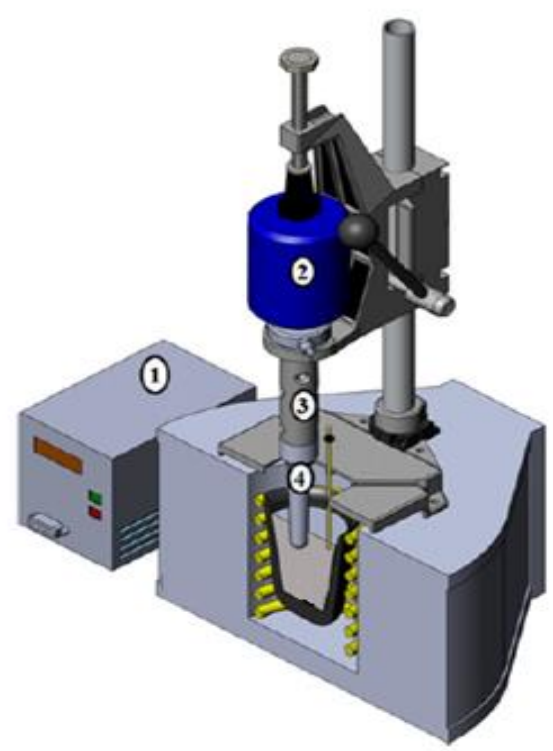

Figure 2. 2 Schematic of ultrasonic equipment. (1) Ultrasonic power Supply, (2) Converter, (3) Waveguide, (4) Sonotrode [54].

Equipment with different specifications have been used in previous studies [50-60] to introduce ultrasonic treatment in molten metals. Chen et al. studied the effect of ultrasonic treatment on the microstructural and mechanical properties of cast magnesium with an 
ultrasonic system that comprised of generator of $1 \mathrm{~kW}$ of power integrated with two watercooling transducers. The probe was made of titanium with a $20 \mathrm{~mm}$ dimeter and $245 \mathrm{~mm}$ in length [44]. Forn et al. reported the use of a $2.5 \mathrm{~kW}$ power generator with a frequency of $20 \mathrm{kHz}$ and a Titanium alloy probe to study the effect of ultrasound on the solidification process of an aluminum alloy [62]. Tzanakis et al. reported the use of an ultrasonic equipment with a $5 \mathrm{~kW}$ generator, with a water cooler transducer and a $20 \mathrm{~mm}$ niobium probe for the characterization of the ultrasonic acoustic spectrum and pressure field in aluminum melt [37].

\subsubsection{Waveguide and Sonotrode}

The system involving transmittance of the vibration from the transducer to the melt is integrated by a waveguide, a booster and the sonotrode. These components need to be designed in such a way that all of them resonate at the same frequency of the transducer and achieve the required amplitude. To assure that each of the element's wavelength and sonotrode will be in resonance with the frequency of the transducer each element is required to have the length equal to half of the wavelength of the wave that is propagating in the melt [13].

Ultrasonic sonotrodes, sometimes referred as probes or horns, are one half wavelength long tools that amplified and transmit to the melt the vibrations generated by the converter. The sonotrode is specially designed to resonate at a specific frequency. The dimensions of the sonotrode is the most important characteristic to ensure the correct operation. Sonotrodes are typically fabricated from titanium alloy (TI-6Al-4V) or niobium, due to its resistances to cavitation erosion, low toxicity, resistance to corrosion and high tensile 
strength. For high temperature applications titanium and niobium are the best options because of the higher melting point of them [61]. In addition, sonotrodes are fabricated in different shapes and diameters. Conical, cylindrical and disc are me most common ones.

\subsection{Ultrasonic Degassing}

The degassing process is related to the concentration of the gas dissolved in the molten metal. The concentration of gas dissolved is usually affected by the temperature of the melt, vapor pressure and limit solubility. Hydrogen is one of the most common gases dissolved in liquid metals, due to its ability to go through the interface between the melt and the atmosphere. The solubility of hydrogen during the solidification process of aluminum reduces by approximately half as compared to its solubility during liquid state of the aluminum. As a result, this reduction in the solubility, forces hydrogen to precipitate and get trapped between solid dendrites generating porosity [13].

Ultrasonic degassing is an effective solution to remove $\mathrm{H}_{2}$ from the melt. Once the UST is applied, cavitation and degassing processes happen simultaneously inside the melt. The UST accelerates the growth of the $\mathrm{H}_{2}$ bubbles, due to the rapid diffusion of $\mathrm{H}_{2}$ from the melt to the bubbles. These bubbles quickly reach the required size to move to the top of the melt and are able to escape [63]. Reduction of two or more times in the content of hydrogen in molten metals by ultrasonic degassing has been reported in literature which is comparable with commercial degassing techniques such as vacuum processing [63].

Ultrasonic degassing eliminates the excess of hydrogen $\left(\mathrm{H}_{2}\right)$ in the melt, leading to reduction of the porosity benefiting the densification of the resulting material [13]. 
The degassing process can be divided into three stages: It begins with the formation of cavities from the gaseous products around non-metallic inclusions in the melt. Followed by the growth of cavities due to the diffusion of $\mathrm{H}_{2}$ from the melt into the cavities. Finally, the migration of large cavities to the surface of the melt occurs. In addition, cavities formed near the ultrasonic sonotrode escape from the melt immediately along with surrounding dissolved gases as a result to the high intensity of the ultrasonic waves, as shown in figure $2.3[36,37]$.

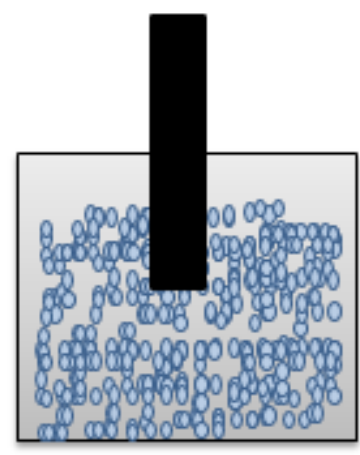

(1)

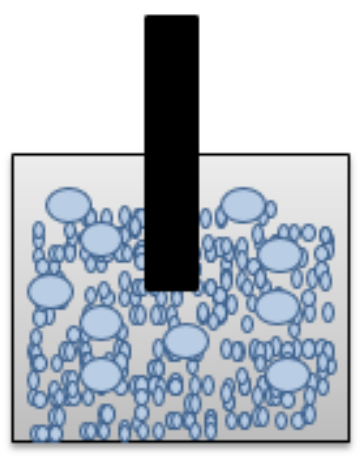

(2)

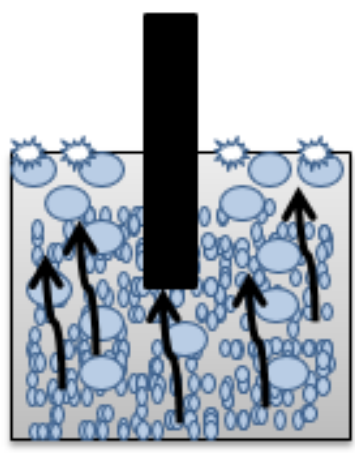

(3)

Figure 2. 3 Schematic of ultrasonic degassing. (1) Formation of cavities, (2) growth of cavities due to the diffusion of $\mathrm{H} 2$ from the melt, (3) the migration of large cavities to the surface of the melt.

\subsection{Microstructure Refinement}

For the refinement of microstructures the addition of grain size refiners (impurities) to the melt is one of the most common method reported in literature. However, the use of grain size refiners is limited to some alloys, and its addition could result in the contamination of the melt as they may remain as impurities. As a consequence, these impurities will decrease the performance of the cast metal [14-16]. To overcome these challenges, thermal and mechanical methods have been introduced to the casting processes. 
These methods could include the control of the cooling rate, mechanical/magnetic stirring and ultrasonic treatments [10-13].

The grain refinement of the cast metal with the addition of UST is controlled by the development of acoustic cavitation in the melt. As shown in Figure 2.4, the acoustic cavitation is believed to lead to an increase in the nucleation rate, enhancing dendrite fragmentation, reducing the porosity and homogenizing the melt.

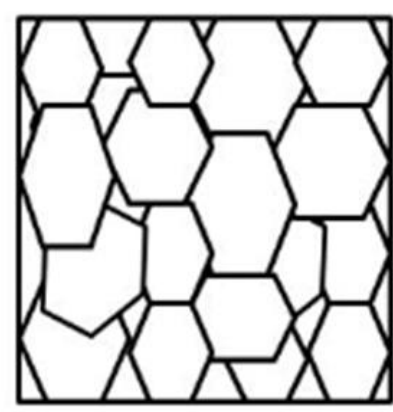

(1)

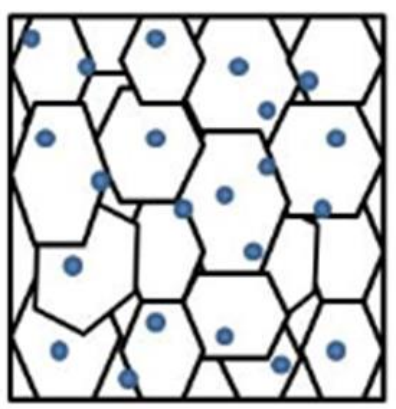

(2)

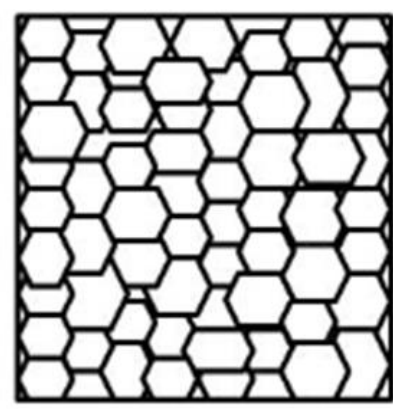

(3)

Figure 2. 4 (1) Resulting microstructure without UST, (2) Representation of added nuclei sites in the microstructure, (3) Resulting microstructure after introduction of UST in the melt

The relationship between the grain refinement and the amplitude can be ascribed as:

$D_{g r}=5.6\left(\frac{D_{Z} T_{n}}{v Q}\right)+\frac{1}{\sqrt[3]{f(A) N_{V}}}$

Where $D_{Z}$ is the diffusion coefficient of solute in the melt, $T_{n}$ is the incremental amount of undercooling required to activate the next nucleation ahead of the solidification front, $v$ is the growth rate of the solid-liquid interface, $\mathrm{Q}$ is the growth restriction factor, A is amplitude and $N_{V}$ in the number density of nucleation sites [13].

\subsubsection{Mechanism of Grain Refinement by UST}

Grain refinement induced by UST is attributed to two mechanisms: 
(i) Heterogeneous nucleation: The addition of ultrasonic treatment to the melting process introduces cavitation, leading to the formation of numerous tiny cavities. This cavities expand and collapse at a fast rate during the cavitation process stimulating heterogeneous nucleation in the melt [64]. The heterogeneous nucleation is enhanced as a result to the three mechanisms present during the cavitation process: (a) all molten metals have nonmetallic inclusion such as oxides and carbides, during the cavitation process gaseous phases present in the surface of these inclusions are removed. This process results in the wetting of inclusion particles generating more nucleation sites for solidification [46]. (b) With the collapsing of the cavities, a high release of energy occurs into the melt increasing the temperature. An increase of melting temperature leads to higher cooling rates enhancing nucleation. Finally, (c) higher cooling rates are experienced at the surface of the collapsing cavities serving as additional nucleation sites. During the expansion state of the cavities, the gas inside of them also expand promoting undercooling on the surface of the cavity resulting in the formation of nuclei sites [65].

Grain refinement due to heterogeneous nucleation has been reported by several researches on different metals. Eskin et al., Faraji et al. and Xin-tao et al., studied this phenomena and concluded that addition of UST to the melting process enhances heterogeneous nucleation and increases the number of nuclei sites in the solidification front. This leads to refinement of the microstructure [66-68]. 
(ii) Dendrite fragmentation: UST is capable of breaking dendritic structures due to the strong shock waves generated during the process [13]. Shock waves promote high temperature and strong jets of pressure into the melt inducing breakage of dendrites [13]. Zhang et al. report dendritic fragmentation due to acoustic cavitation, considering this as the main reason for grain refinement [69].

Combining these two mechanism Jian et al. studied the effect of ultrasound on solidification of aluminum A356 alloy. As a result, grain refinement observed as a result to the introduction of acoustic cavitation was mainly dominated by the heterogeneous nucleation as compared to the dendritic fragmentation.

Also non-dendritic structures have been reported due to the effect of UST. Nondendritic structures are characterized by globular grains with no dendritic branches. The condition for the formation of non-dendritic structures are accelerated nucleation and excess amount of solidification sites. During the UST all these conditions are satisfied. Eskin et al. reported the presence of non-dendritic structures in the microstructures of aluminum alloys after the introduction of UST during the casting process [63]

\subsubsection{1. $\quad$ Heat flow during solidification}

Heat flow during the solidification process contributes to the reduction of the grain size in the microstructure. The microstructure after solidification for a pure metal, an alloy or any metal with UST will be different as shown in Figure 2.5. In a pure metal, heterogonous nucleation begins on the walls of the crucible with smaller grains. This behavior results from the heat being dissipated rapidly through the wall of the crucible. However, in the 
middle of the melt columnar zones will be created due to the slow cooling rate experienced in that area.

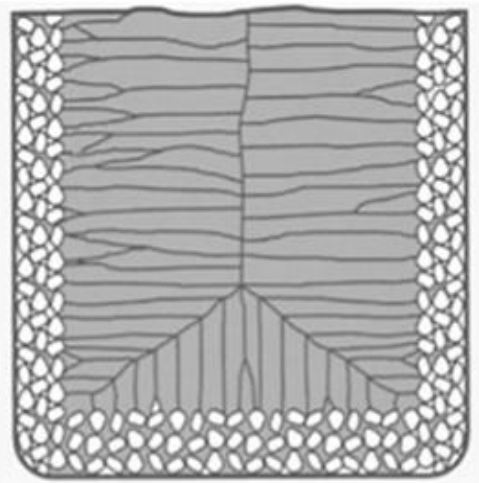

(A)

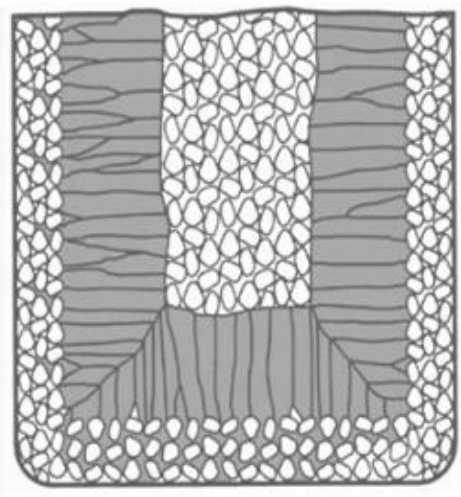

(B)

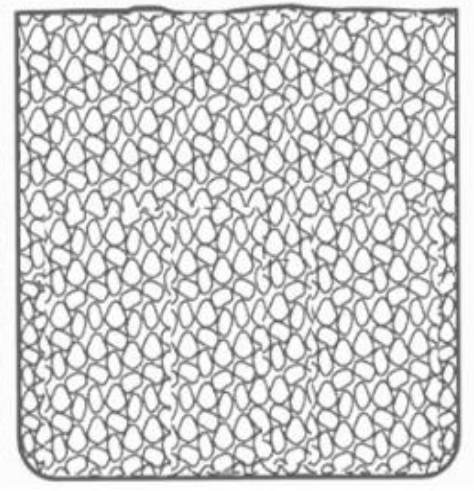

(C)

Figure 2. 5 (A) Microstructure of pure metal, (B) microstructure of an alloy and (C) microstructure of a metal after UST [70].

For metal alloys heterogeneous nucleation, occurs in the walls of the crucible and also within the melt due to the presence of secondary phases. The presence of secondary phase leads to the possibility of an equiaxed zone in the central part of the microstructure. However, columnar grains will also be present. The accelerated cooling rates experienced by the melt as a result of UST, in combination with the increasing heterogeneous nucleation, contribute to smaller grains in all the microstructure [70].

\subsubsection{Grain size reduction (Hall-Petch relationship)}

The basic principle behind the improvement of the mechanical properties is the grain refinement of the microstructure. This improvement is mathematically expressed by Hall Petch's relationship, where a smaller grain size will result in higher resistance to dislocation movement and plastic deformation (Equation 1) [71]. 
However, it has been reported in literature that for values of grains lower than 20$30 \mathrm{~nm}$ the yield stress of the material decreases as shown in Figure 2.6. For grains lower than $1 \mu \mathrm{m}$, the size of the dislocation is almost the same as the grain, resulting in the obstruction of dislocation pileup leading to grain boundary diffusion. The lattice is forced to diffuse the stress applied by sliding grain boundaries, and this sliding is the reason for the decrease of the yield stress [72].

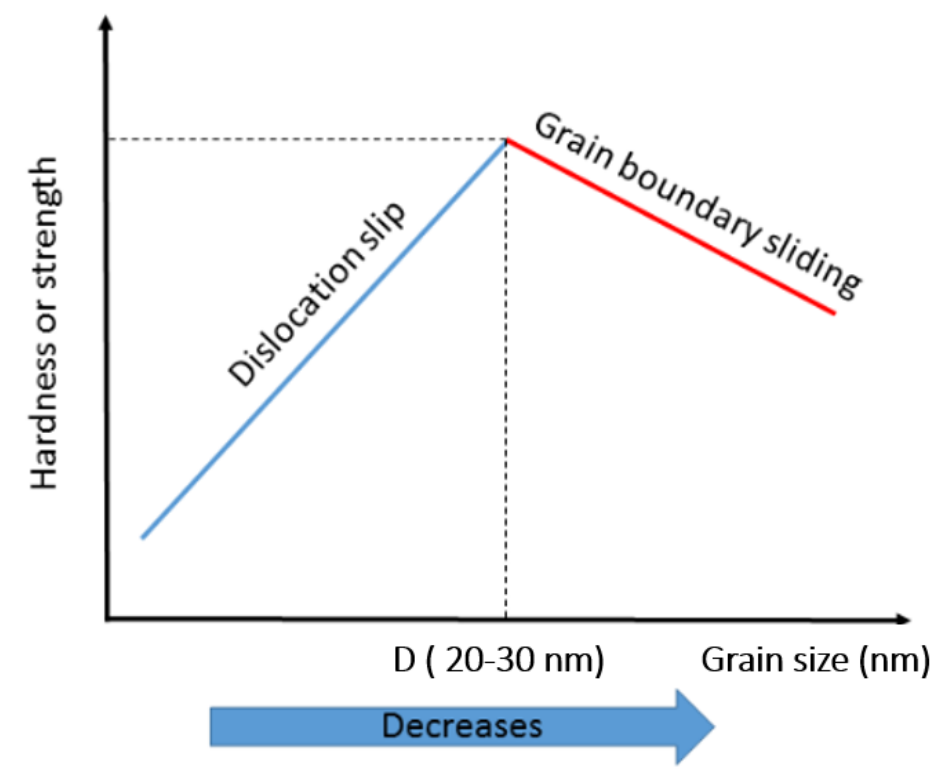

Figure 2. 6 Schematic diagram showing strength as a function of grain size [72].

\subsection{Addition and dispersion of reinforcements particles to Aluminum,}

The introduction of particles in the micron and nano scale to the aluminum matrix, such as Aluminum oxide $\left(\mathrm{Al}_{2} \mathrm{O}_{3}\right)$, Silicon carbide $(\mathrm{SiC})$, Boron Carbide $\left(\mathrm{B}_{4} \mathrm{C}\right)$ and Carbon nanotubes CNT[19-22], have demonstrated potential to develop metal matrix composites (MMC) with low density, enhanced mechanical strength and remarkable wear and abrasion resistances.[20]. As a result, their processing has been extensively studied for aerospace, automobile and military defense applications [23]. 
The most common metals used to fabricate MMC are aluminum and magnesium due to their vast industrial applications. Several methods for the manufacturing of aluminum matrix composites have been reported in literature [17-18]. Stir casting, high energy ball milling, powder metallurgy and spray deposition are the most common methods used for manufacturing aluminum MMC $[17,73-76]$. Poor wettability and agglomeration of the reinforcement particles are the main limitation of these techniques [13].

The incorporation of solid particles into molten metal requires an exchange between the solid-gas interfaces in the particle to a solid-liquid interface interaction in the molten metal, leading to the activation of the particle in the melt. [77, 78]. The combination of high surface energy and poor wettability of reinforcing particles result in a not uniform distribution on the microstructure. This behavior is attributed to process experienced during the solidification where the particles are pushed to the intergranular and inter dendritic zones of the matrix due to the advance of the solidification front $[79,80]$.

To overcome these challenges, UST has been implemented as a technique to manufacture MMCs. Several studies revealed that during the UST process, the acoustic waves increased the pressure inside the molten metal leading to the formation of cavities. These cavities will go through a compression and expansion cycle until they finally collapse resulting in a high release of energy as shown on Figure 2.7 [81]. This release of energy generates a local increase of temperature up to $1000{ }^{\circ} \mathrm{C}$ and pressures of 10.000 MPa [41]. It is known that the release of energy during the UST process is high enough to strip off the gaseous phases from the surface of the reinforcing particles forcing the melt to fill the surface of the particles. As a result, the exchange between the solid-gas interfaces 
and solid-liquid interfaces of the particles occur becoming active to the melt and acting as solidification sites. [13, 82]

(a)
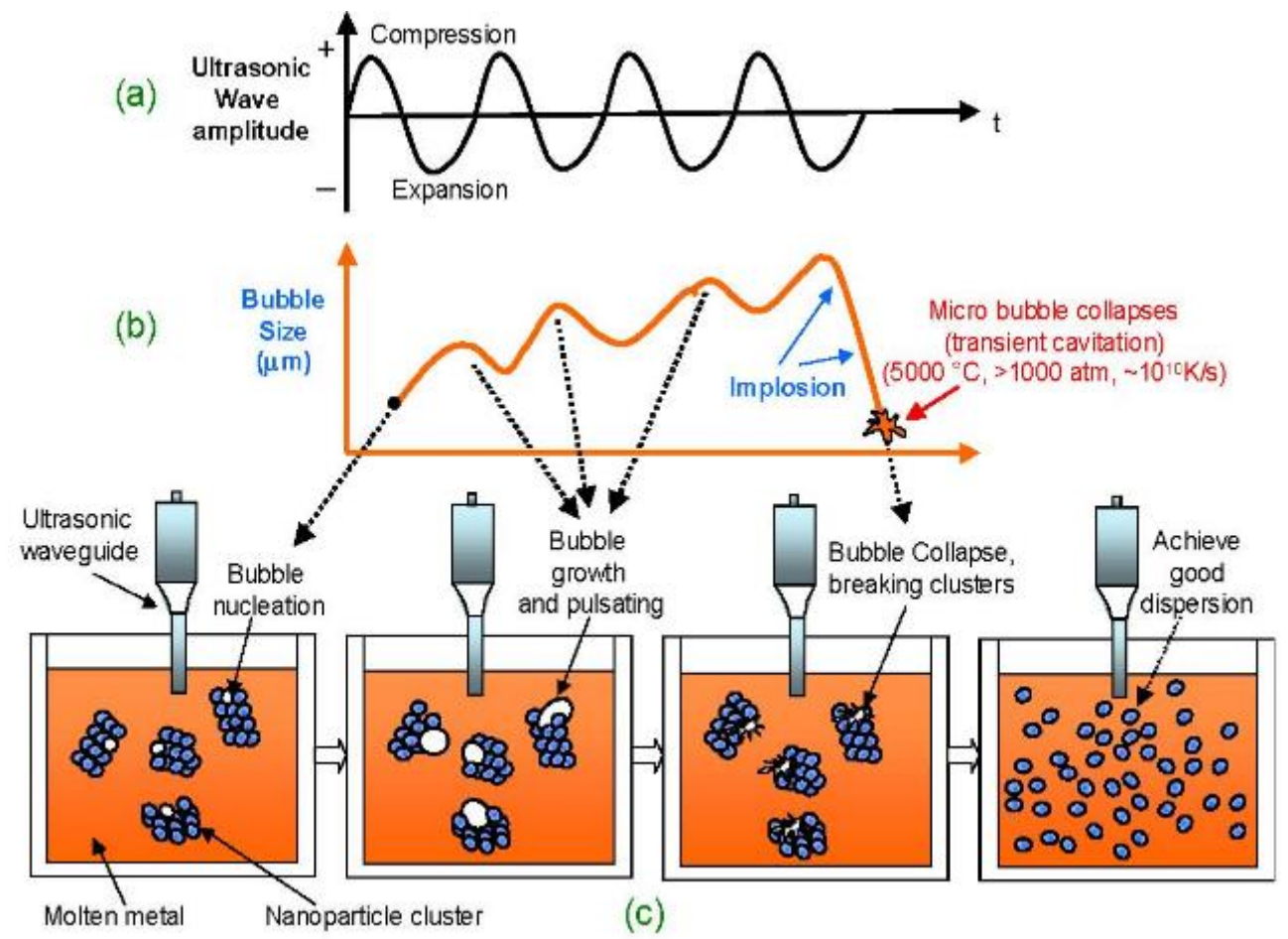

Figure 2. 7 Schematic of the dispersion of particles by the addition of UST to the casting process [81].

Different feeding techniques to add the particles into molten metals for the manufactured of MMCs have been reported by researcher, such as spraying them in the surface of the melt, wrap them as capsules on metallic foil, placing them between the metal as a layered structure and also using perforated containers (niobium cage) placed under the sonotrode $[13,22,82,83]$. Srivastava et al. reported the effect of temperature on the fabrication of aluminum reinforced with $\mathrm{Al}_{2} \mathrm{O}_{3}$ composites. Temperatures of $700^{\circ} \mathrm{C}, 725^{\circ} \mathrm{C}$, $750^{\circ} \mathrm{C}$ and $775^{\circ} \mathrm{C}$ were studied, for each experiment where $300 \mathrm{~g}$ of A16061 was melted and $1 \mathrm{wt} . \%$ of $\mathrm{Al}_{2} \mathrm{O}_{3}$ wrapped in aluminum foil were injected into the bottom of the crucible [82]. The melt was manually stirred for $5 \mathrm{~min}$ and UST was applied for $3 \mathrm{~min}$, using a 
niobium probe with a frequency of $20 \mathrm{KHz}$ and ultrasonic power of $1.5 \mathrm{~kW}$. The addition of $1 \mathrm{wt} . \%$ of $\mathrm{Al}_{2} \mathrm{O}_{3}$ reduced the grain size by $41-61 \%$ as compared to the based alloy. Also hardness and yield strength of the composite increased between $20-61 \%$ and $20-67 \%$ respectively. The improvement is attributed to the uniform dispassion and wetting of $\mathrm{Al}_{2} \mathrm{O}_{3}$ particles enhancing heterogeneous nucleation [82].

Yan et al. reported the successful fabrication of A1365 alloy reinforced with carbon nanotube (CNT). 0.8 wt.\% CNTs/A356 was fabricated by UST processing with a $2.1 \mathrm{~kW}$ ultrasonic equipment, titanium probe, $20 \mathrm{KHz}$ frequency for about 20 min under argon protective atmosphere. CNTs were added to the melt as pre-fabricated CNT/A356 extrudates that were cut into small pieces. Micro hardness, ultimate tensile strength and yield strength increased by $27.8,17$ and 29.2 percent respectively as compare with the base alloy [22]. In a separate study, Cao et al. reported the fabrication of a magnesium matrix nanocomposite reinforced with silicon carbides (SiC). $800 \mathrm{~g}$ of Magnesium was melt at $700{ }^{\circ} \mathrm{C}$. Pure aluminum and Al-50 were added to created Mg-2Al-1Si and Mg-4Al-1Si matrices. UST was applied to the melt using a niobium probe with a frequency of 17.5 $\mathrm{KHz}$ and ultrasonic power of $4 \mathrm{KW}$. Simultaneously $2 \mathrm{wt} \% \mathrm{SiC}$ was slowly added to the melt using through a steel tube. Yield strength increased 52\% and 33\% for $\mathrm{Mg}-2 \mathrm{Al}-$ $1 \mathrm{Si} / 2 \% \mathrm{SiC}$ and $\mathrm{Mg}-4 \mathrm{Al}-1 \mathrm{Si} / 2 \% \mathrm{SiC}$ respectively. Grain size of both magnesium composite was reduced. However some clusters were found suggesting that the conditions for UST were not optimized [84]. Table 2.2 summarizes the MMCs synthesized by ultrasonic treatment. 
Table 2. 2 MMC manufactured by the addition of UST to the casting process.

\begin{tabular}{|c|c|c|c|c|}
\hline Metal & $\begin{array}{l}\text { Particle } \\
\text { added }\end{array}$ & Parameters of UST & Outcomes & Ref. \\
\hline $\begin{array}{l}\text { Al-7Si-Mg } \\
\text { (A356) }\end{array}$ & $\begin{array}{l}0.8 \text { wt. } \% \text { CNT } \\
0.5-2 \text { Wt. } \% \mathrm{SiC}\end{array}$ & $\begin{array}{l}\text { Power: } 70-2100 \mathrm{~W} \\
\text { Amplitude: } \mathrm{N} / \mathrm{S} \mu \mathrm{m} \\
\text { Frequency: } 18-20 \mathrm{KHz} \\
\text { Time: } 20 \mathrm{~min} \\
\text { Volume: N/S ml } \\
\text { Temperature: } 610-750^{\circ} \mathrm{C} \\
\text { Feeding technique: } \\
\text { - Pre-fabricated } \\
\text { CNT/A356 extrudes that } \\
\text { were cut into small } \\
\text { pieces } \\
\text {-Spray in the top }\end{array}$ & $\begin{array}{l}\text { * Uniform } \\
\text { dispersion of the } \\
\text { particles in the } \\
\text { matrix } \\
\text { *Strong interfacial } \\
\text { bonding formed } \\
\text { *Micro hardness, } \\
\text { ultimate tensile } \\
\text { strength } \\
\text { and yield strength } \\
\text { increases } 27.8 \% \text {, } \\
17 \% \text { and } 29.2 \%\end{array}$ & {$[22,85]$} \\
\hline Al-6061 & $\begin{array}{l}0.5-1.5 \mathrm{Vol} . \% \\
\mathrm{SiC} \\
0.5 \mathrm{Vol} \% \mathrm{~B}_{4} \mathrm{C} \\
1 \text { wt. } \% \mathrm{Al}_{2} \mathrm{O}_{3}\end{array}$ & $\begin{array}{l}\text { Power: } 1.5-2 \mathrm{KW} \\
\text { Amplitude: } \mathrm{N} / \mathrm{S} \mu \mathrm{m} \\
\text { Frequency: } 20 \mathrm{KHz} \\
\text { Time: } 3-60 \mathrm{~min} \\
\text { Volume: } 110 \mathrm{ml} \\
\text { Temperature: } 680-775^{\circ} \mathrm{C} \\
\text { Feeding technique: } \\
\text { - Particles wrapped in } \\
\text { aluminum foil were } \\
\text { injected into the bottom } \\
\text { of the crucible } \\
\text {-Spray in the top }\end{array}$ & $\begin{array}{l}\text { *Nano particles } \\
\text { were successfully } \\
\text { added to the melt. } \\
\text { *Grain size was } \\
\text { reduce between } 41- \\
61 \% \text { compared to } \\
\text { the based alloy. } \\
\text { *Hardness and yield } \\
\text { strengths of the } \\
\text { composite increases } \\
\text { between } 20-61 \% \\
\text { and } 20-67 \%\end{array}$ & $\begin{array}{l}6,17 \\
82,86]\end{array}$ \\
\hline $\begin{array}{l}\text { Mg-2Al-1Si } \\
\text { Mg-4Al-1Si }\end{array}$ & $1-2 \mathrm{wt} \% \mathrm{SiC}$ & $\begin{array}{l}\text { Power: } 3.5 \mathrm{KW} \\
\text { Amplitude: } \mathrm{N} / \mathrm{S} \mu \mathrm{m} \\
\text { Frequency: } 17,5-\mathrm{KHz} \\
\text { Time: } 15 \mathrm{~min} \\
\text { Volume: } 560 \mathrm{ml} \\
\text { Temperature: } 700{ }^{\circ} \mathrm{C} \\
\text { Feeding technique: } \\
\text { - Added through a steel } \\
\text { pipe to the top of the } \\
\text { melt } \\
\text {-Niobium cage with a } \\
\text { shape of truncated cone } \\
\text { was used to hold } \\
\text { nanoparticles inside the } \\
\text { melt }\end{array}$ & $\begin{array}{l}\text { *Nano particles } \\
\text { uniform dispersed } \\
\text { *Grain size } \\
\text { reduction } \\
\text { *Yield strength } \\
\text { increase between } \\
33-52 \% \\
\text { *Micro hardness } \\
\text { increase from } 19 \text { - } \\
34 \%\end{array}$ & $\begin{array}{l}76,81, \\
83,84]\end{array}$ \\
\hline
\end{tabular}


As discussed, UST has been added to the casting process to improve the mechanical properties on the material: enhancing grain refinement, dendrite fragmentation, reducing the porosity and homogenized the melt. Also UST has been introduced as a technique to fabricated metal matrix Composites, using aluminum and magnesium as a primarily base alloy. However, a parametric study of the effects of ultrasonic treatment parameters (i.e. amplitude, sonication time and temperature of melt) on the resultant A16061 microstructure have not been reported yet. Furthermore, the MMCs described above are mainly fabricated with the addition of $\mathrm{Al}_{2} \mathrm{O}_{3}, \mathrm{SiC}, \mathrm{B} 4 \mathrm{C}$ and $\mathrm{CNT}$ [19-22], this work will present dispersion of Tungsten disulfide particles into Al6061 matrix to serve as solid lubricant material, resulting in a composites with enhanced mechanical properties as a function of ultrasonic treatment applied.

The subsequent chapter will discusses the materials and experimental methods used to study the influences of ultrasonic treatment on the microstructure of Al6061. Followed by the addition of micro particles for the development of micro composites. 


\section{CHAPTER 3: MATERIAL AND METHODS}

This chapter presents the detail of the materials and experimental methods used to conduct the research on studying the effects of ultrasonic treatment on A16061 microstructure and the dispersion of fine particles during solidification.

\section{1 $\quad \underline{\text { Materials }}$}

\subsubsection{Aluminum 6061 alloy}

Al6061 alloy was the metal matrix selected for this study. A16061 is one of the most widely used aluminum alloys for structural applications due to its physical and mechanical properties $[3,4]$. Low density, excellent wear resistance and corrosion resistance make this alloy suitable for aircraft and aerospace components, automobile and military industries [5-8]. Al6061 was obtained from Online metals (Seattle, WA, USA), as a rod with 1,375 in diameter and 12 in length and its chemical composition is shown in Table 3.1 [17].

Table 3. 1 Chemical composition of Aluminum 6061 alloy

\begin{tabular}{|c|c|c|c|c|c|c|c|c|c|c|}
\hline Element & $\mathrm{Al}$ & $\mathrm{Cr}$ & $\mathrm{Cu}$ & $\mathrm{Fe}$ & $\mathrm{Mg}$ & $\mathrm{Mn}$ & $\mathrm{Si}$ & $\mathrm{Ti}$ & $\mathrm{Zn}$ & Others \\
\hline wt. $\%$ & Balance & $\begin{array}{c}0.04- \\
0.35\end{array}$ & $\begin{array}{c}0.15- \\
0.40\end{array}$ & 0.7 & $\begin{array}{c}0.8- \\
1.2\end{array}$ & 0.15 & $\begin{array}{c}0.4- \\
0.8\end{array}$ & 0.15 & 0.25 & 0.15 \\
\hline
\end{tabular}

\subsubsection{Reinforcement Particles}

In this study, tungsten disulphide $\left(\mathrm{WS}_{2}\right)$ and carbon nanotubes $(\mathrm{CNT})$ are used as the reinforcement for Al 6061 alloy.

Tungsten disulphide $\left(\mathrm{WS}_{2}\right)$ powder was obtained from Graphene Supermarket (Calverton, NY, USA). SEM images of the as-received powder can be seen in Figure 3.1. 
The powder is characterized with an average particle size of $0.4-1 \mu \mathrm{m}$ as specified by the manufacture and hexagonal morphology.

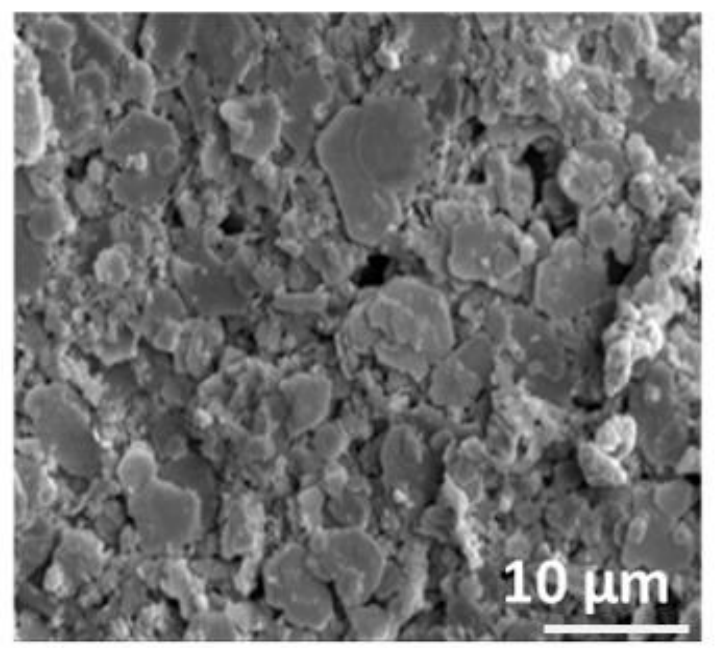

(A)

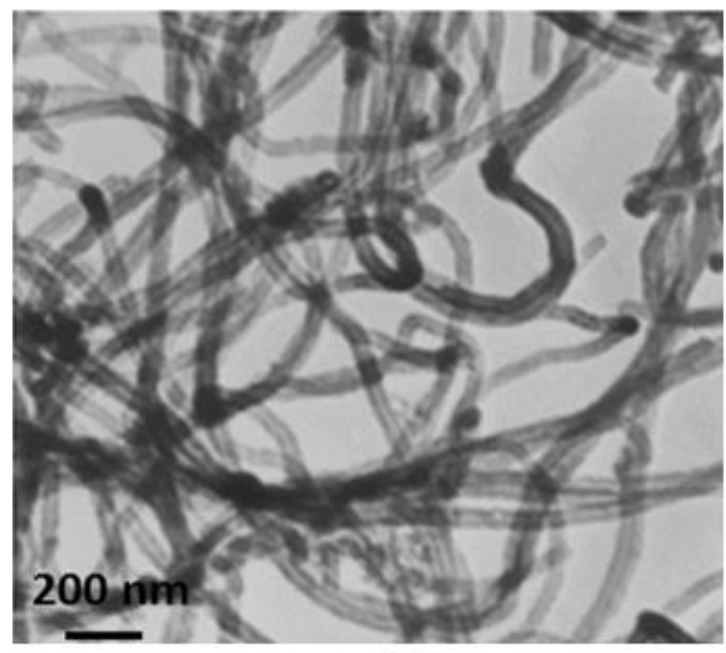

(B)

Figure 3. 1 SEM Images of the reinforcements: (A) Low magnification image of as-received $\mathrm{WS}_{2}$ and (B) High magnification image of as-received CNTs

Tungsten disulfide is a two dimensional material (2D) characterized by a S-W-S layered structure with hexagonal crystals. The layered structures are held by weak Van der Waals forces, while bonding between same elements exhibit strong covalent interactions [25]. The properties of $\mathrm{WS}_{2}$ are shown on Table 3.2.

Table 3. 2 Tungsten disulfide properties.

\begin{tabular}{|c|c|}
\hline Purity & $99 \%$ \\
\hline Average particle size & $0.4-1 \mu \mathrm{m}$ \\
\hline Density & $7.5 \mathrm{~g} / \mathrm{cm}^{3}$ \\
\hline Color & Gray \\
\hline Morphology & Hexagonal \\
\hline
\end{tabular}


Multiwall carbon nanotubes (CNT) were obtained from Nanostructure \& Amorphous Materials Inc. (Houston, TX, USA). SEM images of CNT powder can be seen above in figure 3.1C. As-received CNTs are 30-50 nm diameter and 10-20 $\mu \mathrm{m}$ length with a purity of $95 \%$.

\subsection{Experimental Set-up \& Procedure}

The experimental set-up for the ultrasonic treatment is shown in Figure 3.2. The set up mainly consist of an electric furnace, the ultrasonic processing system and a graphite crucible.

Al6061 was melted in a graphite crucible (30 $\mathrm{mm}$ inner diameter and $30 \mathrm{~mm}$ height) inside an electric furnace model ProCast $1 \mathrm{~kg}$ (PMC supplies, Lake Katrine, NY, USA). Ultrasonic treatment was performed using a Vibra-Cell VCX750 ultrasonic equipment (Sonic \& Material, Inc., Newtown, CT, USA). The ultrasonic system consists of a $19 \mathrm{kHz}$ and $750 \mathrm{~W}$ ultrasonic unit with variable operational time and amplitude of UST, converter, air cooling system and $6 \mathrm{~mm}$ diameter Niobium $(\mathrm{Nb})$ sonotrode. 


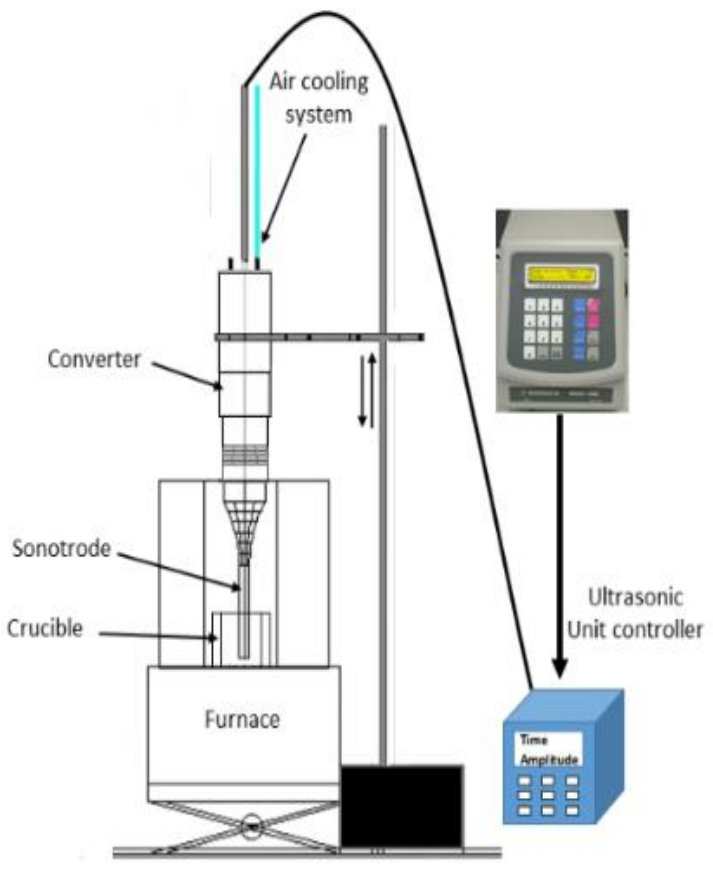

(A)

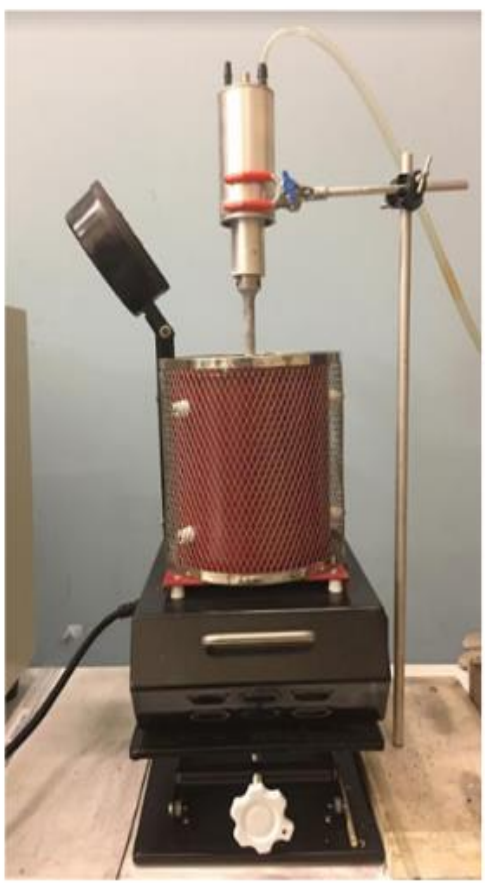

(b)

Figure 3. 2 (A) Schematic of the set-up, (B) real set-up

\subsubsection{Casting Process}

$6061 \mathrm{Al}$ rod was sectioned in small pieces weighing $30 \mathrm{~g}$. Before melting, each piece was grinded with silicon carbide paper to remove the oxide layer. The removal of the oxide layer by the grinding of the surfaces will result in the homogeneous melting of the aluminum. The melting process was carried out at temperature of $700^{\circ} \mathrm{C}$ and $750^{\circ} \mathrm{C}$ in an electric furnace using a graphite crucible.

\subsubsection{Ultrasonic Treatment}

Prior to the introduction of ultra-sonic treatment, the niobium $(\mathrm{Nb})$ sonotrode was pre-heated inside the furnace for approximately 5 min until it reached a temperature of $675^{\circ} \mathrm{C}$. The temperature of the sonotrode was measured with a K-thermocouple, followed 
by the immersion of the sonotrode $10 \mathrm{~mm}$ from the top of the melt. An air cooling system was activated at a pressure of 15 psi. Following parameters were varied to obtain a desired optimum of grain size, microhardness, and density.

- Ultrasonication period (sec)

- Ultrasonication Amplitude (\%)

-Temperature of the melt $\left({ }^{\circ} \mathrm{C}\right)$

The ultrasonic equipment with the micro sonotrode is designed to work in a range of amplitude between $0-27 \mu \mathrm{m}(0-40 \%)$. For this study, $13 \mu \mathrm{m}(20 \%)$ and $20 \mu \mathrm{m}(30 \%)$ were selected as $27 \mu \mathrm{m}(40 \%)$ amp was the upper limit of the equipment. As a result of the high vibrations, loosening of the sonotrode from the equipment starts occurring and could be detrimental to the process and the equipment. One sample was made at $40 \%$ of the amplitude and the results shows inferior properties. Thus $40 \%$ amplitude was not selected for this study. Table 3.3. Shows the parametric studies carried out in the work using different parameters of ultrasonic treatment.

Table 3.3 Processing Parameters for Ultrasonic Treatment of Al 6061 alloy

\begin{tabular}{ccc}
\hline $\begin{array}{c}\text { Amplitude of } \\
\text { UST } \\
(\mu \mathrm{m})\end{array}$ & $\begin{array}{c}\text { Processing } \\
\text { temperature } \\
\left({ }^{\circ} \mathrm{C}\right)\end{array}$ & $\begin{array}{c}\text { Time of UST } \\
(\mathrm{s})\end{array}$ \\
\hline Control sample & 700 & 0 \\
\hline \multirow{2}{*}{13} & 750 & 5 \\
& 700 & 30 \\
& 750 & 45 \\
\hline \multirow{2}{*}{20} & 700 & 5 \\
& 750 & 30 \\
\hline
\end{tabular}




\subsubsection{Addition of Secondary Phase with UST}

Two types of particles were used as reinforcement $\mathrm{WS}_{2}$ and CNT. 1 wt. \% $\mathrm{WS}_{2}$ (micron size particle) was added to the $30 \mathrm{~g}$ of Al6061. $\mathrm{WS}_{2}$ particles were placed between the aluminum pieces creating a sandwich structure. However, for the CNT addition, a hole was made in the center of a $30 \mathrm{~g}$ aluminum rod. $0.15 \mathrm{wt} . \% \mathrm{CNT}$ was placed inside the hole and sealed with another piece of aluminum as seen in Figure 3.3.

The optimized conditions found from the parametric study were used in the manufacturing of Al-based composites. Therefore, UST was applied for a period of 45 seconds, using $30 \%$ amplitude $(20 \mu \mathrm{m})$ of UST and a casting temperature of $700^{\circ} \mathrm{C}$ to achieve the dispersion and wetting of the reinforcement with the aluminum.

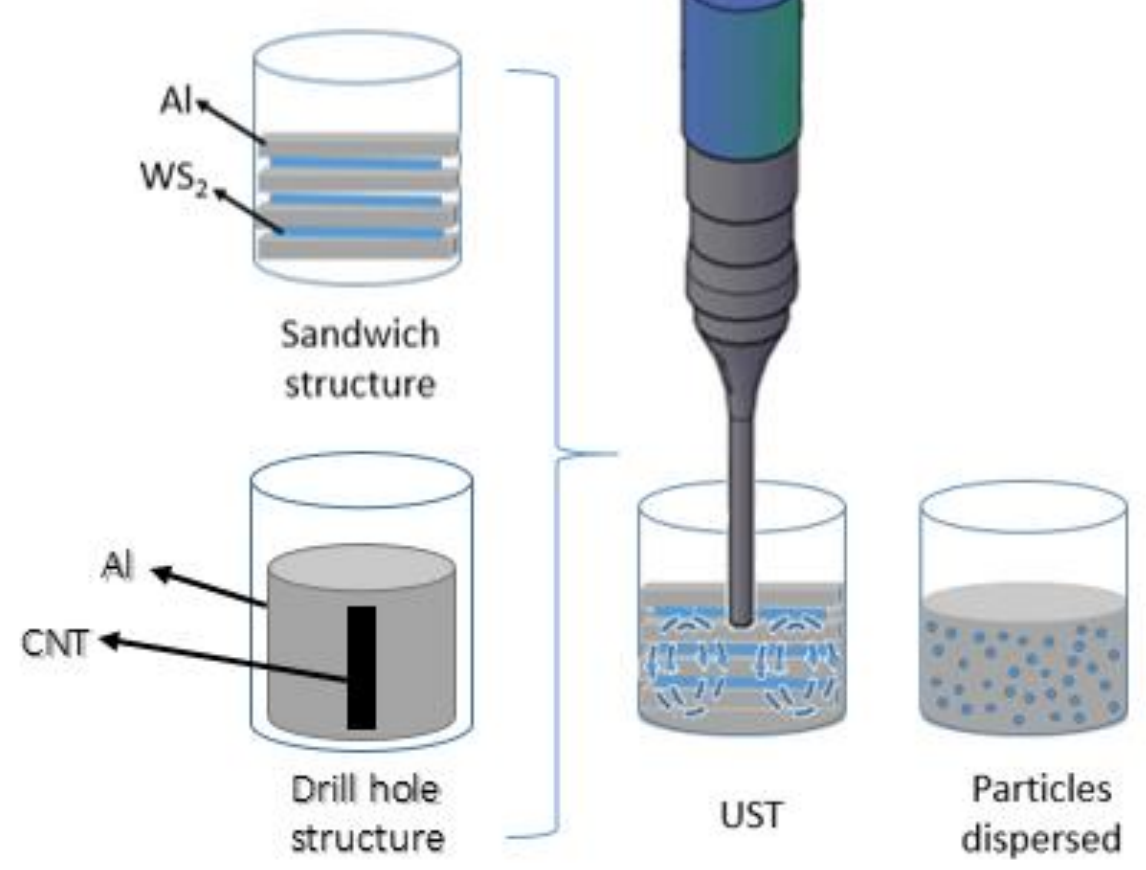

Figure 3. 3 Schematic of sample preparation and UST for manufacture of MMC 


\subsection{Structural and Microstructural Characterization}

Density measurement of the Al6061, Al-1wt. \%WS 2 and Al-0.15 wt. \% CNT with and without UST were performed using Archimedes method.

$\rho=\frac{M_{\text {air }}}{M_{\text {air }}-M_{\text {water }}}$

Where, $M_{\text {air }}$ is the weight of the sample in air and $M_{\text {water }}$ is the weight of the sample in water. These measurements were compared with theoretical density of Aluminum 6061 and that obtained by rules of mixtures for the MMC.

$\rho_{\text {composite }}=f_{W S_{2}} \rho_{W S_{2}}+\left(1-f_{W S_{2}}\right) \rho_{A l}$

Where $\rho_{\text {composite }}, \rho_{W S_{2}}$ and, $\rho_{A l}$ represent the density of the composite, $\mathrm{WS}_{2}$ particles and aluminum respectively. Similarly, $f_{W S_{2}}$ represents the weight fraction of the added particle. Densification was obtained dividing Archimedes density by the theoretical density and multiplying by $100 \%$.

Phase identification was performed by X-Ray diffraction using a Bruker D5000 Xray diffractometer (Billerica, MA, USA). The operating voltage and current used were 40 $\mathrm{kV}$ and $35 \mathrm{~mA}$ respectively, using a $\mathrm{Cu} \mathrm{K} \alpha$ radiation (wavelength of $1.542 \AA$ ) at scan rate of $2 \%$ minute.

For microstructural characterization, the cross-section of all samples were metallographically prepared, grinded with silicon carbide paper until 1200 grit and polished with $0.5 \mu \mathrm{m}$ alumina particles. Polished cross-sections were etched using Keller reagent. A Buehler Versamet 3 Optical Microscope was used to observe the resulting microstructure. Measurements of the grain size were performed using ImageJ software. To 
determine the average grain size, a total of 80 measurements were made at different locations throughout the sample.

Morphological studies of the powder and cast samples were carried out using Scanning Electron Microscopy (SEM). Using a JEOL JSM-6330 field emission scanning electron microscope (JEOL USA, Inc., Peabody, MA, USA) with an operating voltage of 15 $\mathrm{kV}$. SEM was used to characterize the powder, the fracture surface and polished crosssection of the sample. Such characterizations provided information regarding the dispersion of particles added, the interactions between particle and matrix, and morphology of the metal matrix and the reinforcement particles after UST process. Compositional analysis of the top polished cross-section and fracture surface was performed through Energy-dispersive Spectroscopy (EDS) using a JEOL JIB 4500 SEM to evaluate the distribution of the particles throughout the cast Al composite.

\subsection{Hardness test}

Hardness of the samples were measured using a LECO LM910AT Micro hardness tester with a $50 \mathrm{gf}$ load and dwell time of 10 seconds. To obtain the micro hardness values, 10 indentations were performed on each sample and the average for each sample was reported.

\subsection{Evaluation of Tribological Behavior}

Wear tests were carried out using a ball-on-disk tribometer (Nanovea, Irvin, CA, USA) using a $3 \mathrm{~mm}$ diameter alumina ball. This was done to evaluate the coefficient of friction and wear resistance of $1 \mathrm{wt} . \% \mathrm{WS}_{2}$ and $\mathrm{Al}-0.15 \mathrm{wt} . \% \mathrm{CNT}$ samples with and without UST. The tests were performed at room temperature using a normal load of $1 \mathrm{~N}$ with a $4 \mathrm{~mm}$ track diameter and a linear speed of $0.021 \mathrm{~m} / \mathrm{s}$ for a period of $15 \mathrm{~min}$. 
Three tests were performed on each sample and the worn surfaces were scanned by a non-contact optical profilometer (Nanovea, Irvin, CA, USA) to obtain a 3D representation. The worn tracks were later analyzed using Scanning Probe Image Processor (SPIP) software (Horsholm, Denmark) to obtain the respective wear depth and width. Five positions on each wear track were selected to calculate the average cross-sectional area and compute the corresponding volume loss. Volume loss was computed by multiplying the average cross-sectional area by the diameter of the wear track. 


\section{CHAPTER 4: RESULTS AND DISCUSSIONS}

This chapter presents the results and discussions obtained from the parametric studies of UST on A16061. Microstructural and morphological studies, micro hardness and phase determination of cast Al6061 with and without UST were performed to determine the effect of UST on the microstructure of Al6061. After parametric studies, ideal parameters were selected for the manufacture of MMC using UST as a dispersion technique for the reinforcement. The addition of $\mathrm{WS}_{2}$ and $\mathrm{CNT}$ as reinforcements in MMC are also discussed.

\subsection{Effect of UST Parameters on the Microstructure and Mechanical Properties of}

\section{$\underline{\mathrm{Al6061}}$}

In order to prove the presence of cavitation during the casting process, the following mathematical relations are used: The sound pressure and intensity of ultrasound are given by the following equations (2) and (3). Where $W$ is the acoustic power from the ultrasonic equipment, $\rho$ is the density of Al6061 and $c$ is the speed of sound in liquid, $s$ is the sonotrode's face area, $A$ refers to the sonication amplitude and $f$ is the frequency of the equipment. Table 4.1 shows the compiled results for intensity of ultrasound and sound pressure for all conditions of the parametric studies.

Table 4. 1 Variation of ultrasound intensity and sound pressure with UST parameters.

\begin{tabular}{cccccc}
\hline $\begin{array}{c}\text { Temperature } \\
\left({ }^{\mathbf{0}} \mathbf{C}\right)\end{array}$ & $\begin{array}{c}\text { Amplitude } \\
(\boldsymbol{\mu m})\end{array}$ & $\begin{array}{c}\text { Frequency } \\
(\mathbf{H z})\end{array}$ & $\begin{array}{c}\text { Speed of } \\
\text { sound } \\
(\mathbf{m} / \mathbf{s})\end{array}$ & $\begin{array}{c}\text { Ultrasound } \\
\text { intensity } \\
\left(\mathbf{W} / \mathbf{c m}^{\mathbf{2}}\right)\end{array}$ & $\begin{array}{c}\text { Sound } \\
\text { pressure } \\
(\mathbf{M P a})\end{array}$ \\
\hline \multirow{2}{*}{$\mathbf{7 0 0}$} & 13 & & 4723.6 & 1534.33 & 17.86 \\
& 20 & 19000 & & 3631.56 & \\
$\mathbf{7 5 0}$ & 13 & & 4715.6 & 1531.74 & 17.84 \\
\hline
\end{tabular}


Eskin et al. reported that acoustic cavitation in molten aluminum begins when the sound-induced pressure inside of the molten metal exceeds $1 \mathrm{MPa}$, and the intensity of ultrasound is more than $80 \mathrm{Wcm}^{-2}$ [13]. The addition of UST to the casting process is expected to cause acoustic cavitation.

The speed of sound is affected by the processing temperature and the melting temperature of the material. At lower temperatures the melt is closer to its solid state. Also, sound travels faster on solids than liquids. Therefore, speed of sound changes as a function of processing temperature. For this study, the computed speed of sound for $700^{\circ} \mathrm{C}$ is 4723.6 $\mathrm{m} / \mathrm{s}$ and for $750^{\circ} \mathrm{C}$ is $4715.6 \mathrm{~m} / \mathrm{s}$. For a density of $2.7 \mathrm{~g} / \mathrm{cm}^{3}$, frequency of $19 \mathrm{kHz}$, amplitudes of $13 \mu \mathrm{m}$ and $20 \mu \mathrm{m}$, and sonotrode surface area of $6 \times 10^{-5} \mathrm{~m}^{2}$. The evaluated ultrasound intensity lies between $1500 \mathrm{Wcm}^{-2}$ and $3650 \mathrm{Wcm}^{-2}$. While the computed sound pressure is $17 \mathrm{MPa}$. As a result, both conditions exceed the minimum required values to develop cavitation in liquid aluminum $\left(1 \mathrm{MPa}, 80 \mathrm{Wcm}^{-2}\right)$.

Once cavitation is proven to be present during the casting process, densification of the cast metal and grain refinement are two expected outcomes.

\subsubsection{Densification of Cast Al6061 with and without UST}

With the addition of UST to the casting process of A16061, the primary mechanism influencing the reduction of porosity is based on the degassing process which consist on the release of the gases trapped in the melt during the casting process. As a result the porosity after solidification will be reduced. 
Our casting process is open to the atmosphere which results in having air and hydrogen as the two principals sources of gases in the melt. The air comes from the gaps between the aluminum pieces when they were placed for melting and the $\mathrm{H}_{2}$ diffuse into the melt through the interface between the melt and the atmosphere. The introduction of UST to the casting process accelerates the growth of the gas bubbles due to the rapid diffusion of gases from the melt to the bubbles. These bubbles quickly reach the required size to move to the top of the melt and are able to escape.

As can be seen in Figure 4.1, porosity measurements are affected by the sonication time. Moreover, sonication amplitude and temperature also have influence on the intensity of cavitation (Eq.4) which will impact the densification of the material. However, the dominating parameter increasing the density of cast Al6061 is the ultrasonic processing time.
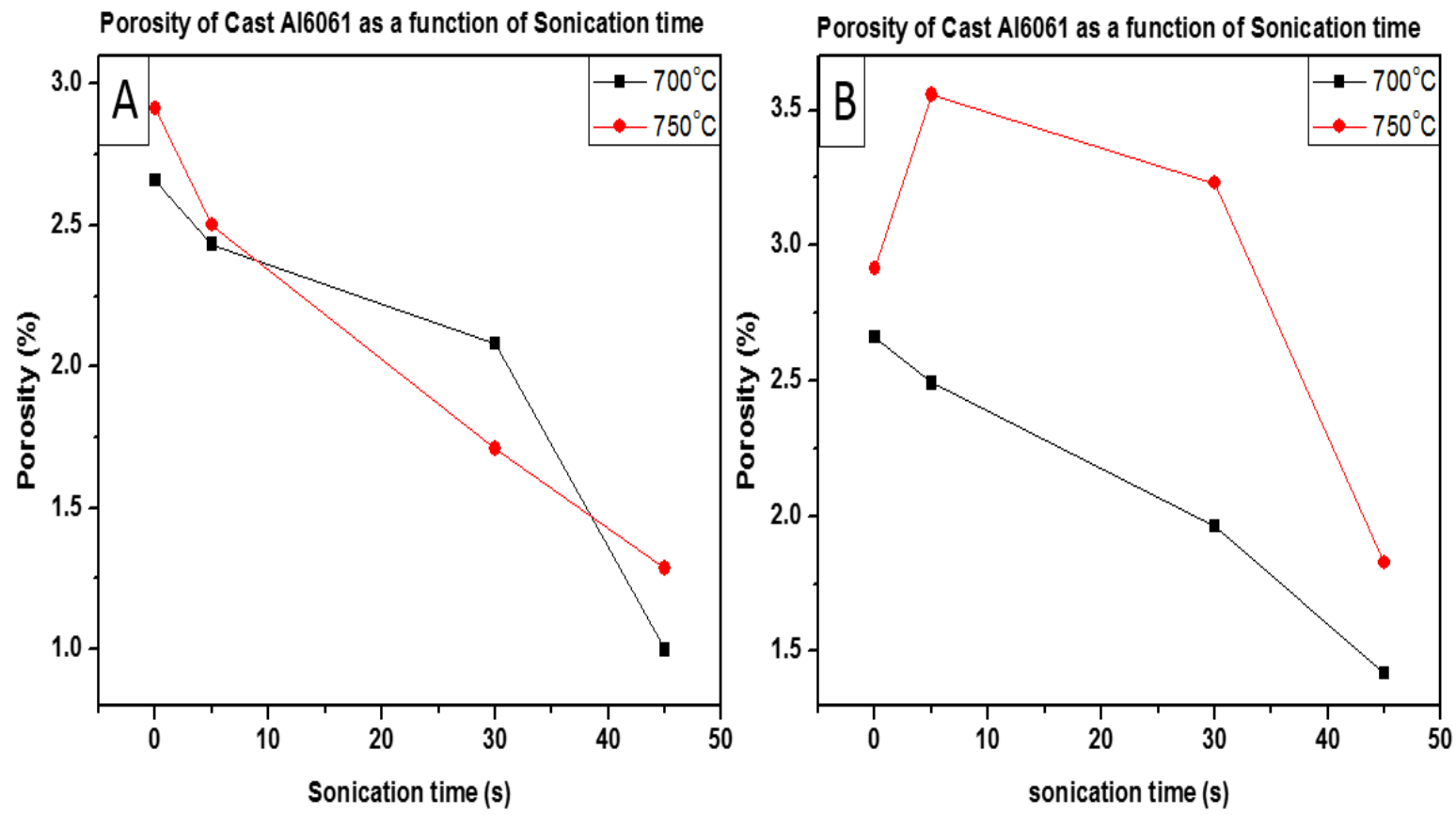

Figure 4. 1 Porosity measurements as a function of sonication time for $700^{\circ} \mathrm{C}$ and $750^{\circ} \mathrm{C}$ melting temperature, (A) 20 micron sonication amplitude, (B) 13 micron sonication amplitude. 
As can be seen in Table 4.1, the higher intensity of cavitation was exhibited at $700^{\circ} \mathrm{C}$. Higher intensity during the cavitation process results in more bubbles growing and escaping from the melt. Table 4.2 shows the compiled results obtained for porosity calculations. The lowest percentages of porosity were observed for the cast aluminum with the addition of UST. Sample with UST processing time of 45 seconds, implementing 20 microns of amplitude, and a melt temperature of $700{ }^{\circ} \mathrm{C}$, showed $1 \%$ of porosity resulting in the lowest observed with the addition of UST to the casting process.

Table 4. 2 Porosity measurements as a function of UST parameters

\begin{tabular}{|c|c|c|c|c|}
\hline \multicolumn{5}{|c|}{ Porosity (\%) } \\
\hline \multirow{2}{*}{$\begin{array}{l}\text { UST time } \\
(\mathrm{Sec})\end{array}$} & \multicolumn{2}{|c|}{$20 \mu \mathrm{m}$} & \multicolumn{2}{|c|}{$13 \mu \mathrm{m}$} \\
\hline & $700\left({ }^{\circ} \mathrm{C}\right)$ & $750\left({ }^{\circ} \mathrm{C}\right)$ & $700\left({ }^{\circ} \mathrm{C}\right)$ & $750\left({ }^{\circ} \mathrm{C}\right)$ \\
\hline 0 & 2.66 & 2.91 & 2.66 & 2.91 \\
\hline 5 & 2.43 & 2.50 & 2.49 & 3.56 \\
\hline 30 & 2.08 & 1.71 & 1.96 & 3.23 \\
\hline 45 & 1 & 1.23 & 1.42 & 1.82 \\
\hline
\end{tabular}

\subsubsection{Phase Determination for Cast Al6061 with and without UST}

In order to determinate if there is oxide formation $\left(\mathrm{Al}_{2} \mathrm{O}_{3}\right)$ during the casting process with and without UST, X-ray diffraction was performed.

X-ray diffraction was performed for the following samples:

- Al6061- Melting temperature $750^{\circ} \mathrm{C}$, without UST

- $\quad$ Al6061- Melting temperature $700^{\circ} \mathrm{C}$, without UST

- $\quad$ Al6061- Melting temperature $750^{\circ} \mathrm{C}$, with UST (45 seconds, 20 micron)

- $\quad$ Al6061- Melting temperature $750^{\circ} \mathrm{C}$, with UST (45 seconds, 20 micron) 
Analysis of the possible reaction products in cast specimens with UST were performed solely for $45 \mathrm{~s}$ of UST treatment. Specimens subjected to a higher UST time (45 s) were chosen as it represents the longest exposure of the material to possible oxidation conditions.

Figure 4.2 and Figure 4.3 shows the X-ray diffraction peaks of the 4 samples mentioned above. The index of the peaks with highest intensity corresponds to aluminum in all the cast samples. The presence of aluminum oxide $\left(\mathrm{Al}_{2} \mathrm{O}_{3}\right)$ was only observed in samples casted at $750^{\circ} \mathrm{C}$ with and without UST (Figure 4.2A and 4.2B). Corresponding peaks of $\mathrm{Al}_{2} \mathrm{O}_{3}$ shown in this specimens are attributed to the higher rate of oxidation exhibited by aluminum at higher temperatures [87]. $\mathrm{Al}_{2} \mathrm{O}_{3}$ represents an impurity for the molten aluminum. Impurities have low wettability with the aluminum and are detrimental for the final properties of the material. Even though UST can improve the wettability of impurities with the molten metal, excess of impurities is never desired. 

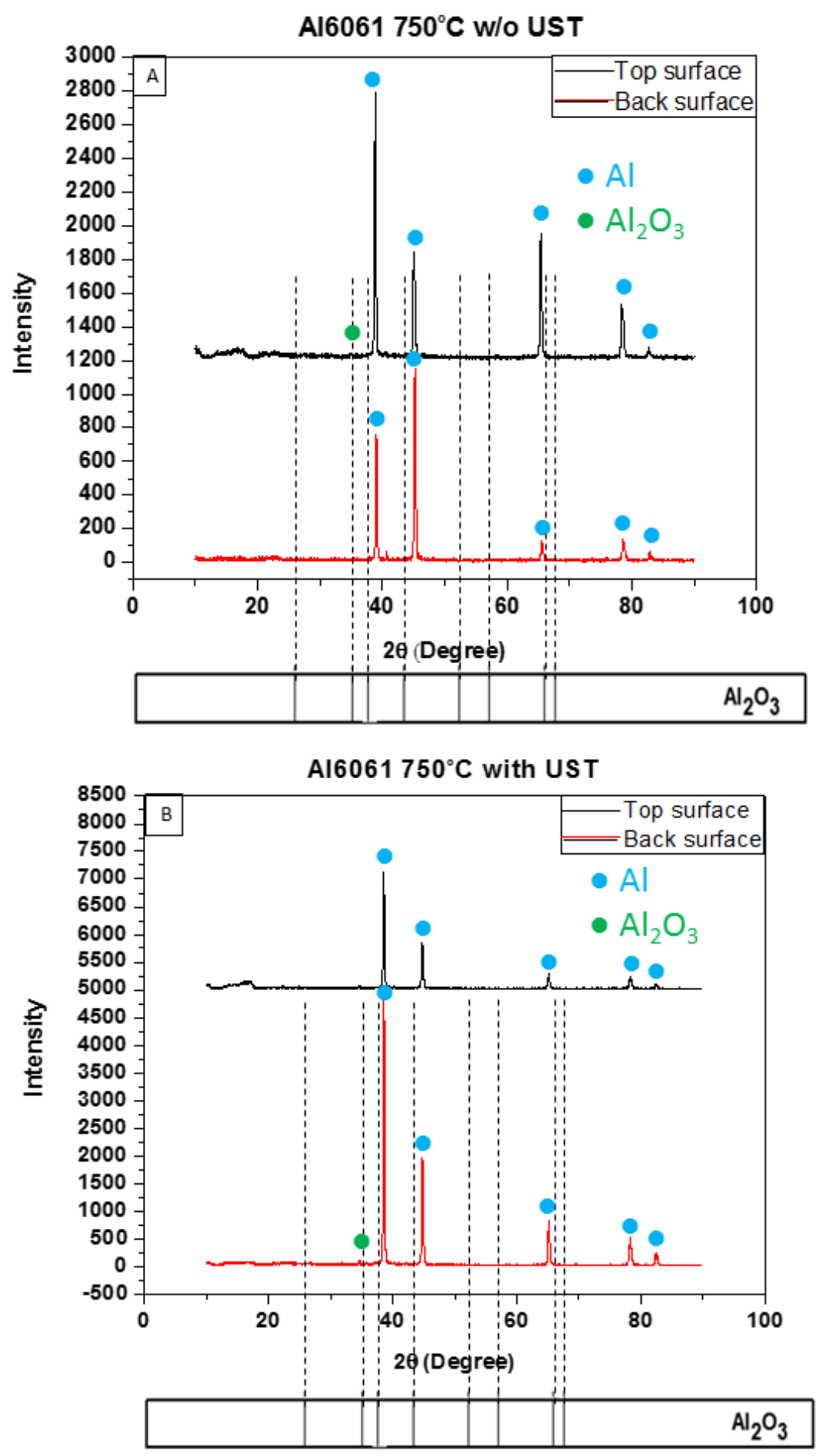

Figure 4. $2 \mathrm{X}$-ray diffraction patterns. (A) Al6061 $750^{\circ} \mathrm{C}$ melting temperature no UST, (B) $750^{\circ} \mathrm{C}$ melting temperature with UST 

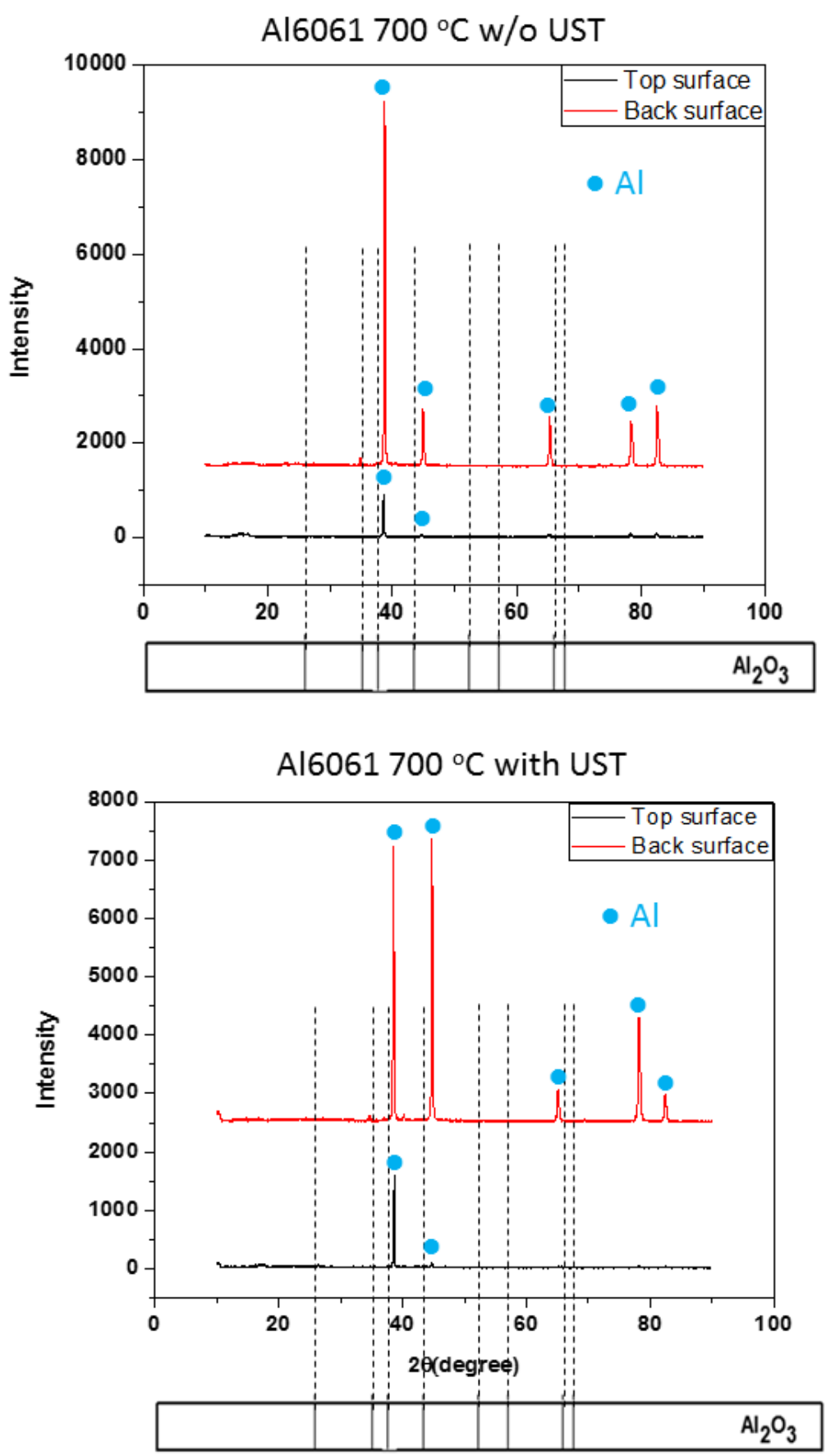

Figure 4. 3 X-ray diffraction patterns. (A) Al6061 $700^{\circ} \mathrm{C}$ melting temperature no UST, (B) $700^{\circ} \mathrm{C}$ melting temperature with UST 


\section{$\underline{\text { 4.1.3 Microstructure Analysis for Cast Al6061 with and without UST }}$}

Figure 4.4 - 4.7 shows optical images of the microstructure of cast Al6061 with and without UST at all the conditions of the parametric study. Cast samples at $700^{\circ} \mathrm{C}$ and $750^{\circ} \mathrm{C}$ without UST (Figure 4.4A and 4.6A) resulted in microstructures composed of large columnar dendritic structures with an average grain size of $309 \mu \mathrm{m}\left(750^{\circ} \mathrm{C}\right)$ and $203 \mu \mathrm{m}$ $\left(700^{\circ} \mathrm{C}\right)$. In addition, non-homogeneous distribution of grain size in the microstructure is shown as compared with sample with UST.

In contrast, samples with UST exhibit a microstructure with equiaxed dendritic structures and globular grains (non-dendritic). The microstructural changes in UST treated specimens are attributed to the ability of UST to break the dendritic structures. The formation of globular grains as function of UST are understood as an induced accelerated nucleation. In the presence of excessive solidification sites, the growth of dendritic branches is restricted, resulting in a refined microstructure dominated by globular grains. 


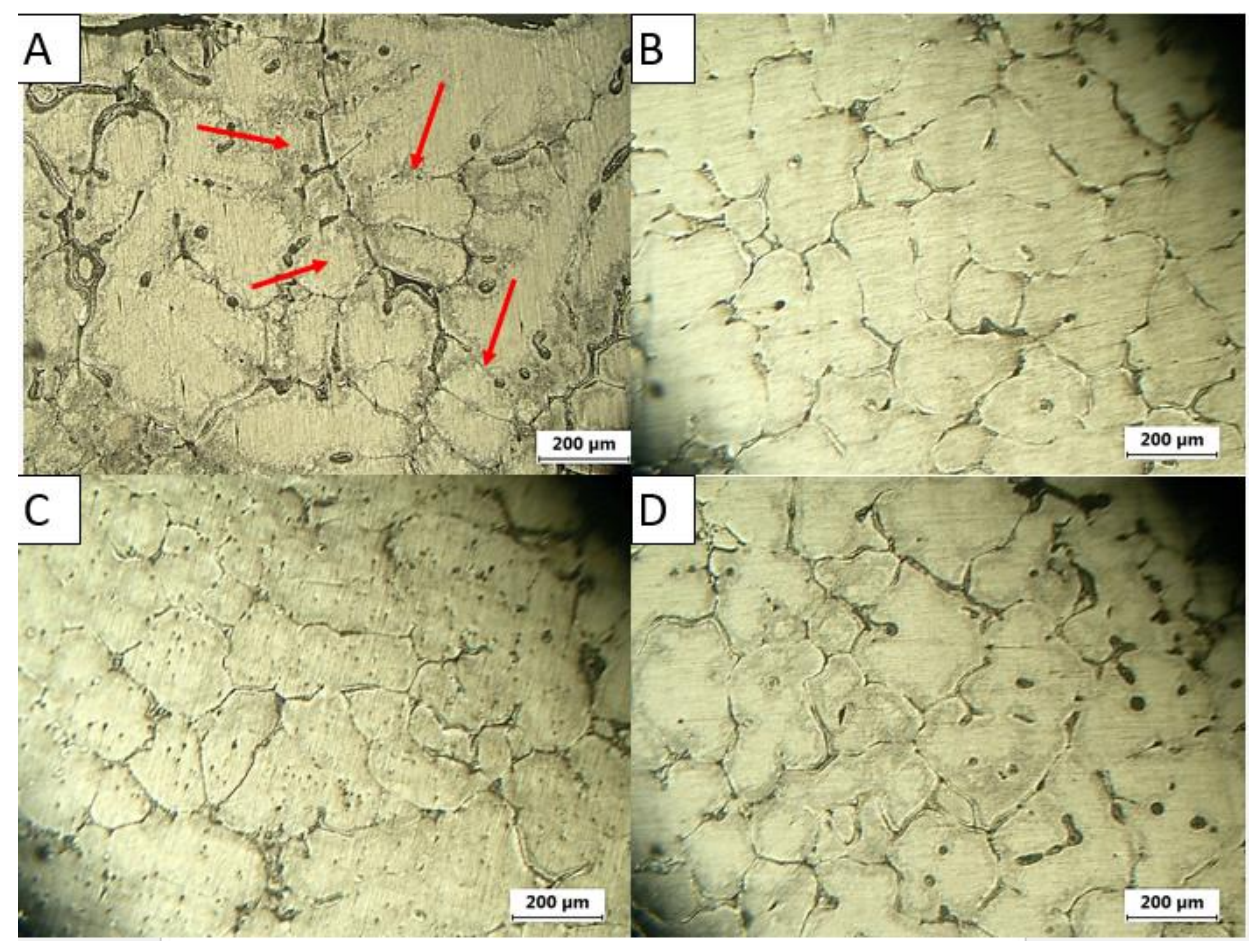

Figure 4. 4 Optical images of the microstructure of Al6061 melting temperature of $750^{\circ} \mathrm{C}$, amplitude of UST $13 \mu \mathrm{m}$, (A) 0 seconds, (B) 5 seconds, (C) 30 seconds, (D) 45 Seconds

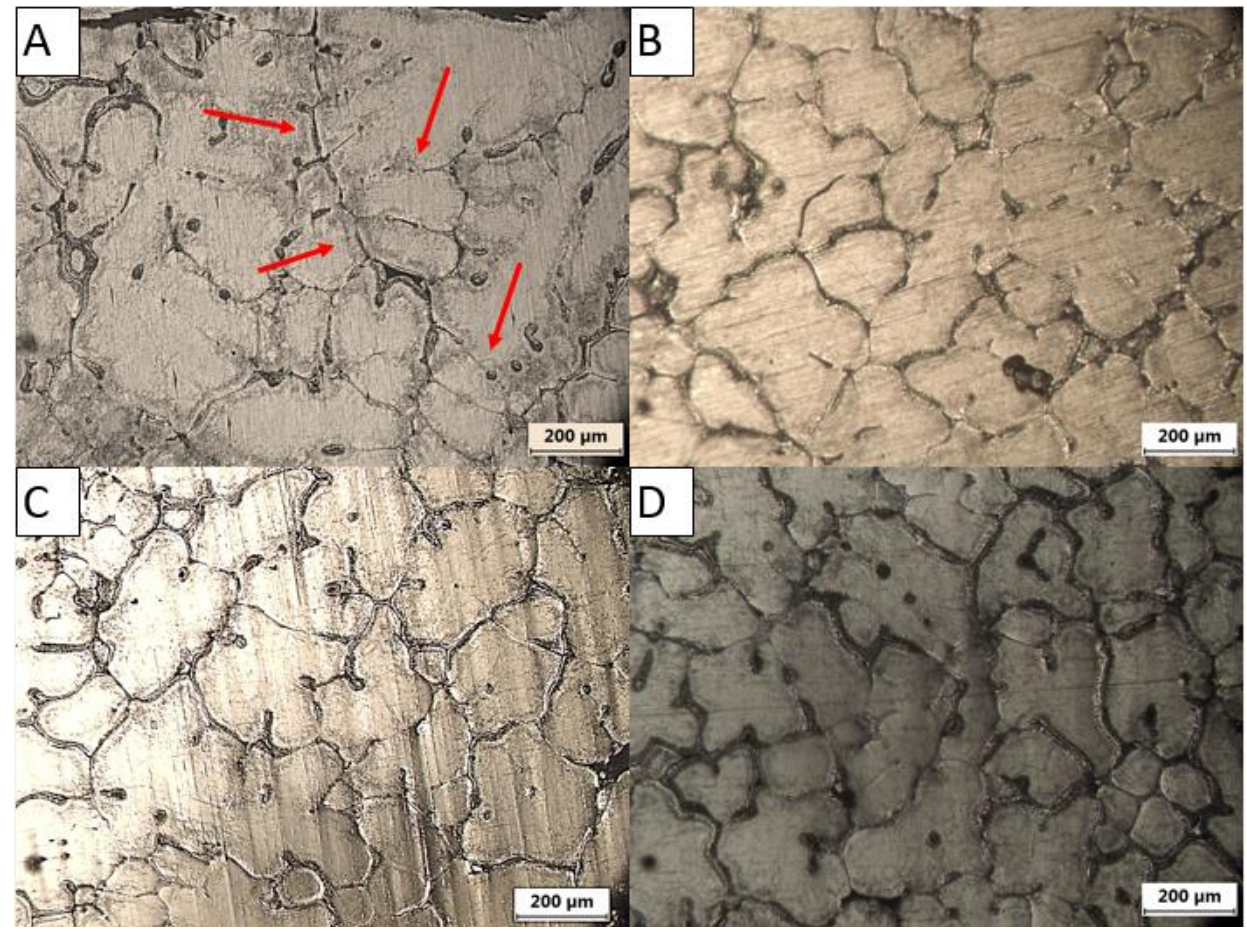

Figure 4. 5 Optical images of the microstructure of Al6061 melting temperature of $750^{\circ} \mathrm{C}$, amplitude of UST $20 \mu \mathrm{m}$, (A) 0 seconds, (B) 5 seconds, (C) 30 seconds, (D) 45 Seconds 


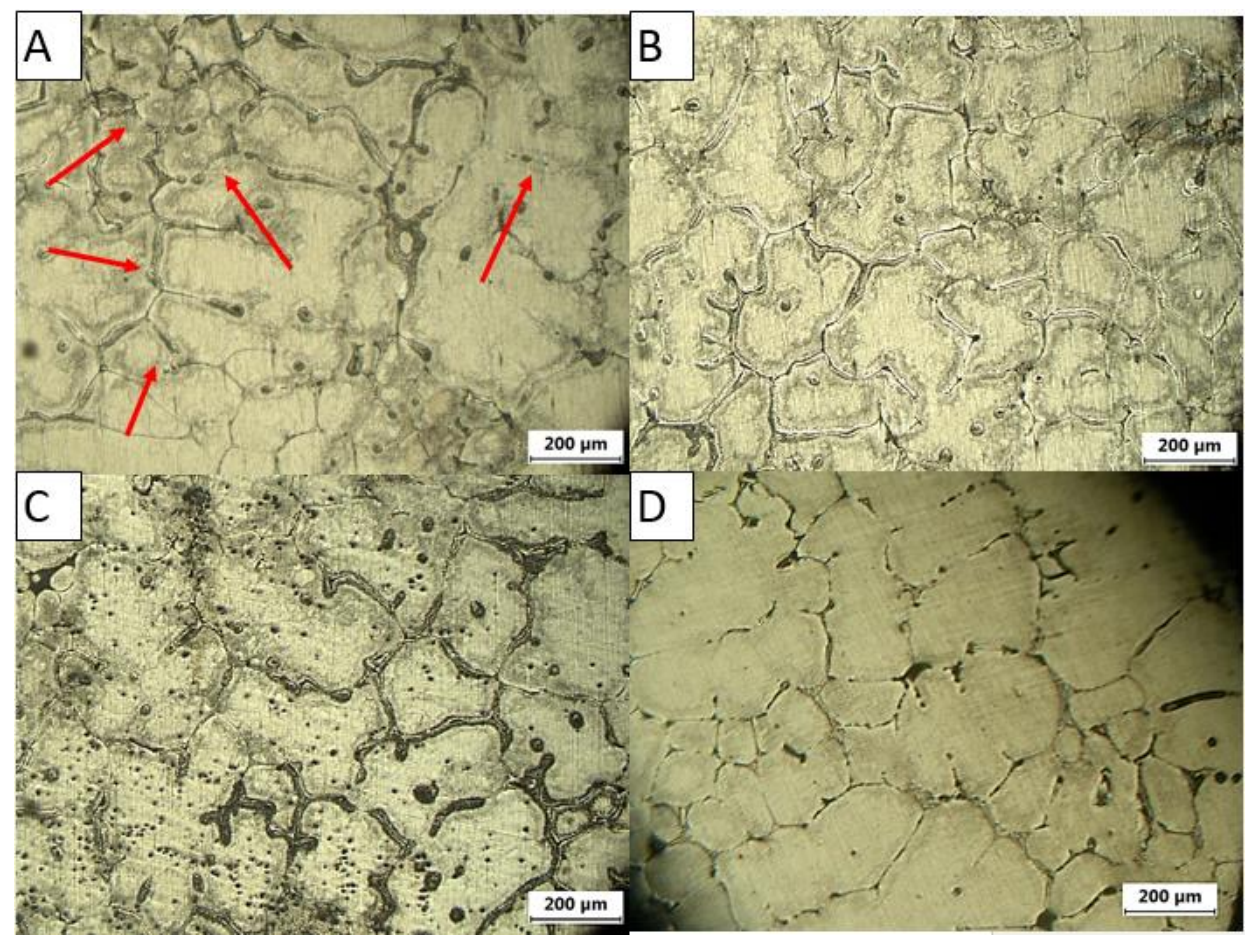

Figure 4. 6 Optical images of the microstructure of Al6061 melting temperature of $700^{\circ} \mathrm{C}$,

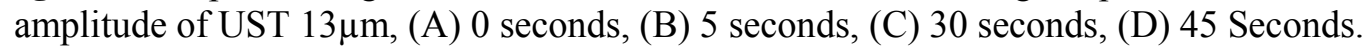

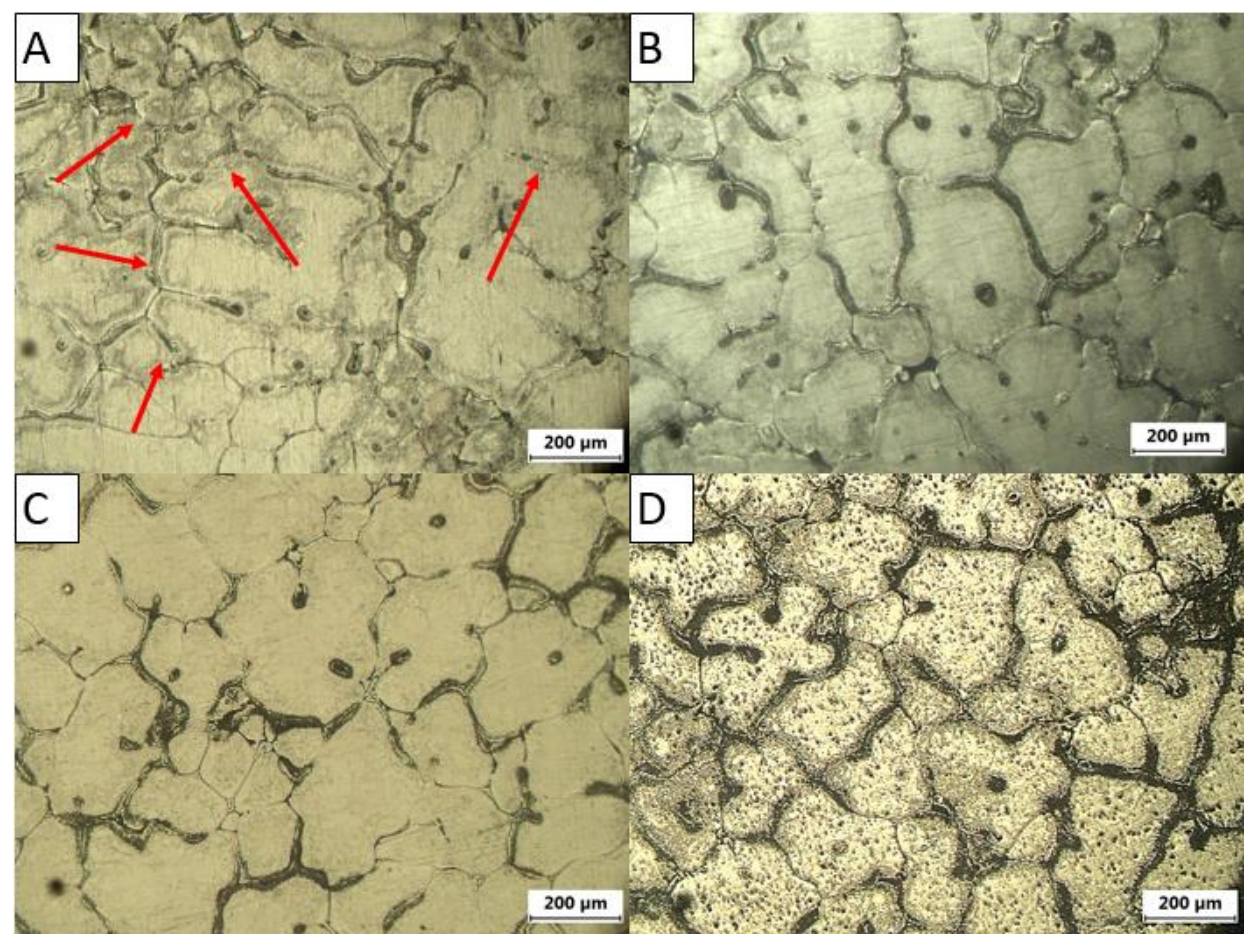

Figure 4. 7 Optical images of the microstructure of Al6061 melting temperature of $700^{\circ} \mathrm{C}$,

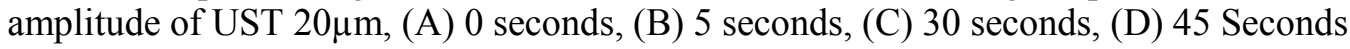


In order to demonstrate the structural change in the microstructure of caste Al6061 at $700^{\circ} \mathrm{C}$ with the addition of UST, three different locations of the cross section of the sample with and with UST were studied. Our samples has a cylindrical shape with a radius of $15 \mathrm{~mm}$, the three sections were selected from half of the cross section, due to the fact that the same behavior is expected from the other half. Section A correspond to the area closer to the walls of the crucible, section B correspond to the area around half of the radius of the sample and section $\mathrm{C}$ correspond to the center point of the sample.

As can be seen in Fig 4.8, For the sample without UST, section 1 present a combination of finer grains, in section 2 well defined columnar structures were visible and a combination between columnar a shrink grains in section 3, while the casted sample at $700^{\circ} \mathrm{C}, 45 \mathrm{sec}$ and $20 \mu \mathrm{m}$ amplitude of UST present an homogenous refined microstructure where columnar grains disappear due to the effect of UST.

The resulted microstructure founded for cast Al6061 without UST is the characteristic microstructure of a cast metal alloy. For metal alloys shrink and finer grains are visible in the area closer to the walls of the crucible and also in the central part of the microstructure due to the fact that, heterogeneous nucleation occurs in the walls of the crucible and also within the melt due to the presence of secondary phases. However, the solidification process is slow allowing the formation of columnar grains in the direction of the heat flow.

In the case of the sample treated with UST, the accelerated cooling rates experienced by the melt as a result of UST, in combination with the increasing heterogeneous nucleation, contribute to smaller grains in all the microstructure without columnar structures. 


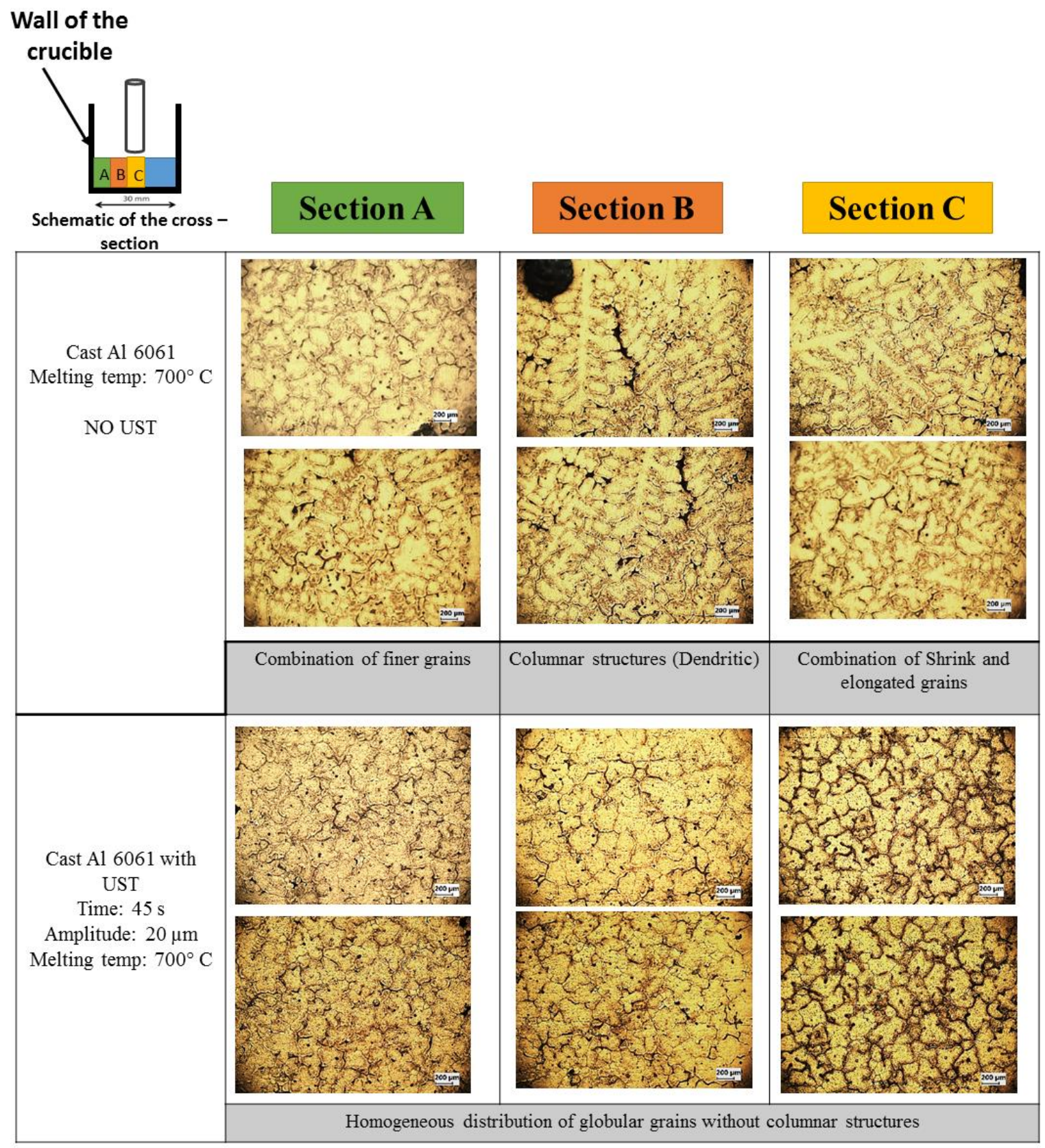

Figure 4. 8 Comparison in the microstructure of cast at $700^{\circ} \mathrm{C}$ Al6061 with and without UST by sections.

Grain refinement was observed with the addition of UST to the casting process. As can be seen in Table 4.3, an overall reduction in grain size in the range of $14 \%-43 \%$ was exhibited on samples with UST as compared with the base alloy. 
Table 4. 3 Complied results of grain size measurements as a function of UST parameters (Time, amplitude and temperature).

\section{Grain size Al6061 ( $\mu \mathrm{m})$}

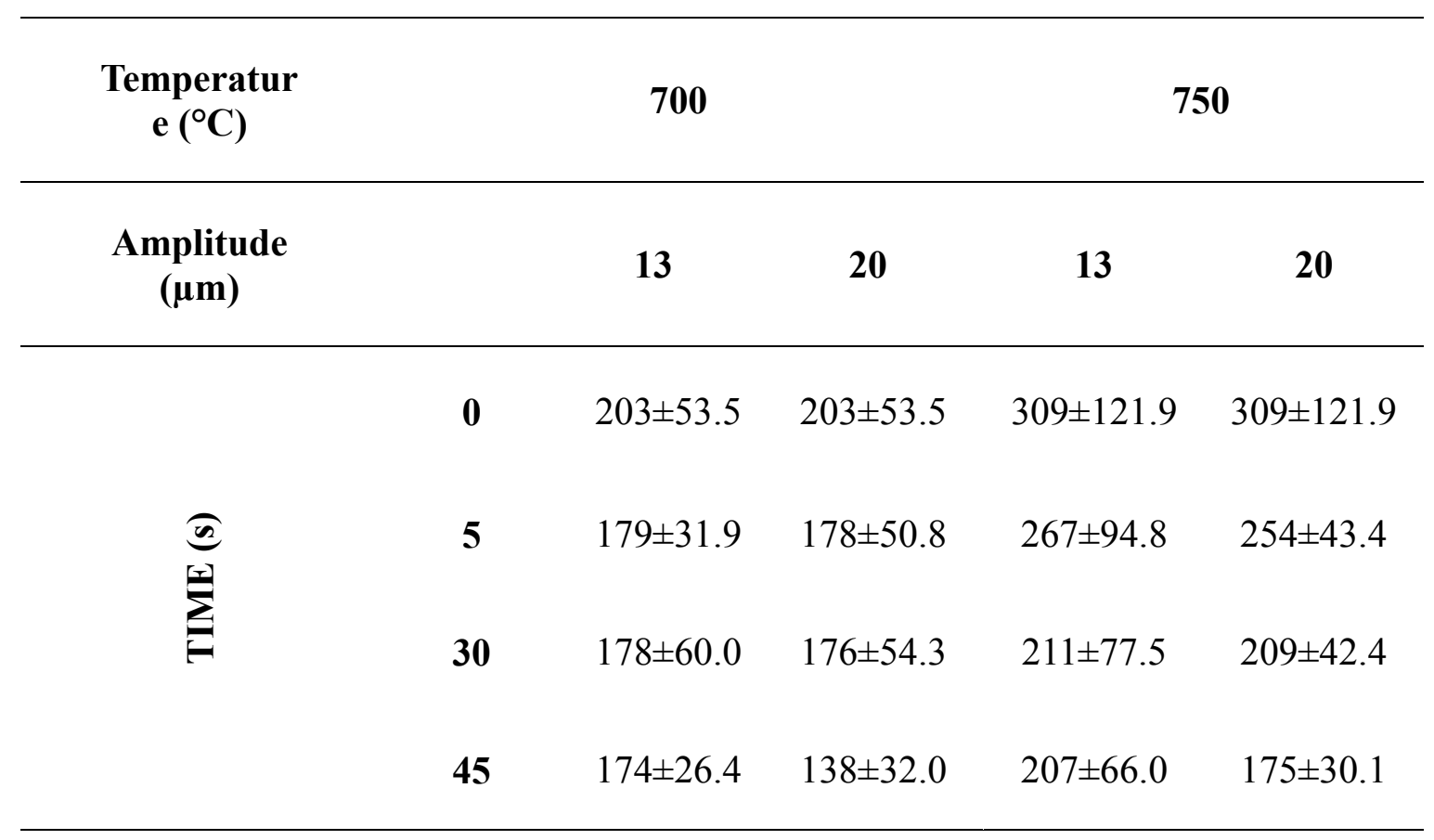

Figure 4.9, 4.11, 4.13 and 4.15, shows the grain size distributions of cast A16061 at melting temperatures of $750^{\circ} \mathrm{C}$ and $700^{\circ} \mathrm{C}$ treated with UST at amplitudes of 13 micron and 20 micron respectively for different time periods of sonication. The grain size distribution plots confirm the presence of a more uniform microstructure with the addition of UST to the casting process due to the bell shape of the plots. The increase of the sonication amplitude and time, result in uniform distribution of grains due to the fact that UST enhances heterogeneous nucleation. Clear evidence to the enhance homogeneity of the resulting cast samples is observed in the reduced standard deviation as shown in Figure 4.9D, 4.11D, 4.13D, 4.15D. 
During the expansion of the cavities, just before collapsing, the gas inside expands promoting undercooling in their surfaces. These cavities expand and collapse at a fast rate during the cavitation process. Consequently, when a cavity collapses, numerous small cavities are created and are distributed all over the melt. Some of these cavities will be responsible of continuing the cavitation process, while others will be responsible of enhancing the heterogeneous nucleation. The enhancement of heterogeneous nucleation with the addition of UST to the casting process of A16061 lies on to the undercooling of the surface of these small cavities that start acting as nuclei sites for solidification. In addition, with the collapsing of the cavities during the UST, the release of energy into the melt increases its temperature leading to higher cooling rates during solidification. Therefore, nucleation is accelerated resulting in a refined microstructure.

The effect of ultrasonic processing time on the grain refinement of the microstructure is visible on Figure 4.4 - 4.7. Not only columnar dendritic structures disappear from the microstructure, also, reduction on grain size is observed in the microstructure with the increase of UST time. In addition, globular grains characteristic of dendritic fragmentation and homogeneous microstructure were observed with the addition of UST. Once cavitations begin inside the molten metal, they will continue as long as the sonication source is inducing vibrations to the melt. Therefore, if UST time increases, the number of nucleation sites for solidification will increase in the same manner. Confirmation of cavitation during the experimentation under the processing conditions was demonstrated on Table 4.1. 
UST amplitude has a direct effect on the intensity of cavitation. Increases in the sonication amplitude will result in an increase of the intensity of cavitation, as it was reported on Table 4.1. Increases in the intensity of cavitation increases the number of cavities collapsing at the same time during the cavitation process. Therefore, an excessive amount of nucleation sites are created at a faster rate, resulting in an accelerated nucleation for solidification which is beneficial for the grain refinement.

In addition, processing temperature of UST and melting temperature of the aluminum have an effect on the speed of sound through the molten metal. The relation between them is described by Eq (5). Showing that at temperatures closer to the melting point of aluminum, the speed of sound is higher. As was presented on Table 4.1 , for $700^{\circ} \mathrm{C}$ speed of sound $(4723.6 \mathrm{~m} / \mathrm{s})$ is higher than at $750^{\circ} \mathrm{C}(4715.6 \mathrm{~m} / \mathrm{s})$.

Figure 4.10, 4.12, 4.14 and 4.16, show the reduction of the grain size as a function of sonication time, presenting a maximum grain size reduction at all conditions at time periods of 45 seconds. As a result, with $32 \%$ reduction in grain size for melting temperature of $700^{\circ} \mathrm{C}$ and sonication amplitude of $20 \mu \mathrm{m}$ (Figure $\left.4.15 \mathrm{D}\right)$ was the best of all.

Figure 4.14, shows the grain size measurement for cast $\mathrm{Al} 6061$ at $700^{\circ} \mathrm{C}$ melting temperature, and an amplitude of 13 micron as a function of sonication time. The main parameter of UST affecting the grain refinement in the cast Aluminum is found to be the processing temperature. The casting of specimens at lower temperature $\left(700^{\circ} \mathrm{C}\right)$ signifies that the viscosity of molten A16061 increases. Such increase in the density of the molten metal represents a barrier for the sound waves to travel through the melt when the amplitude is too low. In samples processed at $700{ }^{\circ} \mathrm{C}$, the UST amplitude of $13 \mu \mathrm{m}$ was 
not enough to generate significant differences in the grain size with the increase of sonication time. Even though the grain refinement due to the cavitation process is visible as compared with the based alloy with no UST. Increasing sonication time does not result in significant grain reduction as compared with samples processed at the same temperature $\left(700^{\circ} \mathrm{C}\right)$ while using $20 \mu \mathrm{m}$ sonication amplitude.
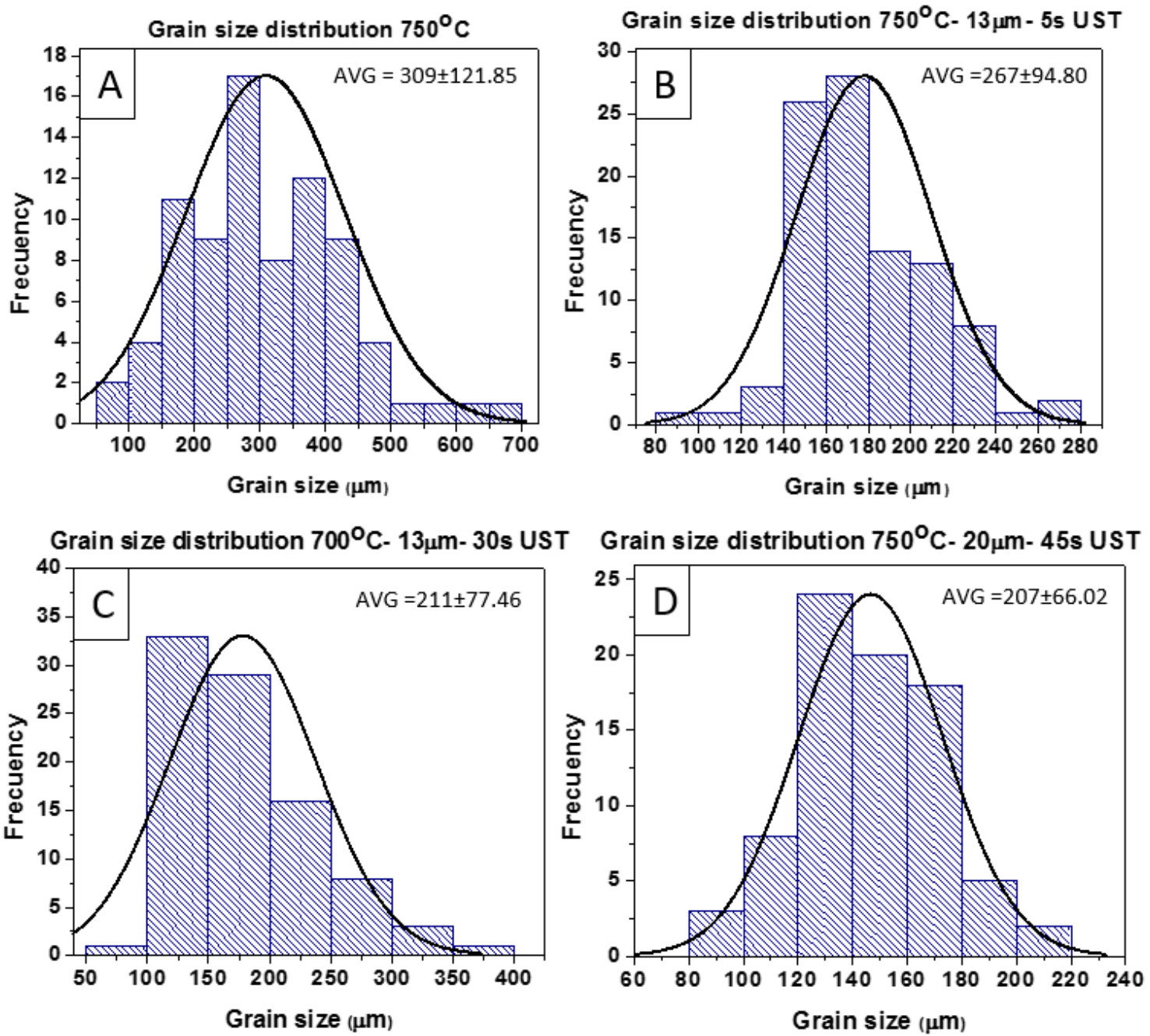

Figure 4. 9 Grain size distribution $\mathrm{A} 16061750^{\circ} \mathrm{C}$ melting temperature, 13 micron sonication amplitude as a function of sonication time, (A) 0 seconds UST, (B) 5 seconds UST, (C) 30 seconds UST, (D) 45 seconds UST. 


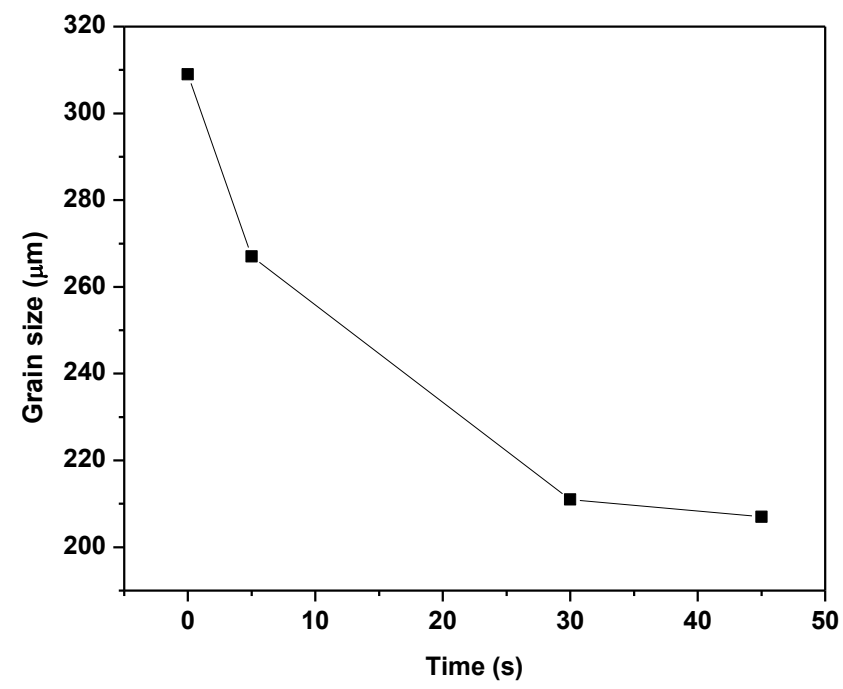

Figure 4. 10 Grain size measurement for cast $\mathrm{A} 16061,750^{\circ} \mathrm{C}$ melting temperature 13 micron amplitude as a function of sonication time.
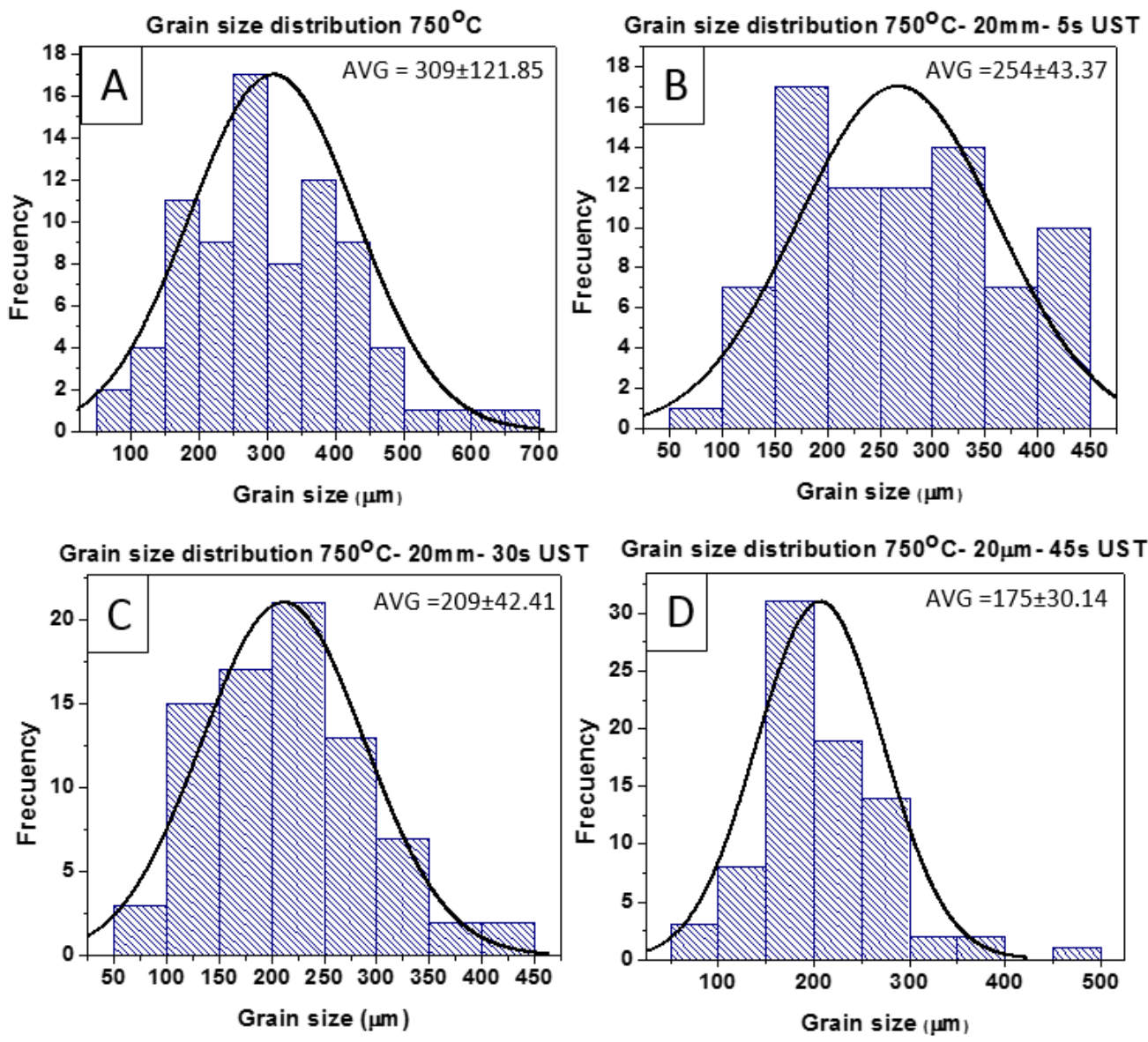

Figure 4. 11 Grain size distribution $\mathrm{A} 16061750^{\circ} \mathrm{C}$ melting temperature, 20 micron sonication amplitude as a function of sonication time, (A) 0 seconds UST, (B) 5 seconds UST, (C) 30 seconds UST, (D) 45 seconds UST. 


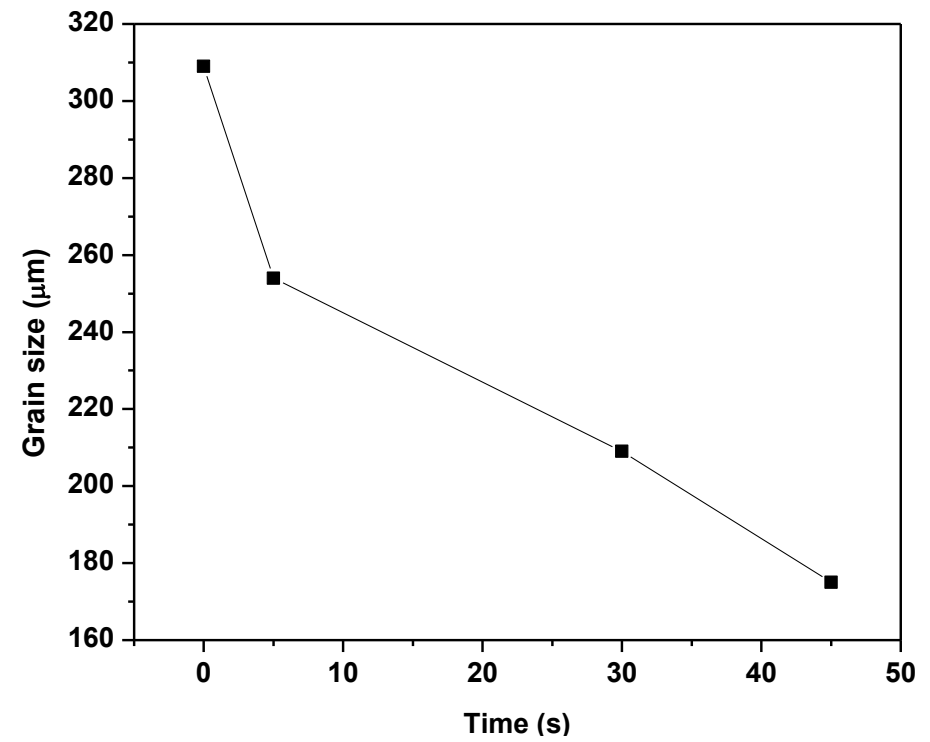

Figure 4. 12 Grain size measurement for cast $\mathrm{A} 16061,750^{\circ} \mathrm{C}$ melting temperature 20 micron amplitude as a function of sonication time.
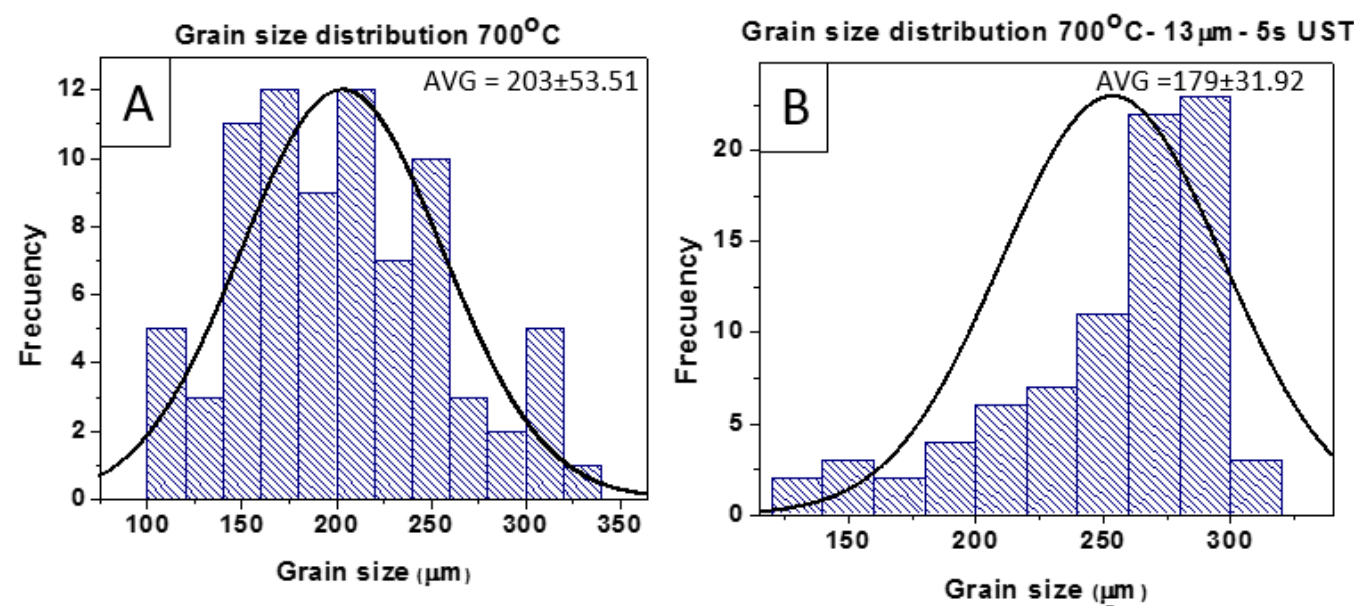

Grain size distribution $700^{\circ} \mathrm{C}-13 \mu \mathrm{m}-30 \mathrm{~s}$ UST Grain size distribution $700^{\circ} \mathrm{C}-13 \mu \mathrm{m}-45 \mathrm{~s}$ UST
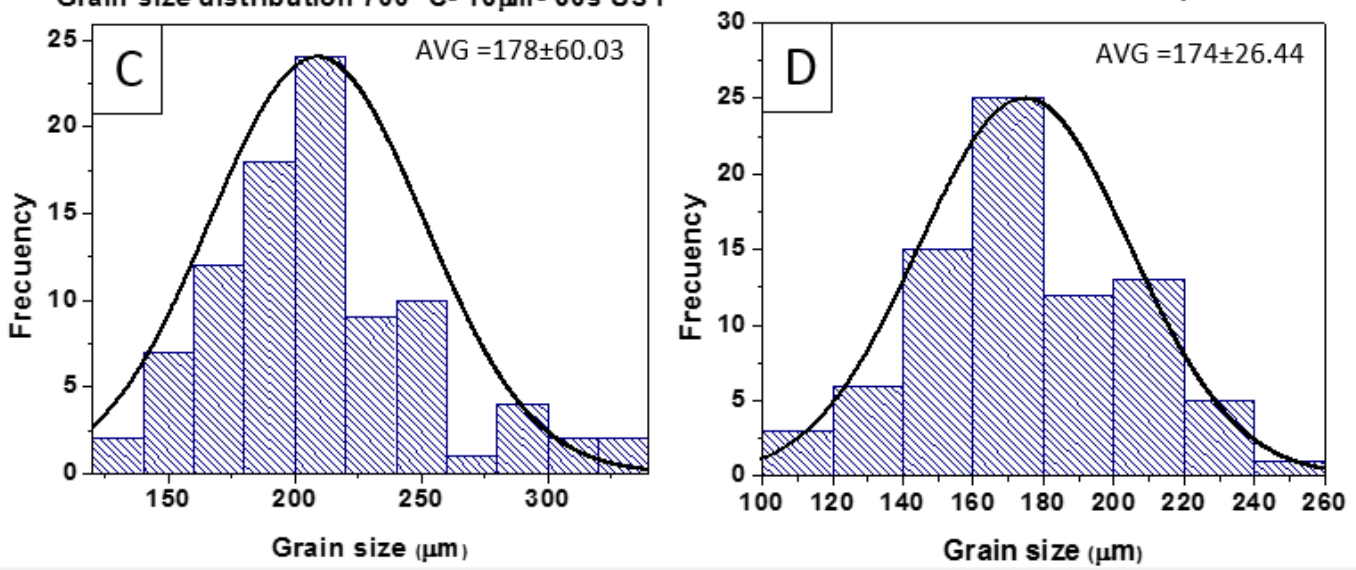

Figure 4. 13 Grain size distribution $\mathrm{Al} 6061700^{\circ} \mathrm{C}$ melting temperature, 13 micron sonication amplitude as a function of sonication time, (A) 0 seconds UST, (B) 5 seconds UST, (C) 30 seconds UST, (D) 45 seconds UST. 


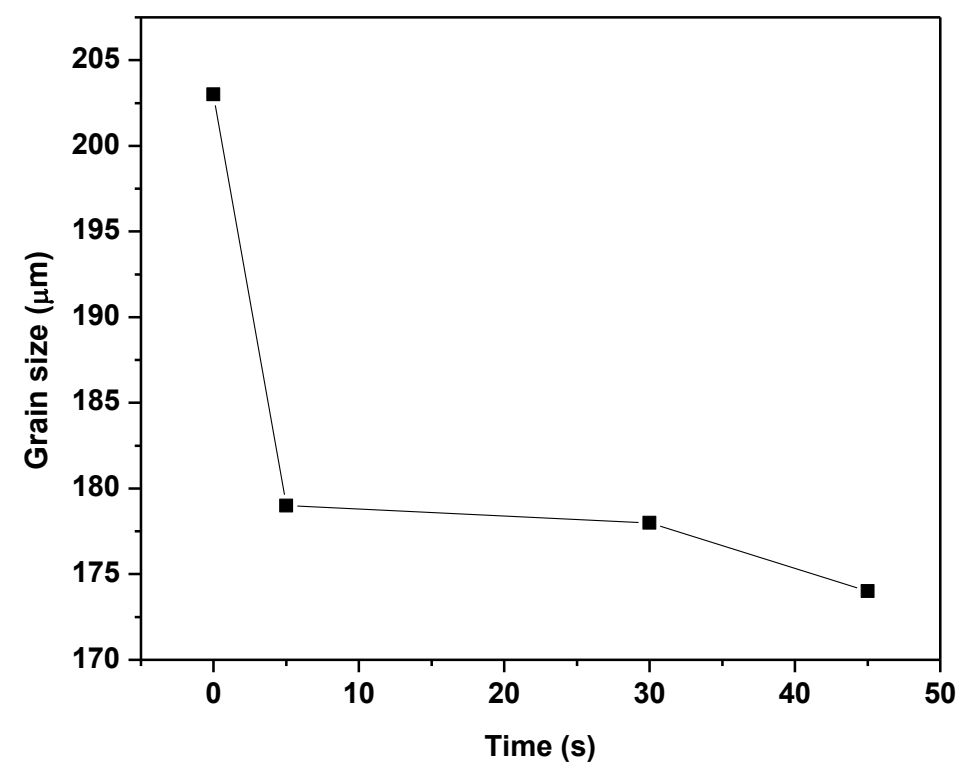

Figure 4. 14 Grain size measurement for cast $\mathrm{A} 16061,700^{\circ} \mathrm{C}$ melting temperature 13 micron amplitude as a function of sonication time.
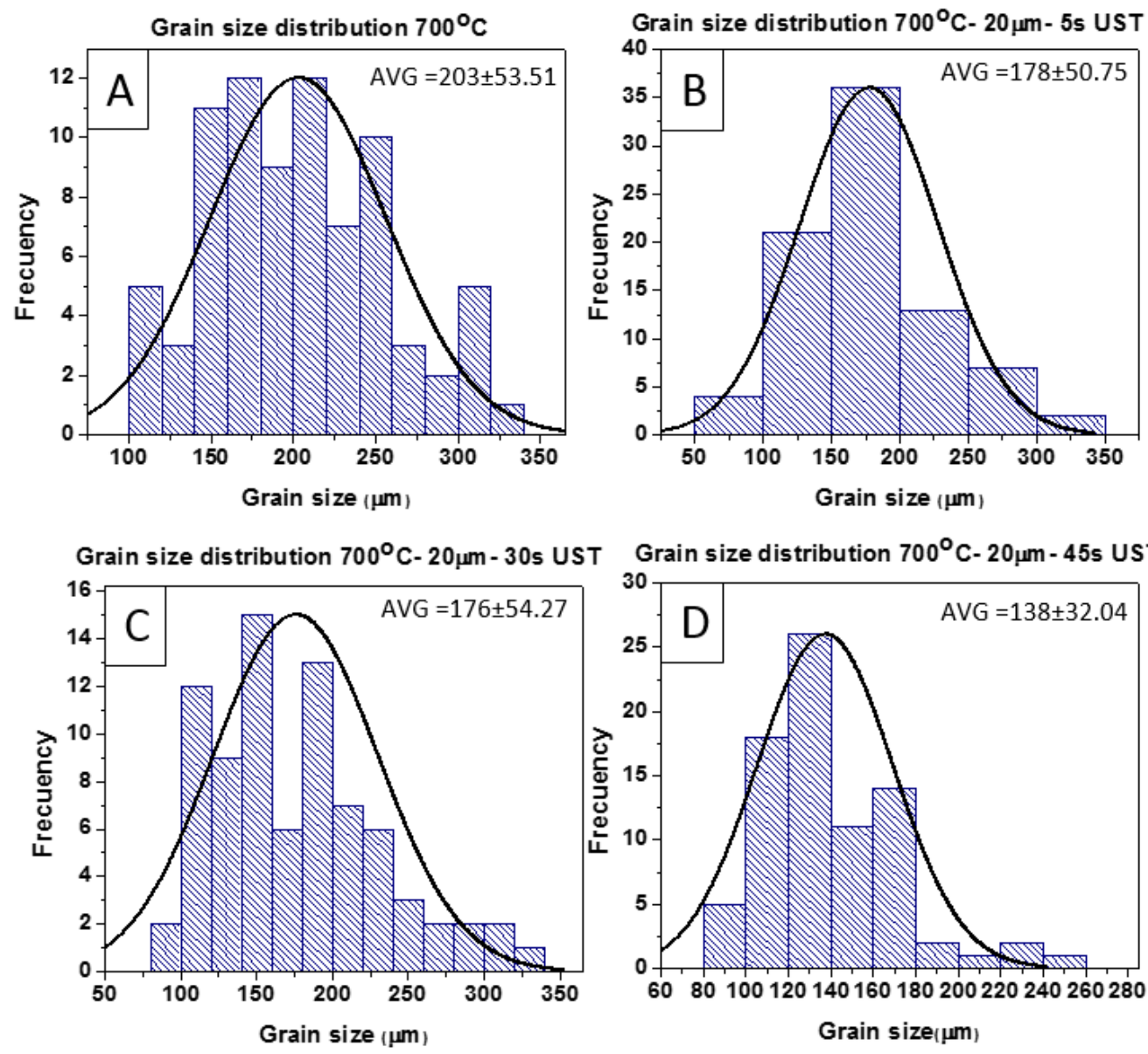

Figure 4. 15 Grain size distribution $\mathrm{A} 16061700^{\circ} \mathrm{C}$ melting temperature, 20 micron sonication amplitude as a function of sonication time, (A) 0 seconds UST, (B) 5 seconds UST, (C) 30 seconds UST, (D) 45 seconds UST. 


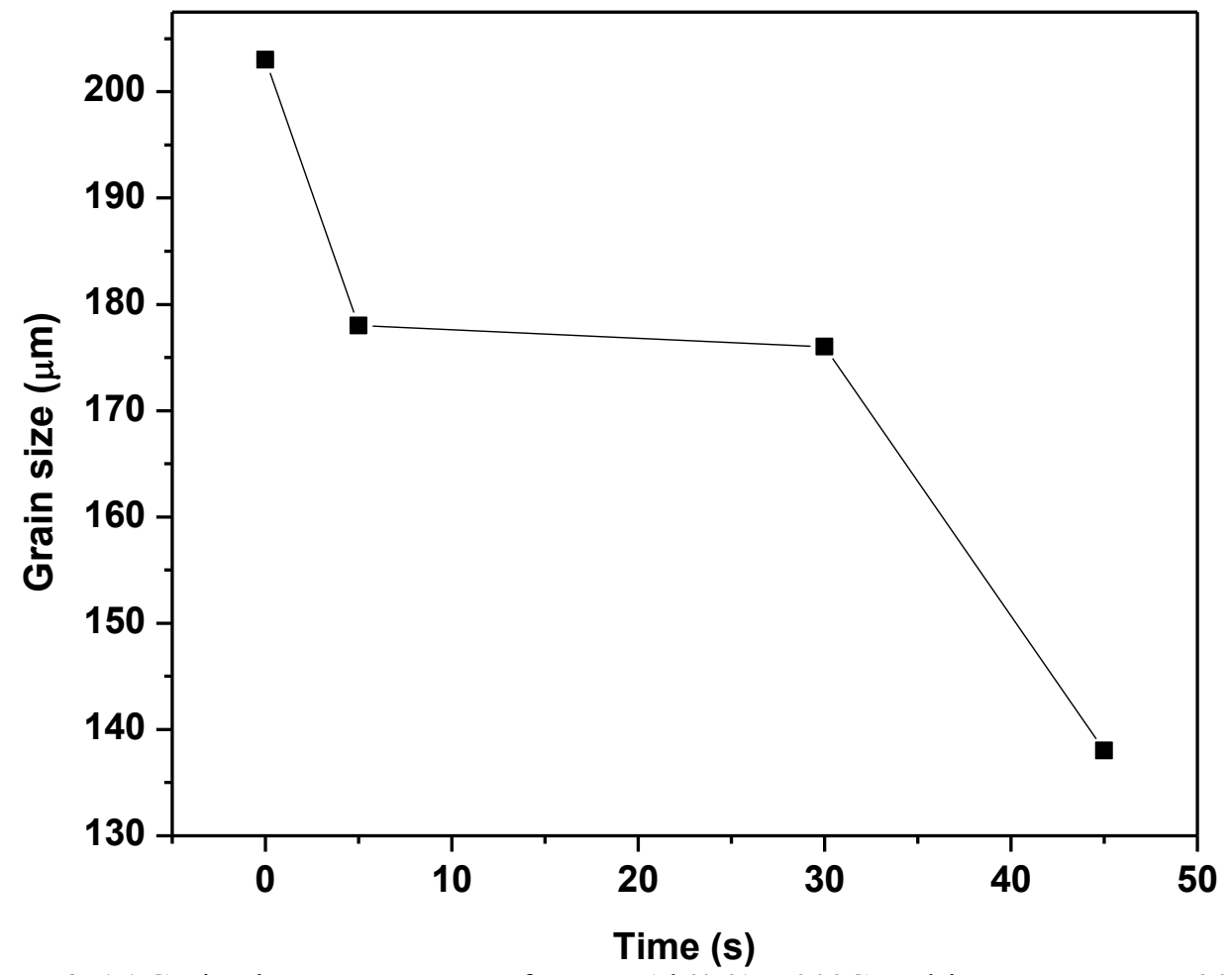

Figure 4. 16 Grain size measurement for cast A16061, $700^{\circ} \mathrm{C}$ melting temperature 20 micron amplitude as a function of sonication time.

Figure 4.17 presents the effect of the UST processing parameters on the final grain size of the microstructure of Al6061. The smallest grain size was obtained for a processing time of 45 seconds, at 20 microns amplitude, and with a melting temperature of $700{ }^{\circ} \mathrm{C}$. At such conditions the cast sample resulted in an average grain size of $138 \mu \mathrm{m}$. A reduction of $32 \%$ was observed in comparison with the sample casted at the same temperature without UST. 


\section{Grain size measuraments as a function of time $\&$ amplitude}

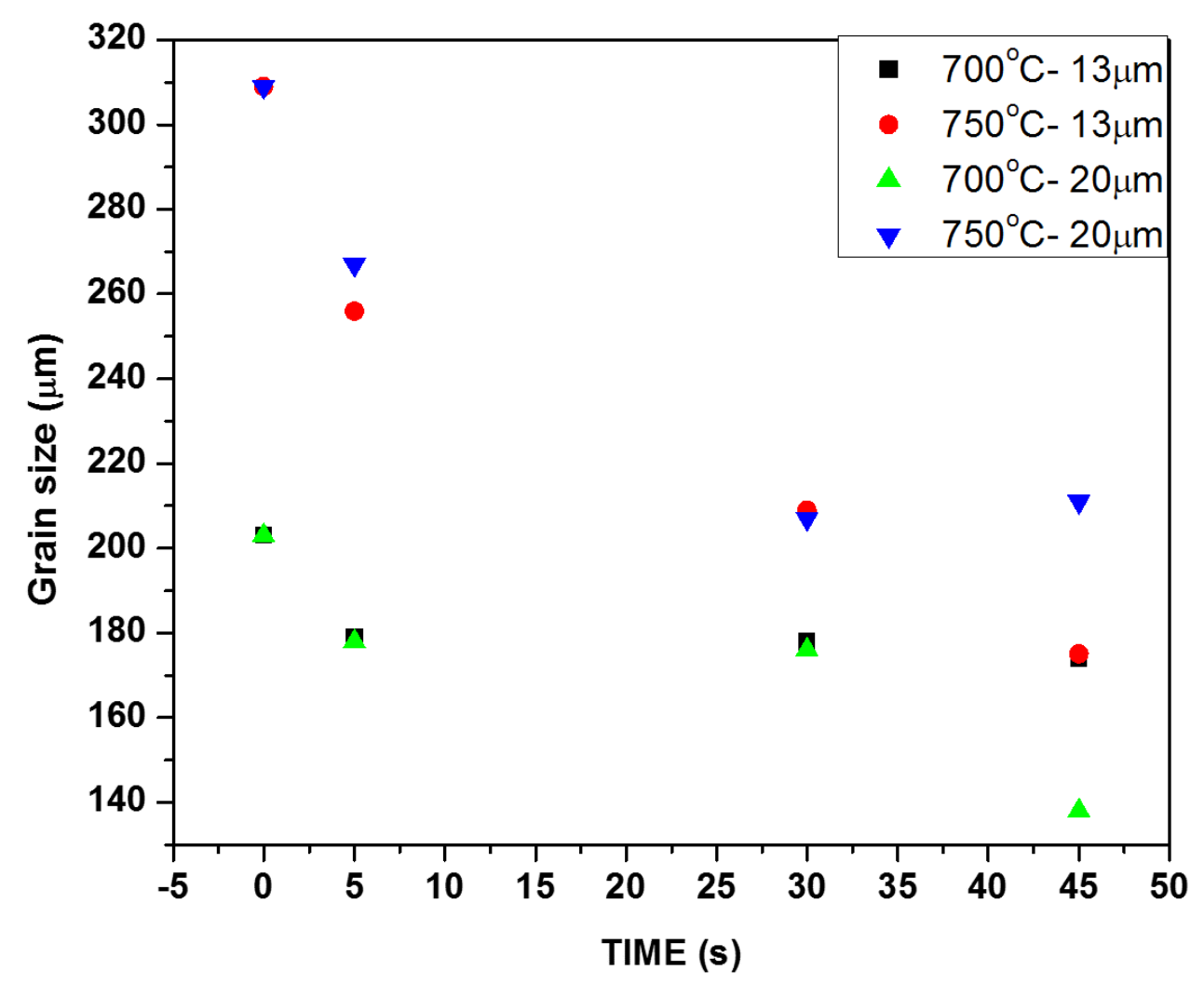

Figure 4. 17 Grain size measurements as a function of UST parameters (Time, amplitude and temperature)

\subsubsection{Fracture surface of the cast $\mathrm{Al} 6061$ at $750^{\circ} \mathrm{C}$ and $700^{\circ} \mathrm{C}$ with and without $\underline{\text { UST. }}$}

Figure 4.17A, C represents SEM of the fracture surface of $\mathrm{Al} 6061$ casted at $750^{\circ} \mathrm{C}$ and $700^{\circ} \mathrm{C}$ without UST respectively. The morphology of the fracture surface is dominated by large pores as a result of the air trapped between the aluminum pieces during casting. Also, intergranular porosity characteristic of $\mathrm{H}_{2}$ trapped in the melt is visible. Figure 4.18B and $4.18 \mathrm{D}$ represents SEM of the fracture surface of $750^{\circ} \mathrm{C}$ and $700^{\circ} \mathrm{C}$ melting temperature with UST (sonication time $45 \mathrm{~s}$ and $20 \mu \mathrm{m}$ amplitude) respectively. The morphology of the fracture surface is denser in comparison with samples without UST. However, small pores 
are still visible in both samples. The reduction in the porosity is related to the degassing process promoted by UST. In addition globular grains, characteristic of the dendritic fragmentation by UST, are clearly visible on the fracture surface.
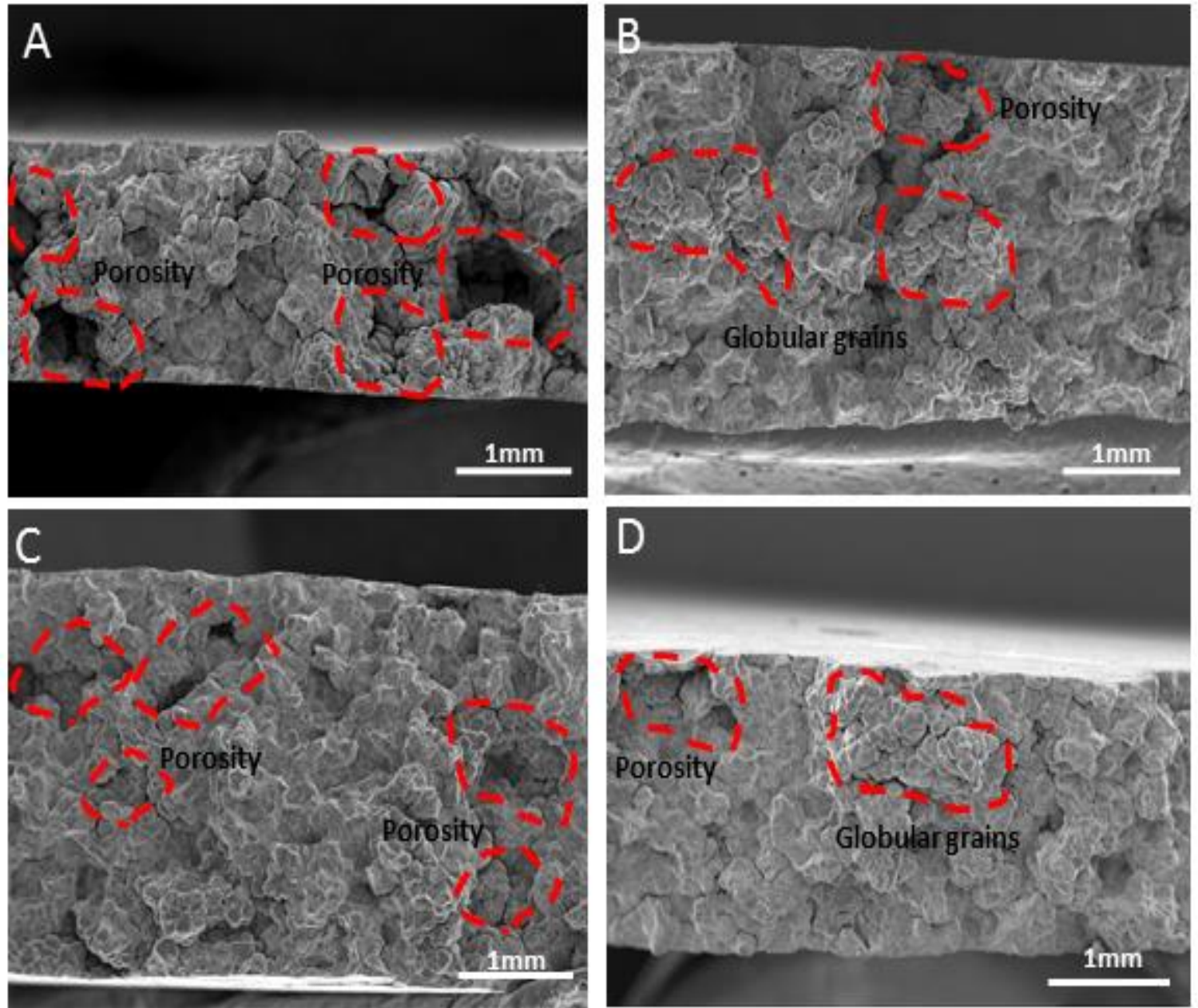

Figure 4. $18 \mathrm{SEM}$ of fracture surface of $\mathrm{Al} 6061$ with $20 \mu \mathrm{m}$ UST amplitude, (A) $750{ }^{\circ} \mathrm{C}$ melting temperature without UST (B) $750^{\circ} \mathrm{C}$ melting temperature with 45 Seconds UST, (C) $700{ }^{\circ} \mathrm{C}$ melting temperature without UST (D) $700^{\circ} \mathrm{C}$ melting temperature with 45 Seconds UST.

In addition, the presence of needle-like structures are visible in the surface of the grains of sample casted at $750{ }^{\circ} \mathrm{C}$ without the introduction of UST (Figure 4.19). To characterize and identify this particles, Energy Dispersive Spectroscopy (EDS) was performed. 
The aluminum and oxygen peaks confirmed the presence of aluminum oxide $\left(\mathrm{Al}_{2} \mathrm{O}_{3}\right)$, which is related with the peaks of $\mathrm{Al}_{2} \mathrm{O}_{3}$ detected on XRD for the same sample. The formation of oxides in the cast specimens without UST are more prominent at higher temperatures.

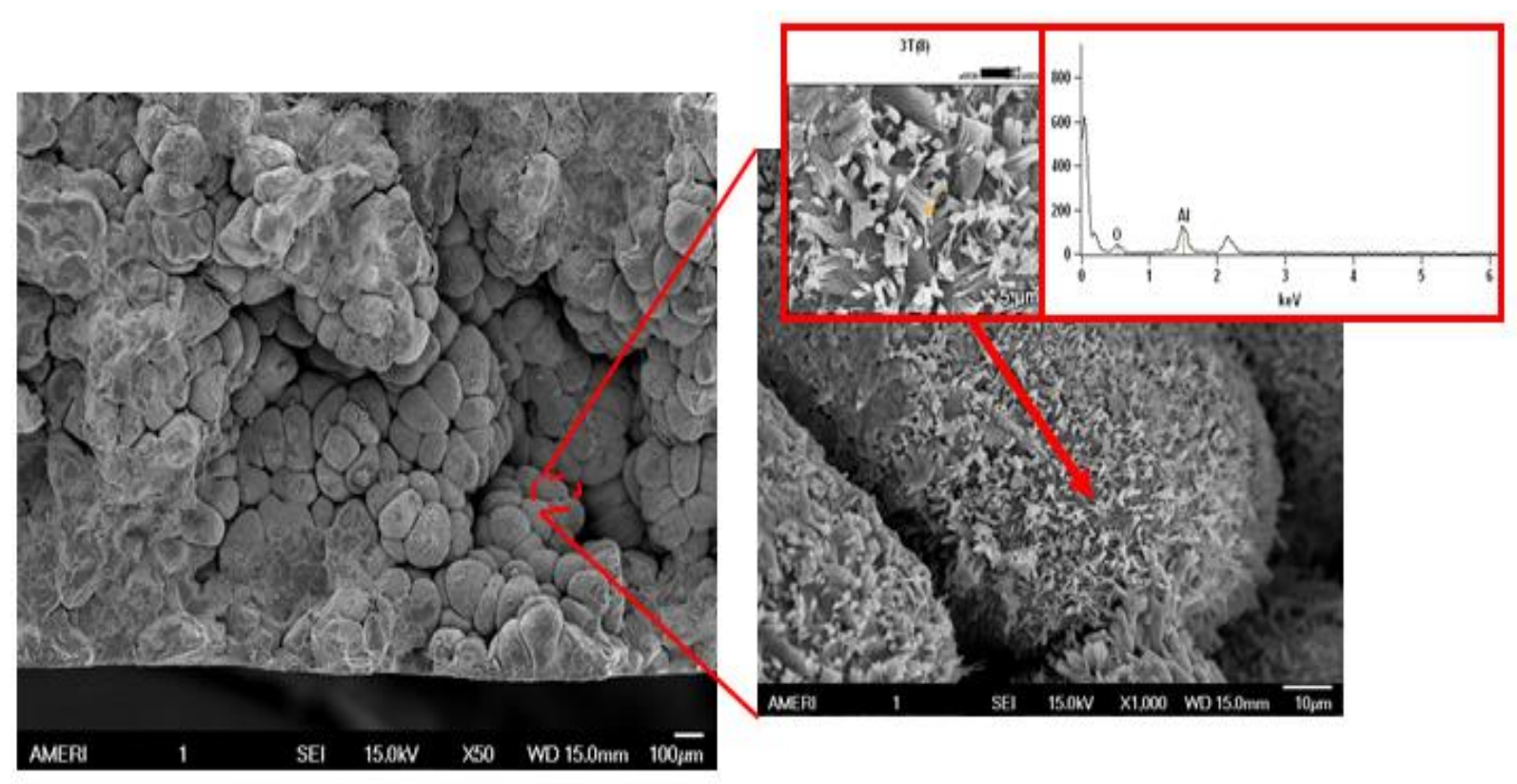

Figure 4. 19 SEM \& EDS of fracture surface of Al $6061750{ }^{\circ} \mathrm{C}$ melting temperature without UST.

\subsection{Effect of ultrasonic treatment on micro hardness of cast Al6061 with and without UST}

In order to evaluate the resulting mechanical behavior of the cast samples as a function of the induced UST process, cast samples at $700^{\circ} \mathrm{C}$ and $750^{\circ} \mathrm{C}$ with and without UST were subjected to Vickers micro hardness tests. Loads of $50 \mathrm{gf}$ and dwell periods of 10 seconds were used for all the specimens. Increase in the microhardness were observed with the addition of UST to the casting process. As can be seen in Table 4.4 an overall 
increase in micro hardness in the range of $0.5 \%-31.5 \%$ was exhibited on samples with UST as compared with the base alloy.

Table 4. 4 Complied results of micro hardness as a function of UST parameters (Time, amplitude and temperature)

\section{Micro hardness (MPa)}

\begin{tabular}{|c|c|c|c|c|}
\hline \multirow{2}{*}{$\begin{array}{l}\text { Temperature }\left({ }^{\circ} \mathrm{C}\right) \\
\text { Amplitude }(\mu \mathrm{m})\end{array}$} & \multicolumn{2}{|c|}{700} & \multicolumn{2}{|c|}{750} \\
\hline & 13 & 20 & 13 & 20 \\
\hline \multirow{4}{*}{ 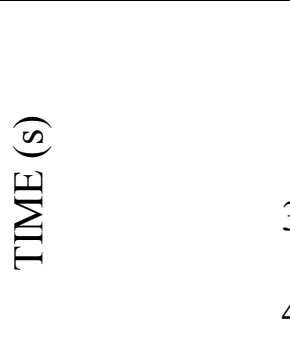 } & $647 \pm 40.01$ & $647 \pm 40.01$ & $496 \pm 22.56$ & $496 \pm 40.01$ \\
\hline & $650 \pm 50.11$ & $651 \pm 83.16$ & $536 \pm 18.14$ & $583 \pm 50.11$ \\
\hline & $652 \pm 49.13$ & $667 \pm 42.17$ & $585 \pm 17.06$ & $630 \pm 49.13$ \\
\hline & $657 \pm 86.69$ & $699 \pm 25.79$ & $616 \pm 34.23$ & $652 \pm 86.69$ \\
\hline
\end{tabular}

Figure 4.20 presents the effect of the UST processing parameters on the final microhardness of Al6061. The highest microhardness was obtained for a processing time of 45 seconds, and 20 microns of amplitude, at a melting temperature of $700{ }^{\circ} \mathrm{C}$, which are the same conditions where smallest grains size were reported. The average micro hardness values of $699 \mathrm{MPa}$ were exhibited. An increase of $8 \%$ was observed in comparison with the sample casted at the same temperature without UST. 


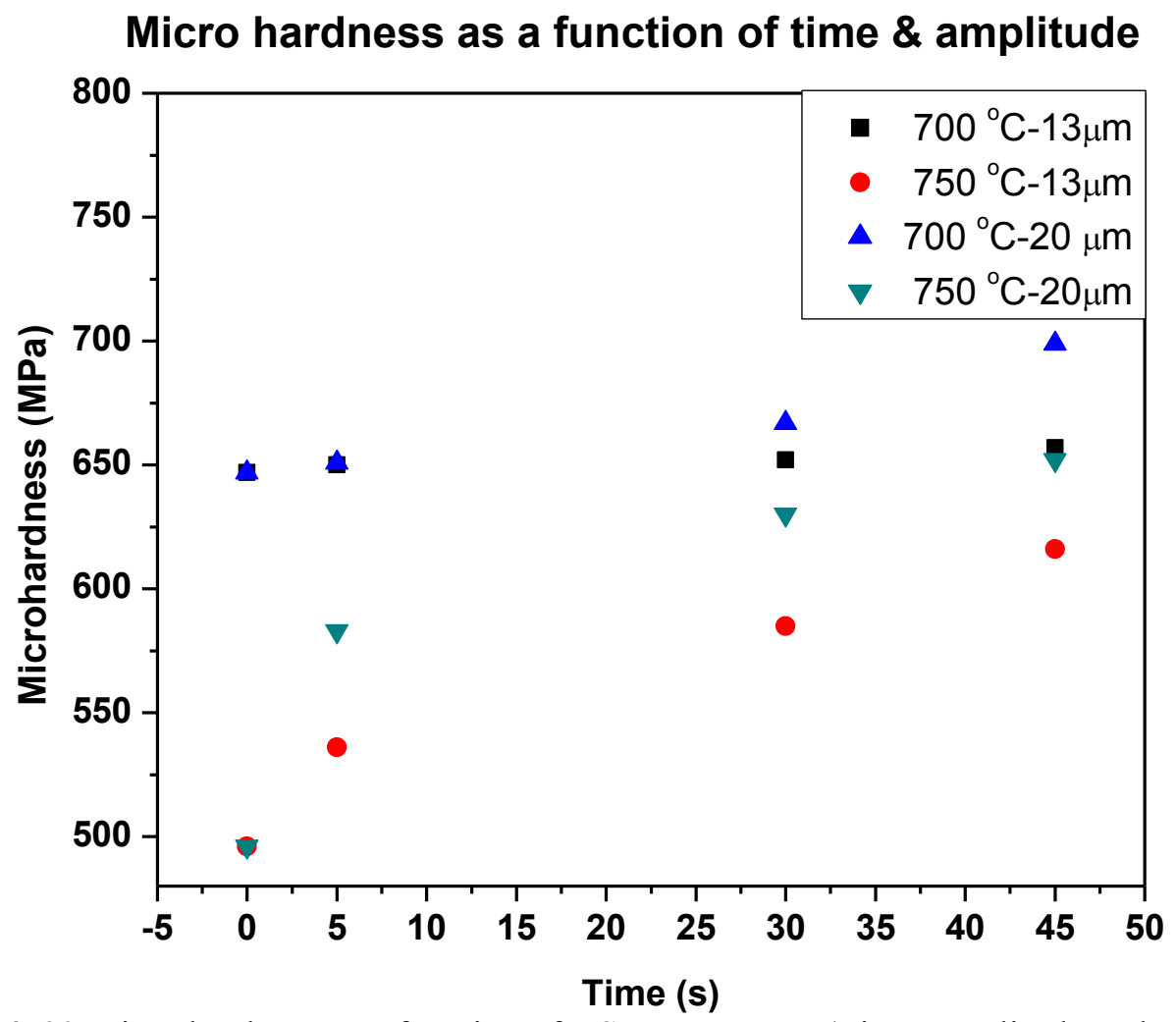

Figure 4. 20 Micro hardness as a function of UST parameters (Time, amplitude and temperature).

\subsubsection{Hall- Petch relationship for cast Al6061 as a function of UST parameters}

The increase number of nucleation sites in the melt as a result to the introduction of vibrations (UST) is responsible for the decrease in grain sizes. As a result, mathematical relations between the evolution of the enhanced microhardness as a function of the UST treatment can be utilized. One of the basic principles behind the improvement of the mechanical properties in cast metals is attributed to the correlation of grain refinement in the microstructure. According to Hall-Petch's relationship, reduction in the grain size of Al alloys increases the hardness of the material, this relationship is expressed by the following expression Eq. (1). 
In order to describe the relation between grain size and microhardness in all UST and no UST cast samples, Hall- Petch's relationship was computed and is found in Figure 4.21 and 4.22 as a function of sonication temperature for $13 \mu \mathrm{m}$ and $20 \mu \mathrm{m}$ sonication amplitude. The coefficient of determination, $\mathrm{R}^{2}$ of fitted lines for $700^{\circ} \mathrm{C}$ and $750^{\circ} \mathrm{C}$ at 13 micron are between 0.84 and 0.98 . Higher values of $\mathrm{R}^{2}$ superiors than $80 \%$ confirm that the variation about the mean for the values plotted follows the Hall-Petch's equation obtained for each one. Values reported for Ho were in a range between 110 to $467 \mathrm{MPa}$ and $\mathrm{K}_{\mathrm{h}}$ in a range between 2487 to $7200 \mathrm{MPa}$ for all the conditions studied.

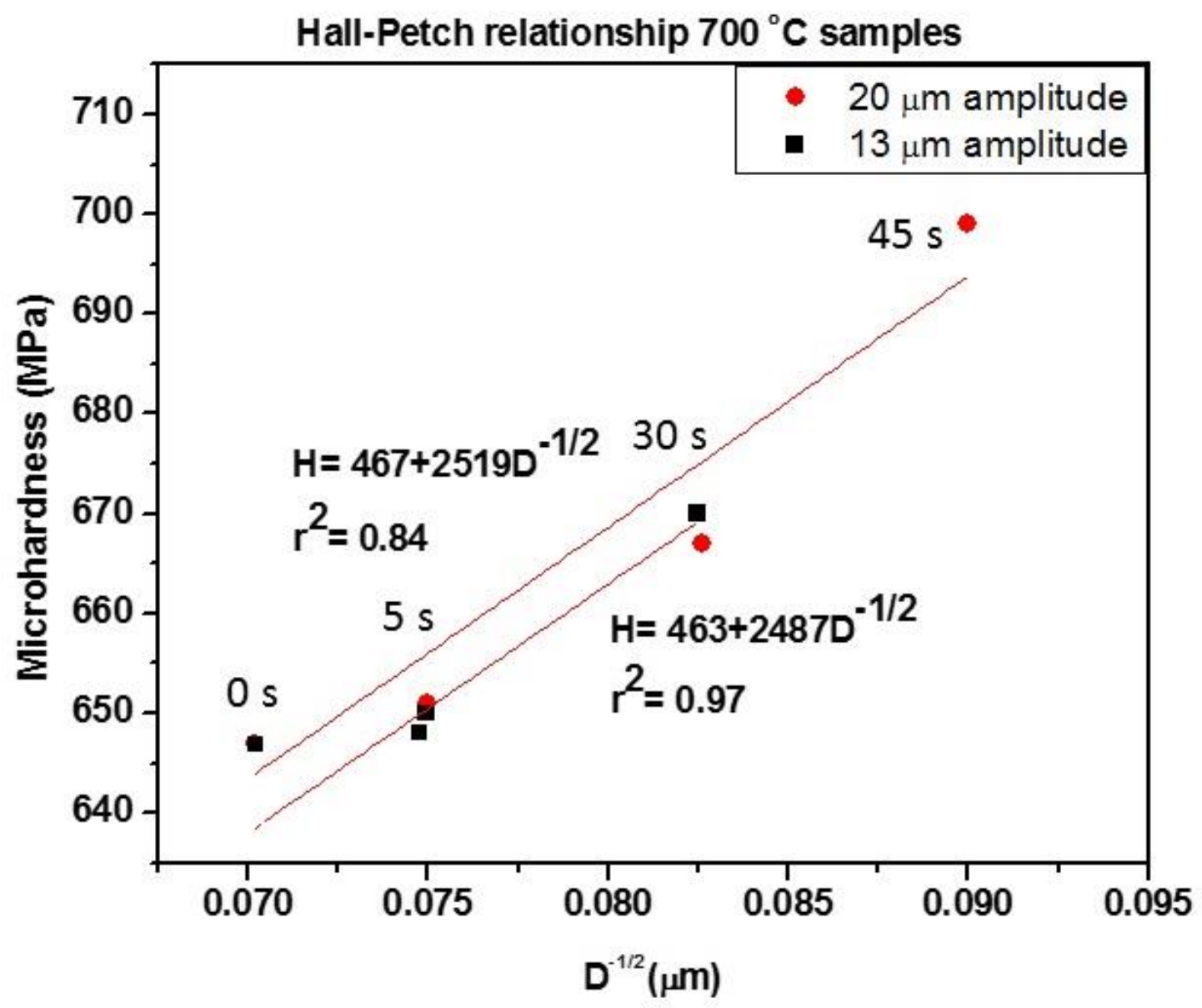

Figure 4. 21 Hall-Petch relationship at $700{ }^{\circ} \mathrm{C}$ melting temperature for $13 \mu \mathrm{m}$ and $20 \mu \mathrm{m}$ sonication amplitude. 


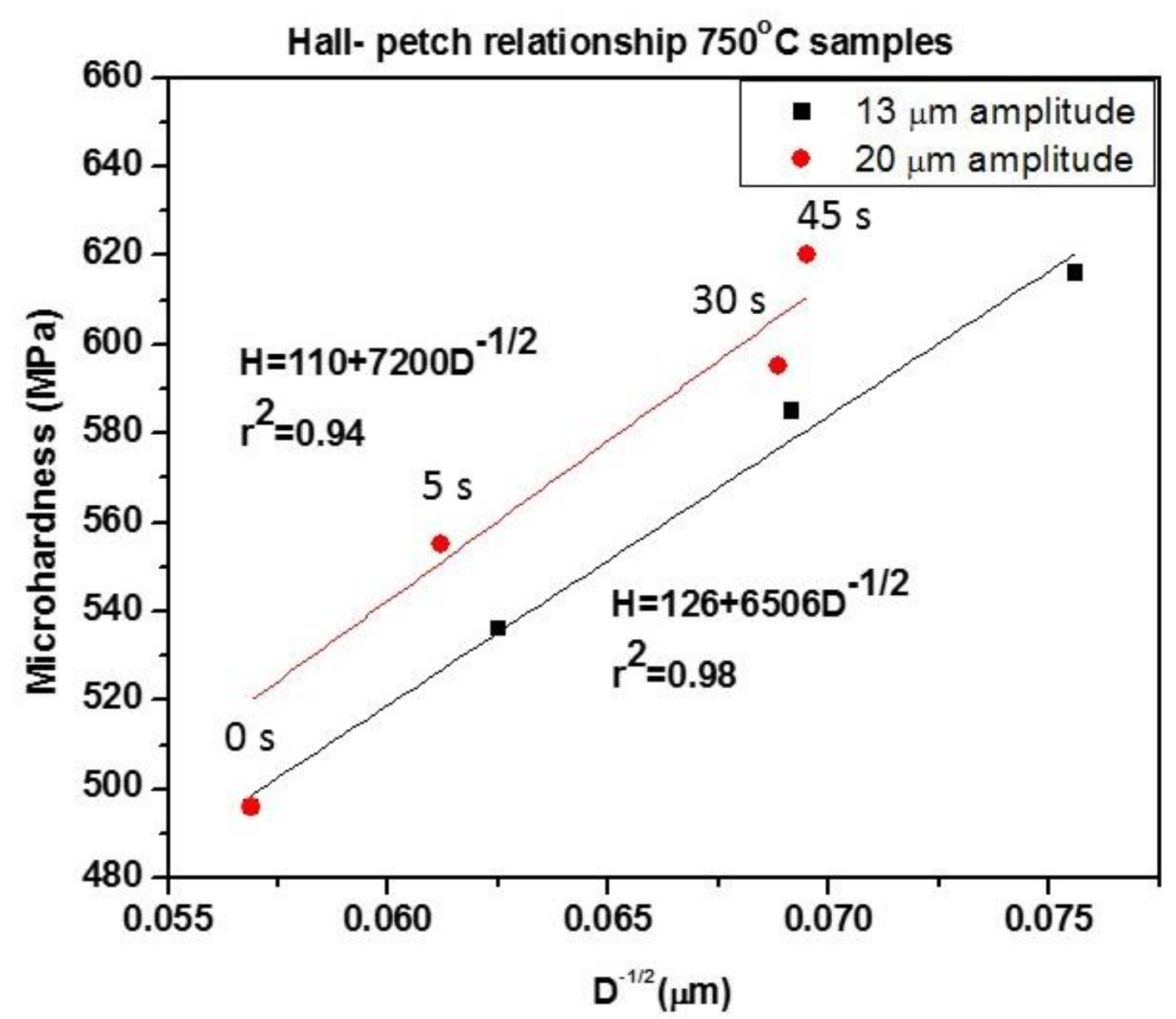

Figure 4. 22 Hall-Petch relationship at $750{ }^{\circ} \mathrm{C}$ melting temperature for $13 \mu \mathrm{m}$ and $20 \mu \mathrm{m}$ sonication amplitude.

In the mathematical relation, $\mathrm{H}_{0}$ represents the minimum stress required to move free dislocations. Such stress was explained by Peierls as lattice frictions experienced in the form of shear stresses moving dislocations. For materials with small grained microstructure, Peierls stress is higher, which is related to the minimum shear stress required to move a free dislocation [88]. Therefore, $\mathrm{H}_{0}$ is higher for $700^{\circ} \mathrm{C}$ treated samples which are the ones with smallest grains size due to refined microstructure obtained after UST. Moreover, $\mathrm{K}_{\mathrm{h}}$ represents the barrier to dislocation motions and is also related to the ductility of the material, increase of $\mathrm{K}_{\mathrm{h}}$ is correlated with reduction in ductility [89]. 
Sonication amplitude has a direct relationship with the intensity of cavitation. Higher intensity of cavitation, increases the number of cavities collapsing at the same time during the cavitation process resulting in a refined microstructure and increase of hardness. In addition, increase in hardness will result in reduction of ductility. Therefore, higher values of $K_{h}$ were obtained with the increases of sonication amplitude.

From the parametric study performed, the UST parameters that exhibited the best results on grain refinement, reduction of porosity and increase of microhardness were selected for the manufacture of MMC. These parameters are the following:

- $\quad$ Sonication time: 45 second

- $\quad$ Amplitude: $20 \mu \mathrm{m}$

- $\quad$ Melting temperature : $700{ }^{\circ} \mathrm{C}$

MMCs were fabricated using Ultrasonic treatment as a dispersion technique with the sonication parameters mentioned above. Al6061 was used as the metal matrix, $\mathrm{WS}_{2}$ and CNTs where used as reinforcements.

As it was demonstrated in the parametric study, with an intensity of cavitation of $3631.56 \mathrm{Wcm}^{-2}$ and a sound pressure of $17 \mathrm{MPa}$ (Table 4.1) corresponding to the condition presented above, cavitation will be developed in the melt. Therefore, the energy released into the melt during the cavitation process is high enough to break the agglomeration of particles. In addition during the cavitation process the gaseous phases on the surface of the reinforcement particles are ripped off, as a result the contact angle between the molten aluminum and these particles is reduced. Once the gaseous phases are removed from the 
particles, the molten aluminum is forced to fill those spaces resulting in the wetting between the aluminum and the particles.

In order to determine if the addition of UST as a dispersion technique to the manufacture of MMC was effective, characterization of $\mathrm{Al}-1 \mathrm{wt} \% \mathrm{WS}_{2}$ and $\mathrm{Al}-0.15 \mathrm{wt}$.

$\%$ CNT MMC were performed. The characterization of the composites included the following: Densification measurements, X-ray diffraction, evaluation of fracture surface morphology, microstructural analysis, and microhardness test. In addition, due to the nature of $\mathrm{WS}_{2}$ and CNT as self-lubricant materials, wear tests was performed in order to study the effect of UST on the lubricious and wear resistance of the composites.

\subsection{Al-1wt. \% WS 2 MMC manufactured using UST as a dispersion technique.}

Theoretical density for Al6061 is $2.7 \mathrm{~g} / \mathrm{cm}^{3}$ and $\mathrm{WS}_{2}$ is $7.5 \mathrm{~g} / \mathrm{cm}^{3}$. Density for Al$1 \mathrm{wt}$. $\% \mathrm{WS}_{2} \mathrm{MMC}$ was calculated using the rule of mixtures resulting to be $2.71 \mathrm{~g} / \mathrm{cm}^{3}$. The purpose of computing the density of the composite by rule of mixtures is to have a theoretical density of the composite to compute the porosity. Archimedes' density of the composite with and without UST were computed resulting on $2.7079 \mathrm{~g} / \mathrm{cm}^{3}$ and 2.6897 $\mathrm{g} / \mathrm{cm}^{3}$ respectively.

As it was demonstrated from the parametric study, the addition of UST to the casting process results in an increment of the densification of the material. Table 4.5 reports porosity measurements for Al-1wt. \% $\mathrm{WS}_{2}$ specimens with and without UST. The porosity was reduced from $1 \%$ to $0.34 \%$ with the addition of UST. 
Table 4. 5 Porosity measurements of $\mathrm{Al}-1 \mathrm{wt} . \% \mathrm{WS}_{2}$ as a function of ultrasonic treatment

\begin{tabular}{cc}
\hline Al-1wt. $\% W_{2}$ & Porosity (\%) \\
\hline No UST & 1 \\
UST & 0.34 \\
\hline
\end{tabular}

In order to determinate the presences of $\mathrm{WS}_{2}$ or any reaction product between the metal matrix and the reinforcements $\left(\mathrm{A} 16061\right.$ and $\left.\mathrm{WS}_{2}\right)$ developed during the casting process with and without UST, X-ray diffraction was performed.

Figure 4.23A shows the X-ray diffraction peaks of the samples mentioned above. The index of the peaks with highest intensity corresponds to aluminum in all the cast samples. Due to the small amount of $\mathrm{WS}_{2}$ added, a slow scan from 10 to 30 degrees was performed (Figure 4.23B-C). The index of the peaks with highest intensity for these two slow scans correspond to $\mathrm{WS}_{2}$ (Red dots). However, the peaks for the sample with UST are not as prominent as the one for the sample without UST. Due to the small amount of $\mathrm{WS}_{2}$ (1 wt. \%) added to the melt after the dispersion by UST, detection of the particles is difficult. On the other hand, the agglomeration of $\mathrm{WS}_{2}$ particles on the samples without UST makes it possible for X-rays to detect them during the slow scan. 

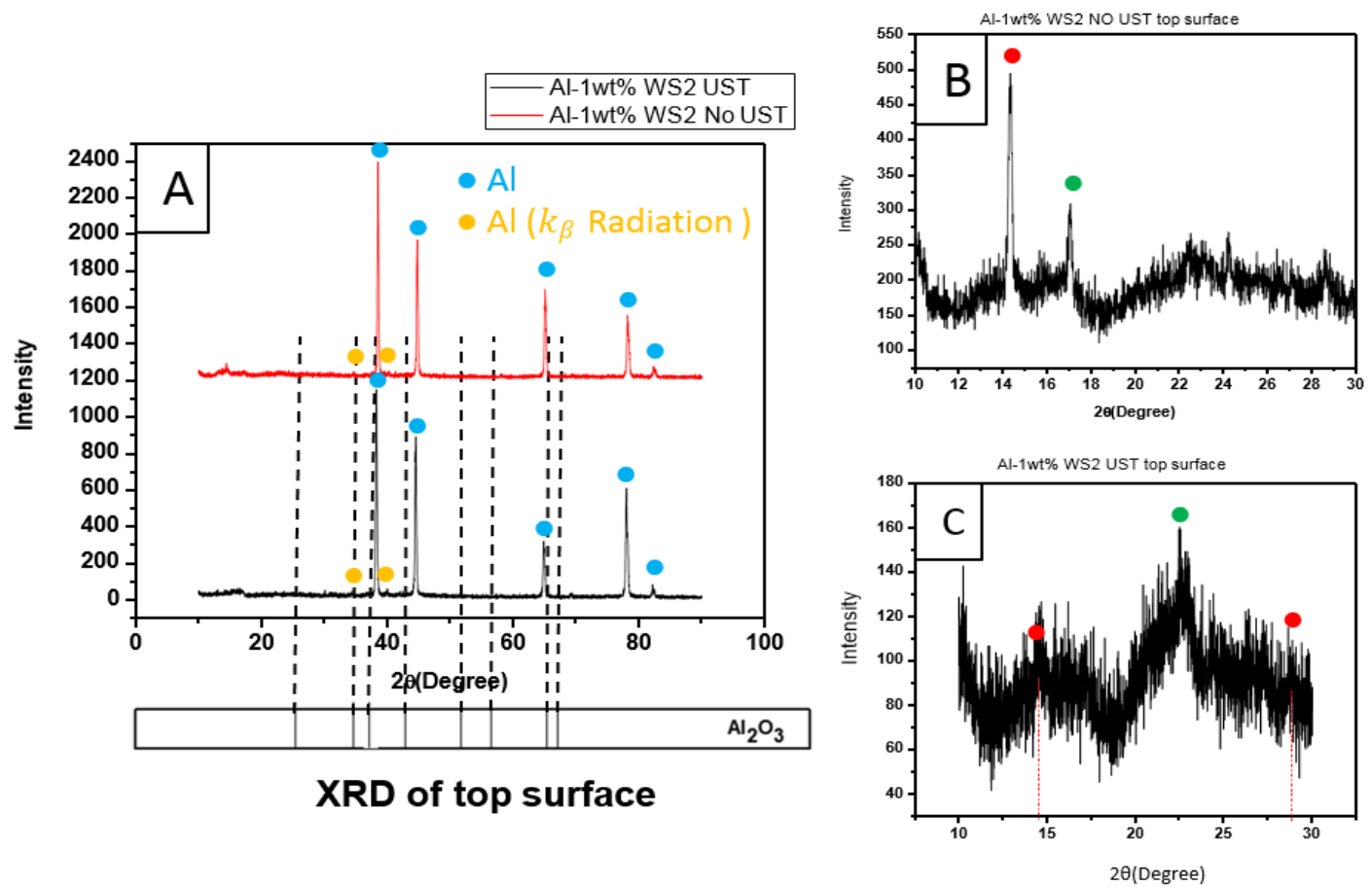

Figure 4. $23 \mathrm{X}$-ray diffraction patterns. (A) Al-1wt. \% $\mathrm{WS}_{2}$ with and without UST, (B) slow scan Al-1wt. \% WS $\mathrm{WS}_{2}$ without UST, (C) Al-1wt. \% WS 2 with UST.

Figure 4.24. Shows optical images of the microstructure of cast Al6061 with UST and Al-1wt $\% \mathrm{WS}_{2}$ with and without UST. Al6061 with UST (Figure 4.23A) and Al-1wt. $\% \mathrm{WS}_{2}$ with UST (Figure 4.23C) exhibit a characteristic microstructure of a metal treated with UST, presenting equiaxed structures and globular grains (non-dendritic). However, the addition of $\mathrm{WS}_{2}$ particles to the $\mathrm{Al}$ matrix and UST treatment resulted in a more refined microstructure as compare with the cast A16061 with UST and Al-1wt.\% $\mathrm{WS}_{2}$ without UST.

The refinement in the microstructure of Al-1wt.\% WS2 with UST is shown by an average grain size of $96 \mu \mathrm{m}$, which represent $30 \%$ of reduction in grain size as compare with the base alloy (A16061). The reason for this reduction is related to two factors: (i) the increase in number of nucleation sites as a result of the $\mathrm{WS}_{2}$ particles that get wet and 
dispersed through the melt by UST, and (ii) $\mathrm{WS}_{2}$ particles can act as barriers to the growth of grains, as grains cannot move forward once they found particles blocking the path. No visible $\mathrm{WS}_{2}$ particles where found in optical images of the microstructure.

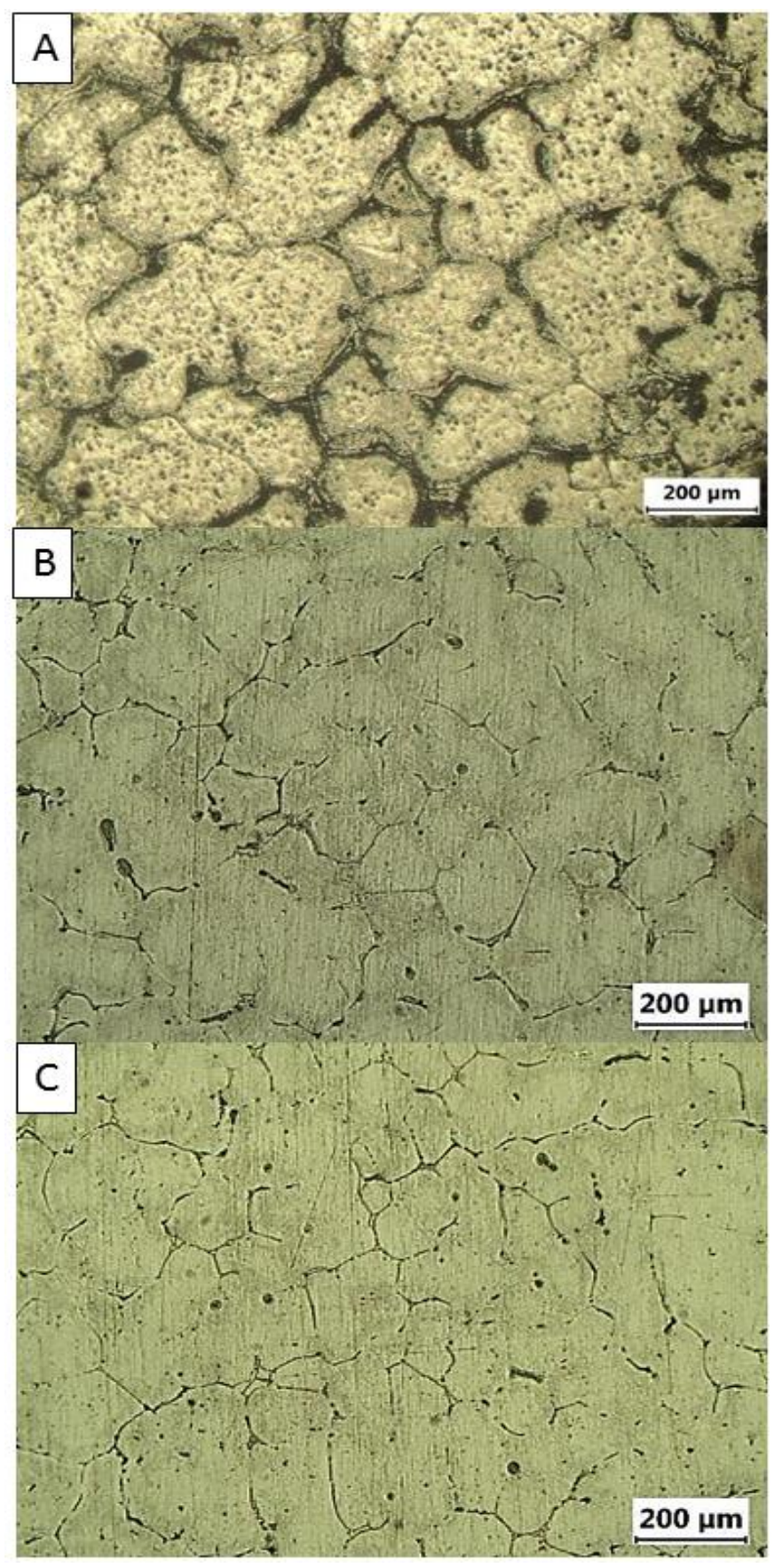

Figure 4. 24 Optical microstructure, (A) Al6061 with UST, (b) Al-1wt. \%WS 2 without UST, (C) Al-1wt. \%WS 2 with UST. 
Grain refinement was observed with the addition of $\mathrm{WS}_{2}$ to the casting process. As can be seen in Table 4.6. An overall reductions in grain size in the range of $27 \%-30 \%$ was exhibited on samples with $\mathrm{WS}_{2}$ as compared with the base alloy.

Table 4. 6 Grain size measurements of $\mathrm{Al}-1 \mathrm{wt} . \% \mathrm{WS}_{2}$ as a function of ultrasonic treatment

\begin{tabular}{|c|c|c|c|}
\hline \multicolumn{4}{|c|}{ Grain size $(\mu \mathrm{m})$} \\
\hline \multicolumn{2}{|c|}{ Temperature $\left({ }^{\circ} \mathrm{C}\right)$} & \multicolumn{2}{|c|}{700} \\
\hline \multicolumn{2}{|c|}{ Amplitude $(\mu \mathrm{m})$} & \multicolumn{2}{|c|}{20} \\
\hline \multicolumn{2}{|c|}{ Time (s) } & \multicolumn{2}{|c|}{45} \\
\hline \multirow{2}{*}{ A16061 } & UST & 1 wt. $\% \mathrm{WS}_{2}$ & $1 \mathrm{wt} \% \mathrm{WS}_{2}-\mathrm{UST}$ \\
\hline & $138 \pm 32.04$ & $101 \pm 24.53$ & $96 \pm 19.12$ \\
\hline
\end{tabular}

Figure 4.25 shows a comparison between the grain size measurements Al 6061 with UST and Al-1wt. \% $\mathrm{WS}_{2}$ with and without UST. Grain refinement due to the addition of WS2 particles is observed on samples without UST reporting an average grain size of 101 $\mu \mathrm{m}$. However, this reduction is lower than the one reported by the Al-1wt. \% $\mathrm{WS}_{2}$ with UST $(96 \mu \mathrm{m})$. In the lack of UST, the agglomeration of the reinforcing particles and poor wettability between $\mathrm{WS}_{2}$ particles and Aluminum create a non-uniform distribution on the microstructure.

Wetting between solid particles by liquid is determined by the contact angle between them. Mathematical relation to calculated contact angle is related to interfacial tensions and is express on Eq. 12. 
$\cos \theta=\frac{\gamma_{s}-\gamma_{s} / l}{\gamma_{l}}$

Where, $\theta$ is the contact angle, $\gamma_{s}$ is the surface energy of the solid phase, $\gamma_{s} / l$ is solid liquid interfacial tension and $\gamma_{l}$ is the surface tension of the liquid phase.

Surface tension of aluminum is dependent of temperature and it was calculated using Eq. 13.

$\gamma_{A l}=1043-0.18 T(\mathrm{mN} / \mathrm{m})$

Where, $\gamma_{A l}$ is the surface tension of $\mathrm{Al}$ and $\mathrm{T}$ is temperature. For $700{ }^{\circ} \mathrm{C}$, surface tension of Aluminum will be $870 \mathrm{mN} / \mathrm{m}$ [90]. Surface energy of $\mathrm{WS}_{2}$ is $40 \mathrm{~mJ} / \mathrm{m}^{2}$ [91]. Higher differences between surface tension of $\mathrm{Al}$ and surface energy of Ws2 accordantly with Eq. 11, will lead high contacts angles resulting in poor wetting between them. During the solidification process non- wetted particles are pushed to the intergranular and inter dendritic zones of the matrix due to the advance of the solidification front.

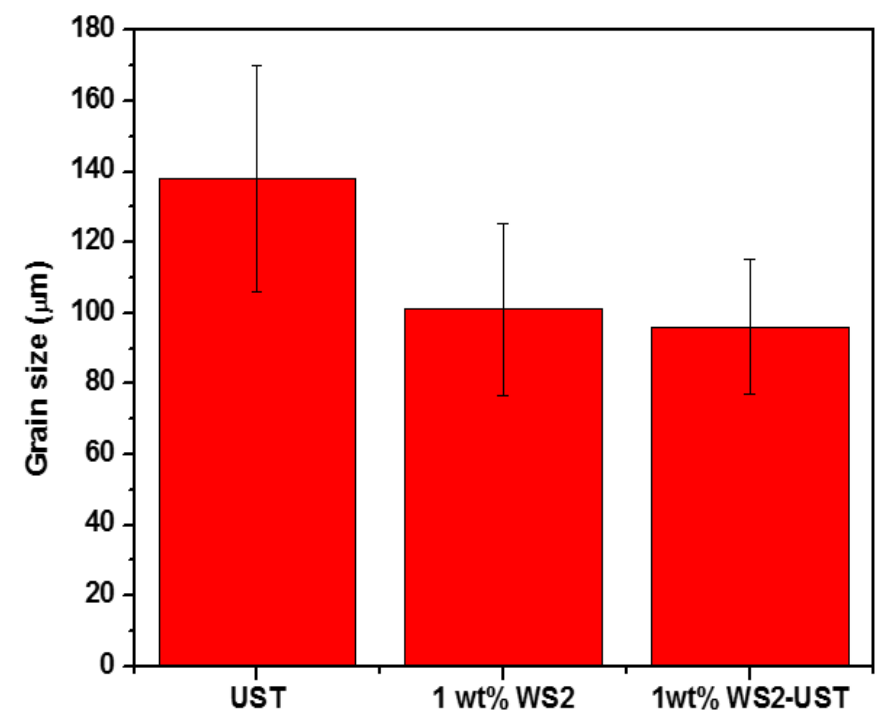

Figure 4. 25 Comparison of grain size measurements of Al 6061 with UST and Al-1wt. \% $\mathrm{WS}_{2}$ with and without UST. 
Statistical analysis was performed in order to determine if there is significant differences between the grain size measurement of the Al- $1 \mathrm{wt} . \% \mathrm{WS}_{2}$ with and with UST samples.

A two sample $\mathrm{z}$ test in SPSS software compares the means of two groups of data to determine if there is significant differences between the means. Z-test was done to test the null hypothesis, which is that both means are equal $\left(\mu_{1}-\mu_{2}=0\right)$ with a $\alpha=0.05$ if $Z$ critical falls inside of the rejection region then it can be conclude that the data provided sufficient evidences to claim that there is significances differences between them. The values obtained from the test were $Z$ value 2.038 and $Z$ critical 1.6448 . The rejection region for the hypothesis is $(-\infty,-2.038 ; 2.038,+\infty), \mathrm{Z}$ critical values falls inside of the rejection region demonstrating that there is significant differences between grain size measurement of Al- 1 wt. \% $\mathrm{WS}_{2}$ with and without UST.

Morphological studies on fracture surface of $\mathrm{Al}-1 \mathrm{wt} . \% \mathrm{WS}_{2} \mathrm{MMC}$ as a function of UST. In order to study the dispersion of the $\mathrm{WS}_{2}$ particles on the MMC, SEM on backscattering mode was performed on the fracture surface of $\mathrm{Al}-1 \mathrm{wt} . \% \mathrm{WS}_{2}$ with and without UST. WS 2 has a higher atomic weight which make them brighter on backscattering mode resulting on an easier detection of them on the fracture surface.

Big clusters of particles with the morphology of $\mathrm{WS}_{2}$ were found on the fracture surface of specimen corresponding to Al-1wt. \% $\mathrm{WS}_{2}$ without UST (Figure 4.26, 4.28A). EDS mapping was performed to identify the particles, as a result EDS mapping and spectrum of Al-1wt. \% $\mathrm{WS}_{2}$ without UST (Fig 4.29-4.30) detect the presence of tungsten (W) and sulfur (S) corresponding to the $\mathrm{WS}_{2}$ particles added. 
In addition, backscattering and SEM of Al-1wt. \% $\mathrm{WS}_{2}$ fracture surface with UST, clearly show well dispersion of $\mathrm{WS}_{2}$ particles on the fracture surface, bright spots in Figure 4.26, correspond to WS2 particles. However, some small agglomerations of $\mathrm{WS}_{2}$ particles are still visible on the fracture surface but not as large as the ones in sample without UST. Also, individual particles of $\mathrm{WS}_{2}$ are dispersed through the fracture surface due to the effect of UST breaking the clusters (Figure 4.28B). EDS was also performed for the fracture surface of Al-1wt. \% $\mathrm{WS}_{2}$ with UST. EDS mapping and spectrum (Figure 4.29 - 4.30) also detect the presence of tungsten (W) and sulfur (S) corresponding to the $\mathrm{WS}_{2}$ particles added.

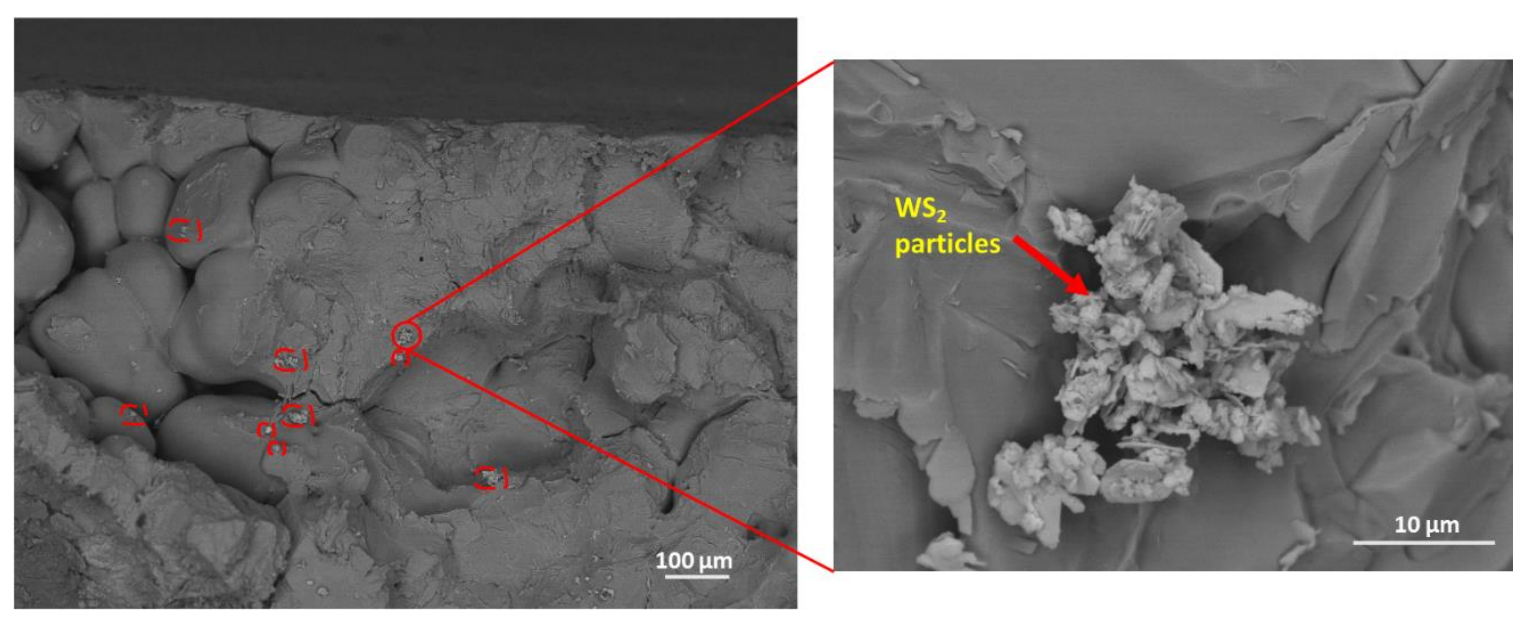

Figure 4. 26 Backscattering and SEM of Al-1wt. \% $\mathrm{WS}_{2}$ fracture surface without UST 


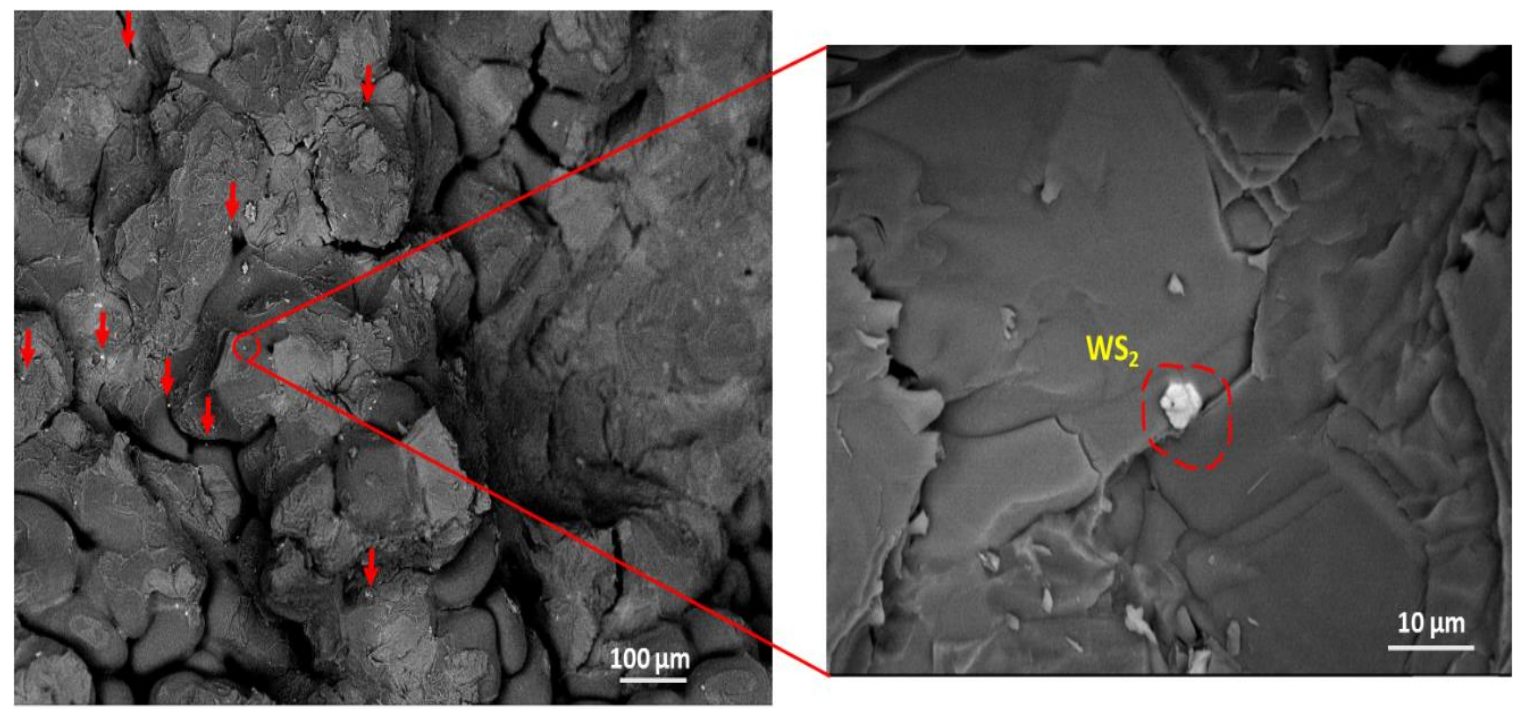

Figure 4. 27 Backscattering and SEM of Al-1wt. \% $\mathrm{WS}_{2}$ fracture surface with UST
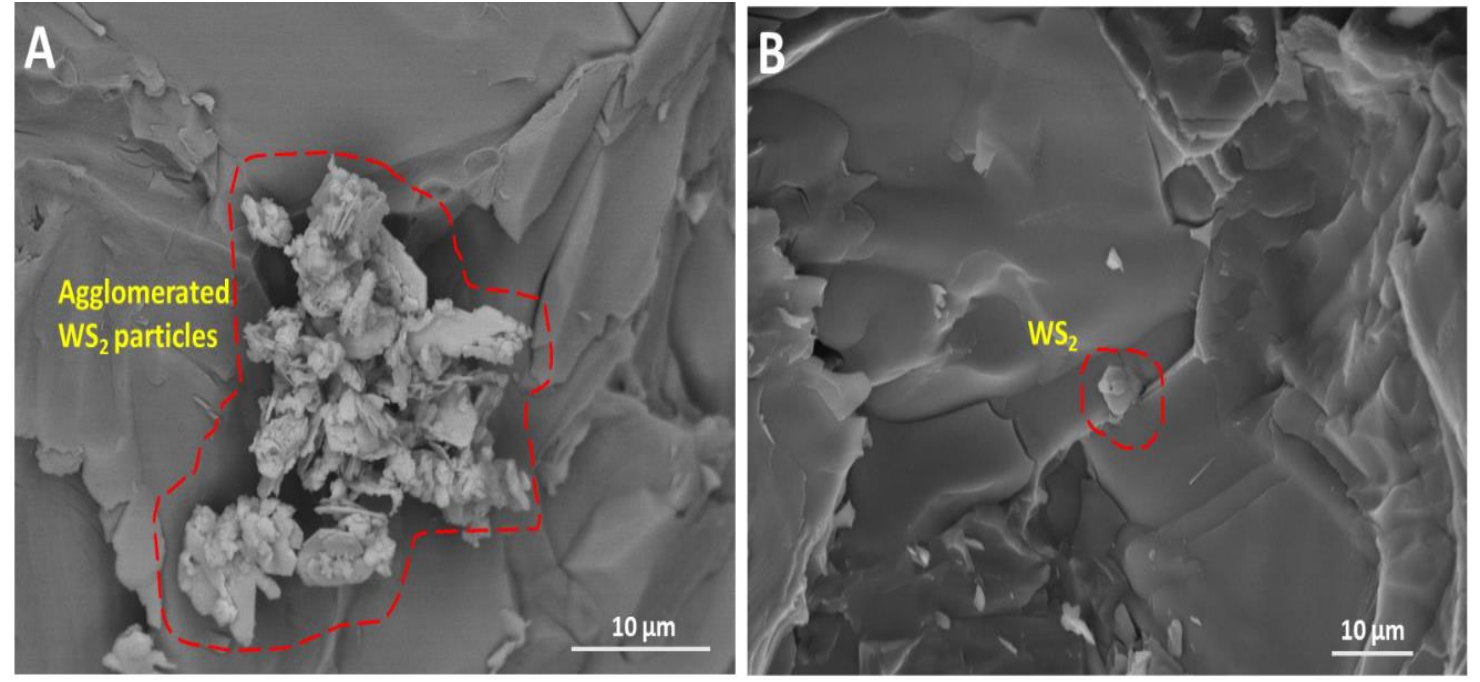

Figure 4. 28 SEM images of fracture surface of Al-1wt. \% $\mathrm{WS}_{2}$, (A) Without UST, (B) With UST 

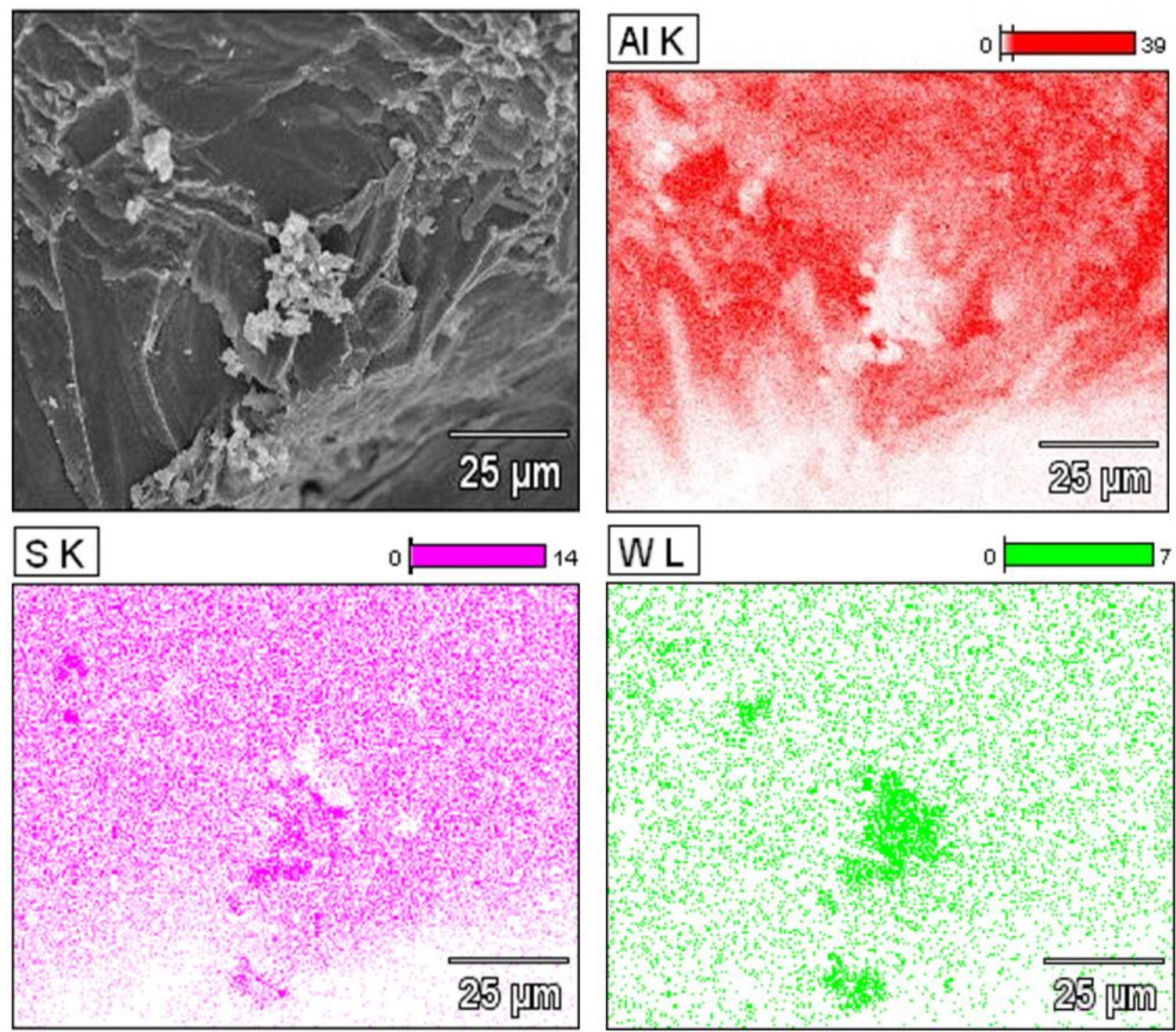

Figure 4. 29 EDS mapping of fracture surface Al-1wt. \% $\mathrm{WS}_{2}$ without UST

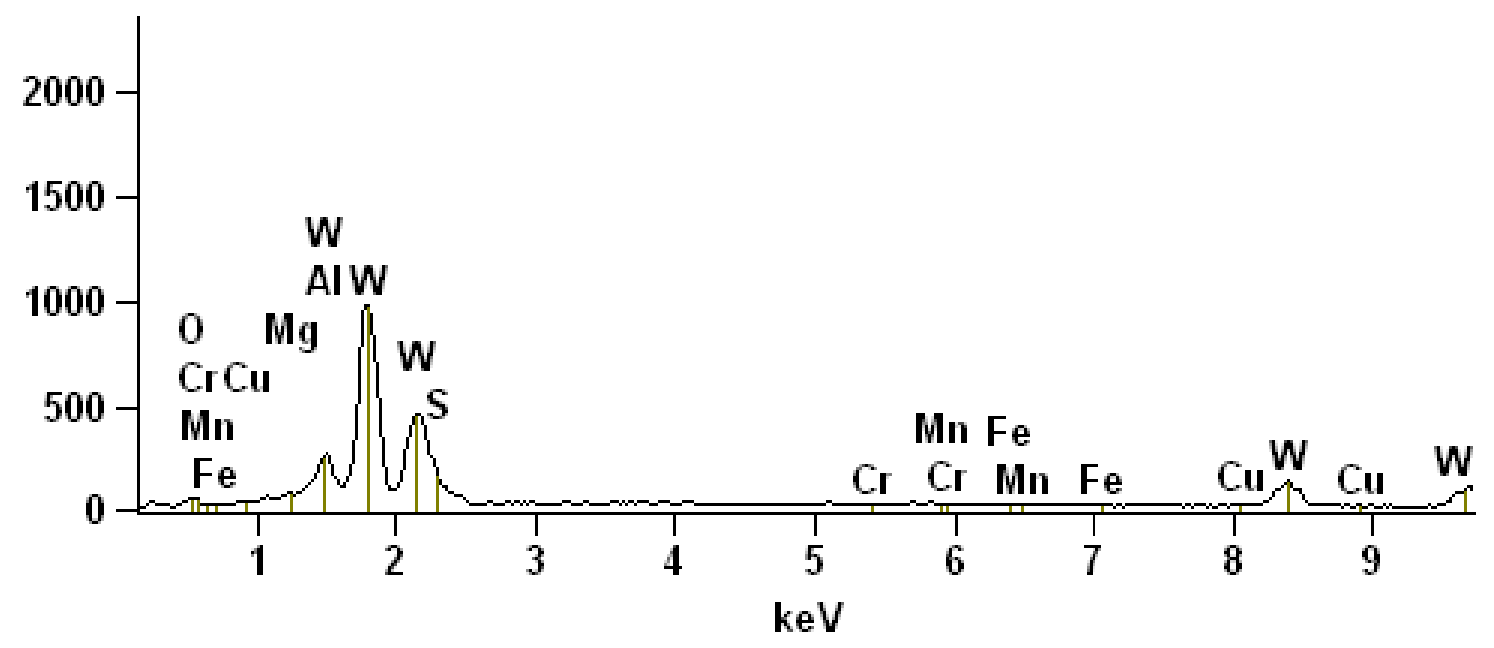

Figure 4. 30 EDS spectrum of Al-1wt. \% $\mathrm{WS}_{2}$ without UST 

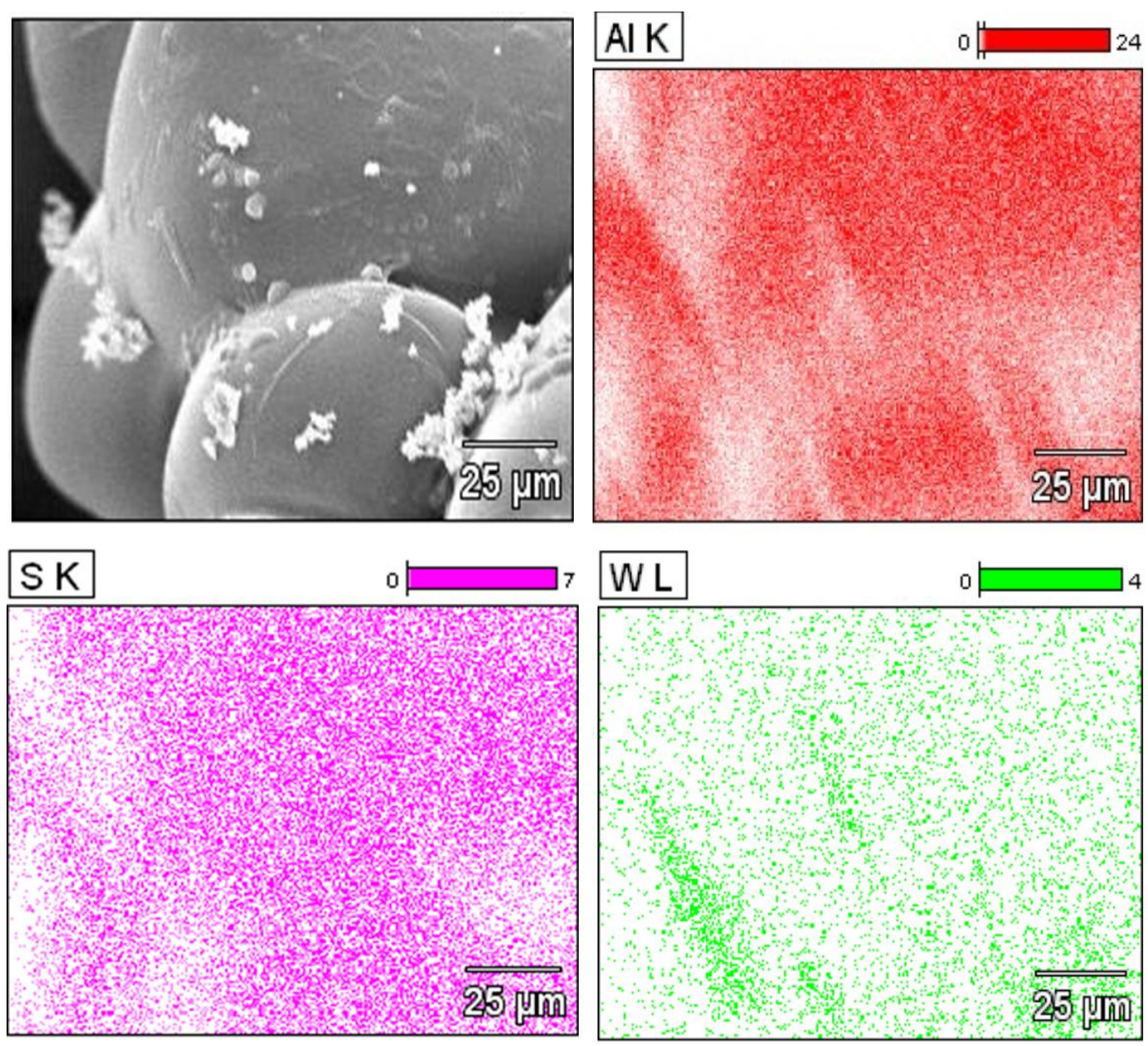

Figure 4. 31 EDS mapping of fracture surface Al-1wt. \% $\mathrm{WS}_{2}$ with UST

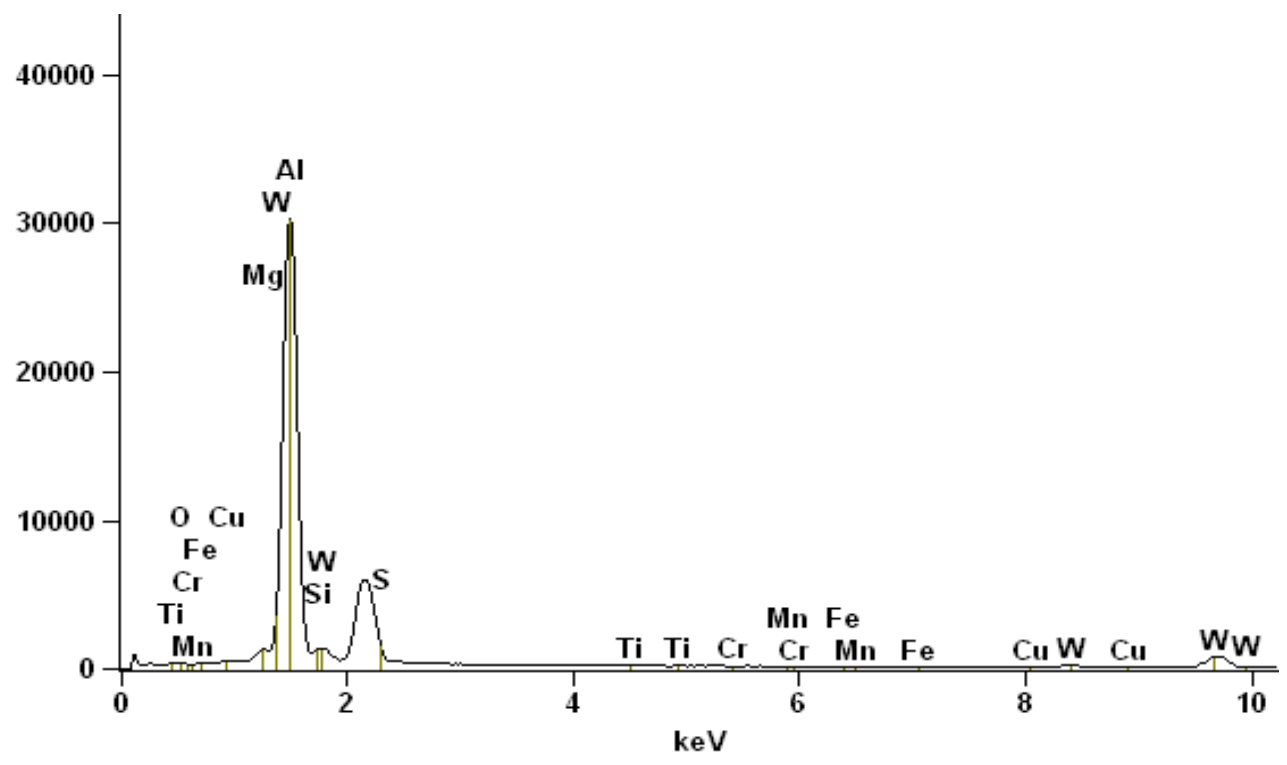

Figure 4. 32 EDS spectrum of Al-1wt. \% $\mathrm{WS}_{2}$ with UST 


\subsubsection{Influence of reinforcements particles on microhardness of Al-1wt. \% WS MMC as a function of UST}

In order to evaluate the resulting mechanical behavior of the cast samples with the addition of $\mathrm{WS}_{2}$ with and without UST, cast samples were subjected to a Vickers microhardness test. A load of $50 \mathrm{gf}$ and a dwell period of 10 seconds were used for all the specimens. Increase in microhardness was observed with the addition of $\mathrm{WS}_{2}$ and UST to the casting process. As can be seen in Table 4.7 an overall increase in microhardness of $15 \%$ was exhibited on samples with $\mathrm{WS}_{2}$ and UST as compared with the base alloy with UST.

Table 4. 7 Micro hardness of Al-1wt. \% $\mathrm{WS}_{2}$ as a function of ultrasonic treatment

\begin{tabular}{|c|c|c|c|}
\hline \multicolumn{4}{|c|}{ Micro hardness (MPa) } \\
\hline \multicolumn{2}{|c|}{ Temperature $\left({ }^{\circ} \mathrm{C}\right)$} & \multicolumn{2}{|c|}{700} \\
\hline \multicolumn{2}{|c|}{ Amplitude $(\mu \mathrm{m})$} & \multicolumn{2}{|c|}{20} \\
\hline \multicolumn{2}{|c|}{ Time (s) } & \multicolumn{2}{|c|}{45} \\
\hline \multirow{2}{*}{ Al6061 } & UST & $1 \mathrm{wt} . \% \mathrm{WS}_{2}$ & $\begin{array}{c}\text { 1wt. } \% \mathrm{WS}_{2}- \\
\mathrm{UST}\end{array}$ \\
\hline & $696 \pm 61.47$ & $771 \pm 68.35$ & $817 \pm 71.59$ \\
\hline
\end{tabular}

In addition, sample with $\mathrm{WS}_{2}$ and no UST presents an increases in the microhardness (Figure 4.33) as compare with the base alloy (696 MPa). However, due to the agglomeration of the particles in the microstructure the improvement in microhardness for the sample without UST (771 MPa) is not as good as the one obtained with the combination of $\mathrm{WS}_{2}$ and UST (817 MPa). 


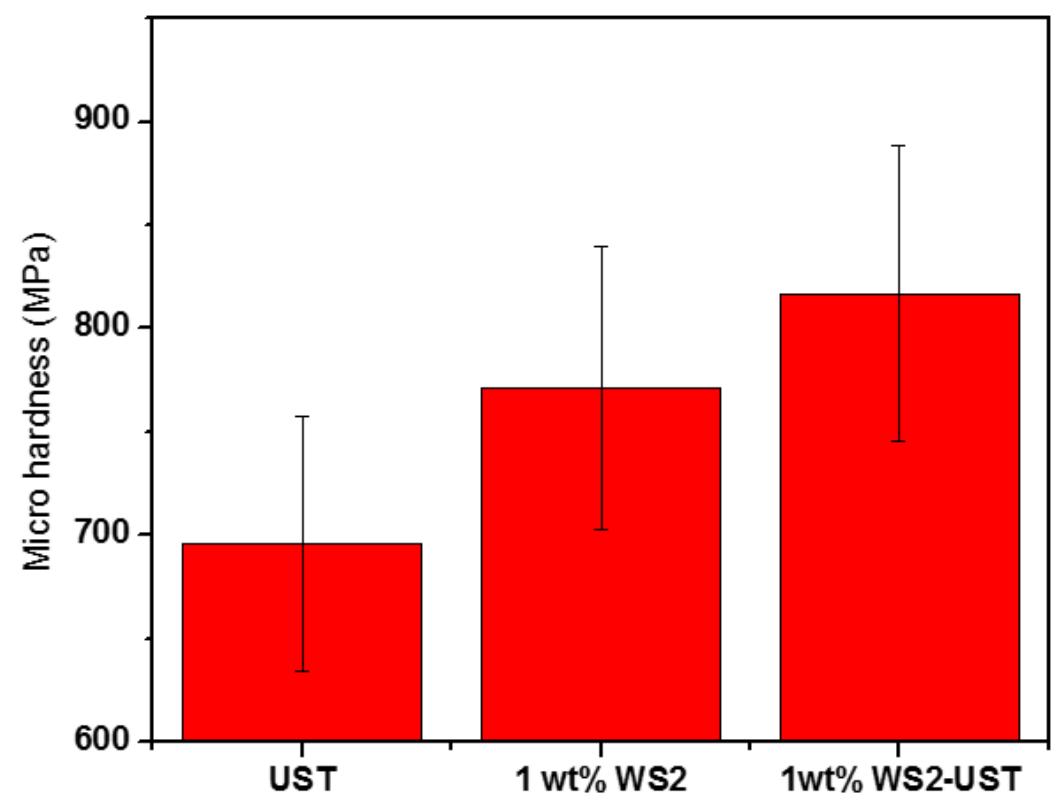

Figure 4. 33 Comparison of microhardness of Al 6061 with UST and Al-1wt. \% $\mathrm{WS}_{2}$ with and without UST.

\subsubsection{Influence of reinforcements particles on wear behavior of Al-1wt. \% WS}

\section{MMC as a function of UST}

In order to study the wear behavior of $\mathrm{Al}-1 \mathrm{wt} . \% \mathrm{WS}_{2}$ with and without UST specimens, wear tests at room temperature were performed for them and cast A16061 with UST (Ideal conditions).

Wear volume loss was calculated as it was described in Chapter 2. As can been seen in Figure 4.34 the wear volume loss for cast Al6061 is $0.76 \mathrm{~mm}^{3}$ and Figure 4.35 the wear volume loss for $\mathrm{Al}-1 \mathrm{wt}$. \% $\mathrm{WS}_{2}$ with UST specimen is of $0.069 \mathrm{~mm}^{3}$ and $\mathrm{Al}-1 \mathrm{wt}$. \% $\mathrm{WS}_{2}$ without UST is $0.070 \mathrm{~mm}^{3}$. The specimen with UST reports an improvement of $4.2 \%$ in wear resistance as compared with the one without UST. This difference in wear volume loss is attributed to the differences in micro hardness between the two samples (Table 4.7) 
as expressed by Archard's equation (Eq.13). Materials with higher hardness will result in better wear resistance.

$d V=\frac{k P}{H} d x$

Where $d V$ is the wear volume loss, $P$ and $H$ are the load and the hardness respectively, $k$ is the wear resistance and $d x$ is the wear distance

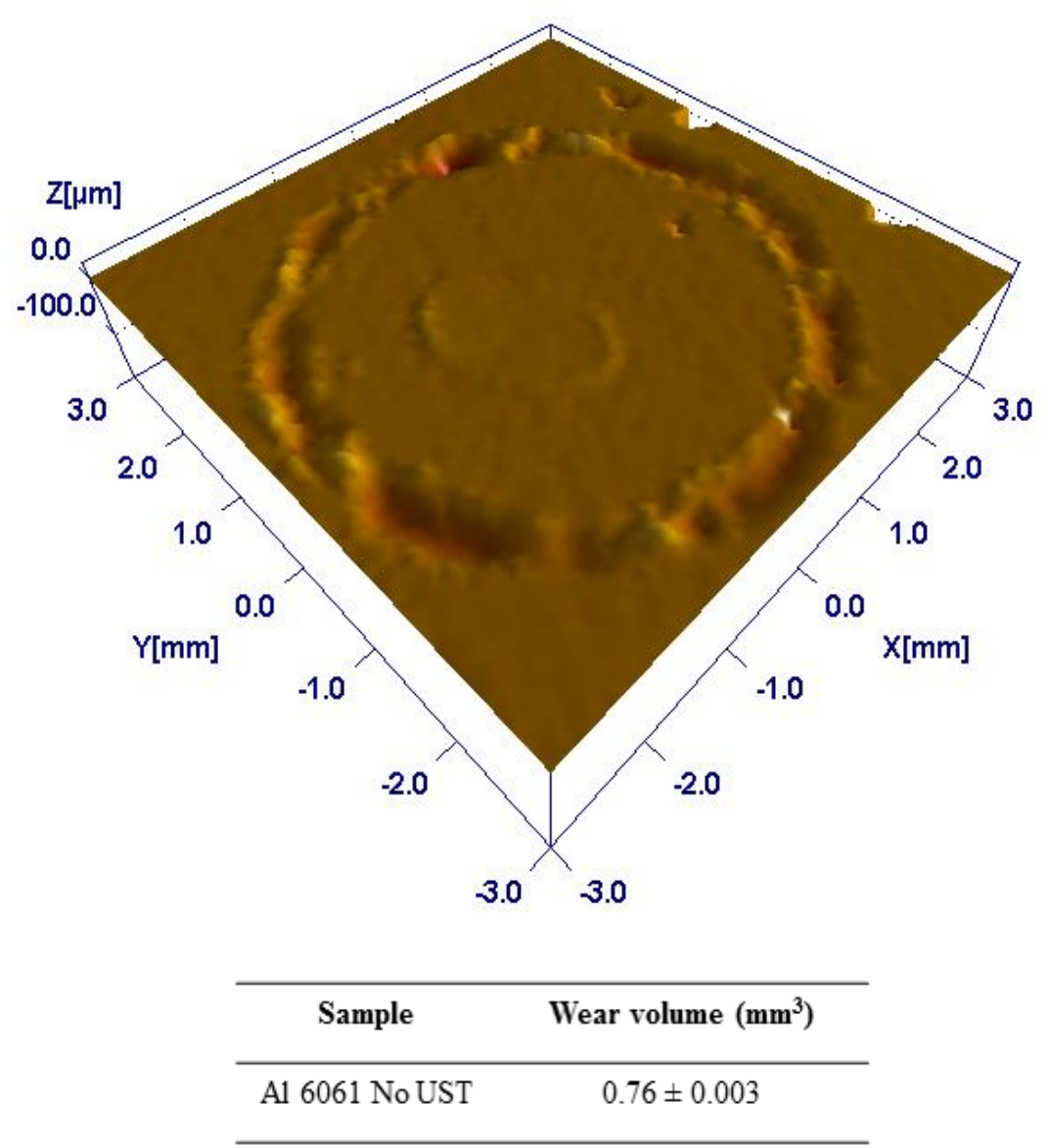

Figure 4. 34 3D optical profiles of wear track of cast $\mathrm{A} 16061$ at $700^{\circ} \mathrm{C}$ 


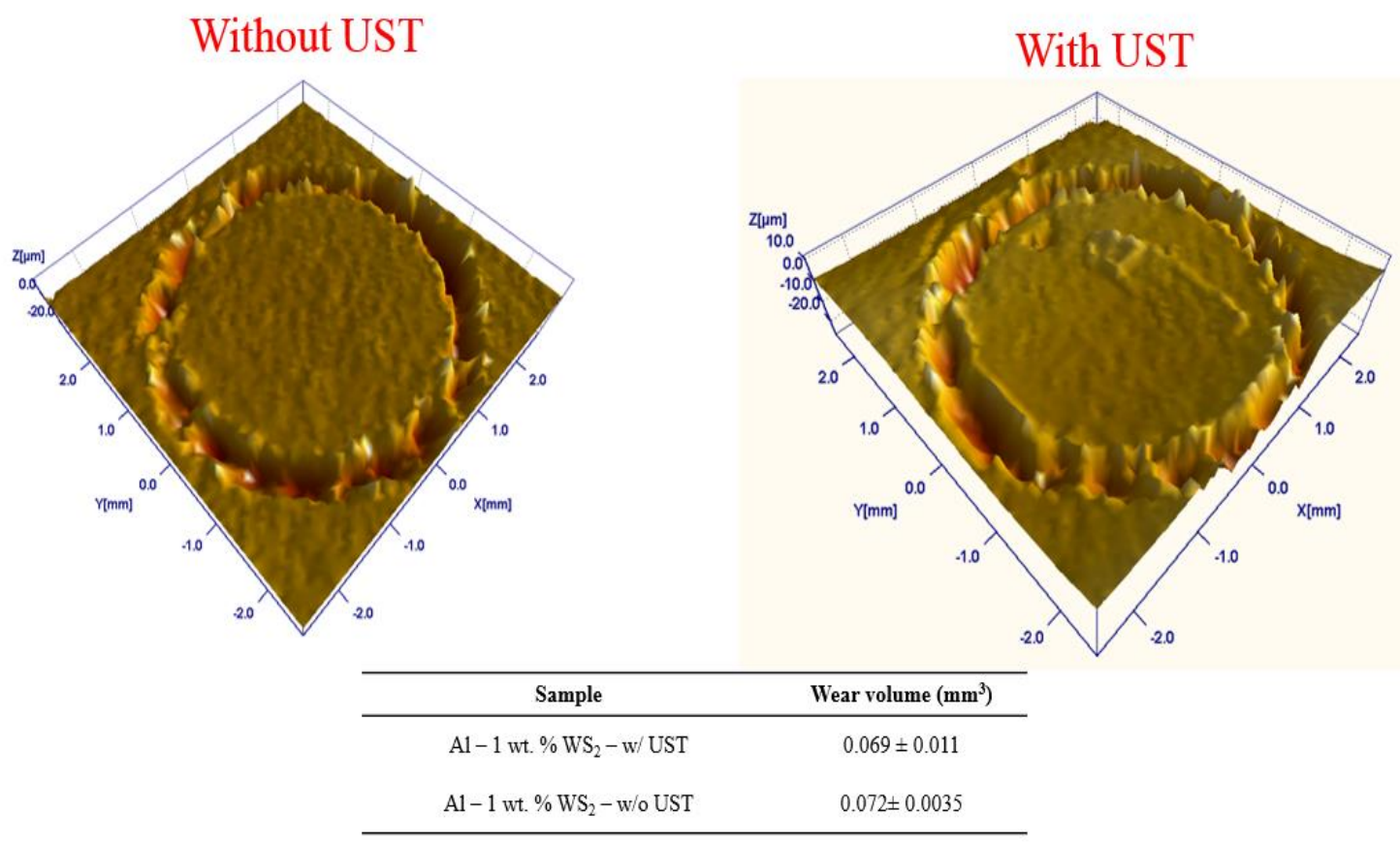

Figure 4. 35 3D optical profiles of wear tracks of Al-1wt. \% $\mathrm{WS}_{2}$ with and without UST

The coefficient of friction was computed for cast $\mathrm{Al} 6061$ and $\mathrm{Al}-1 \mathrm{wt} . \% \mathrm{WS}_{2}$ with and without UST. The results of COF for Cast Al 6061 was 0.43 and for the specimen with UST a COF of 0.038 and a COF of 0.042 for the one without UST (Figure 4.36). The COF reduce as compare with the cast A16061 specimen. However, Comparing between the composites Al-1wt. \% $\mathrm{WS}_{2}$ with and without UST no improvement in COF was observed as a function of UST addition, taking in consideration the standard deviation of the COF measured there are statistically the same. Therefore, no negative effect was observed in the lubricious properties with the addition of UST. 


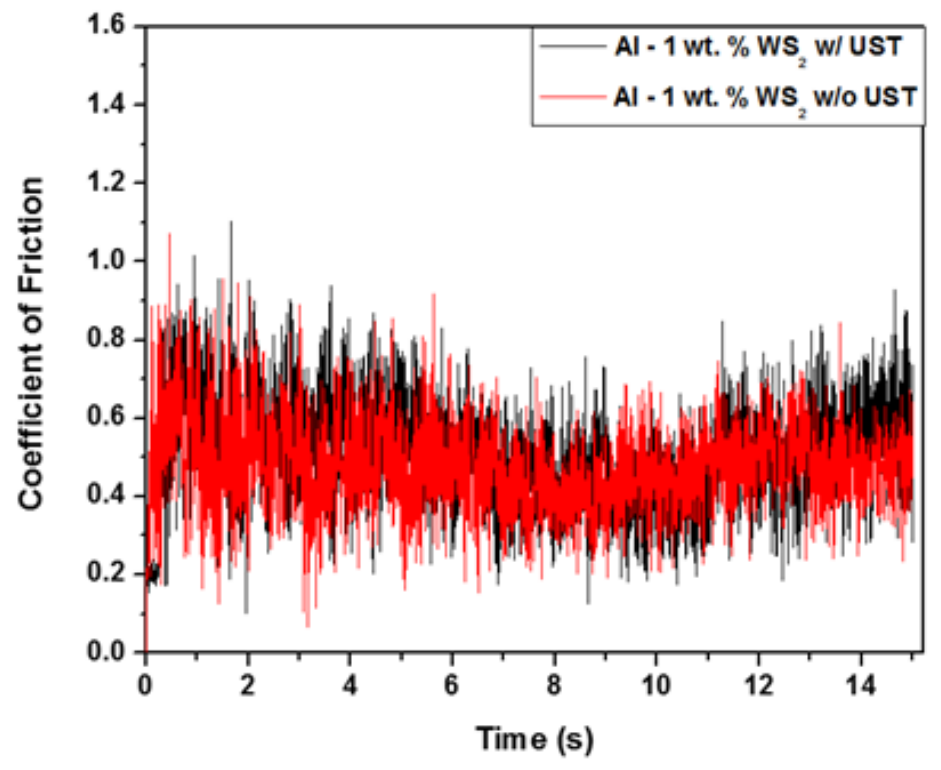

\begin{tabular}{ccc}
\hline Sample & Avg. COF & Wear volume $\left(\mathrm{mm}^{3}\right)$ \\
\hline Al- 1 wt. \% WS2- w/UST & $0.38 \pm 0.045$ & $0.069 \pm 0.011$ \\
Al- 1 wt. \% WS2- w/o UST & $0.42 \pm 0.07$ & $0.072 \pm 0.0035$ \\
\hline
\end{tabular}

Figure 4. 36 Coefficient of friction for Al-1wt. \% $\mathrm{WS}_{2}$ with and without UST

\subsubsection{SEM of the worn surface of Al-1wt. \% WS 2 MMC with and without UST}

To understand the wear mechanism the samples undergo, the worn surface of specimens with and without UST were observed under SEM (Figure $4.37-4.39$ ). The surfaces of both worn tracks have a rough appearance and reveal crack formation. Large particles detachments were observed on the worn surface of specimen with UST (Figure 4.37), due to the brittle behavior of the material.

Uniform dispersion of $\mathrm{WS}_{2}$ particles increases the hardness, enhancing the wear resistance of the composite. However, due to the low concentration of $\mathrm{WS}_{2}$ added to the 
aluminum matrix the lubricious effect of $\mathrm{WS}_{2}$ on the COF was not evidenced. While UST enhance the wear resistances due to the increase of hardness of the composite, no damaging was reported on the lubricious properties.

In Figure 4.38, $\mathrm{WS}_{2}$ particles are visible in the worn track. During the test the removal of material in the worn surface makes possible for the dispersed $\mathrm{WS}_{2}$ particles to resurface and contribute to the wear resistance.

During the wear test the formation of cracks was visible in both samples (Figure $4.37,4.39)$. Crack formation is related to the large temperature differences generated from the high normal stress of the test. The formation of cracks in the surface is a sign of abrasive wear.

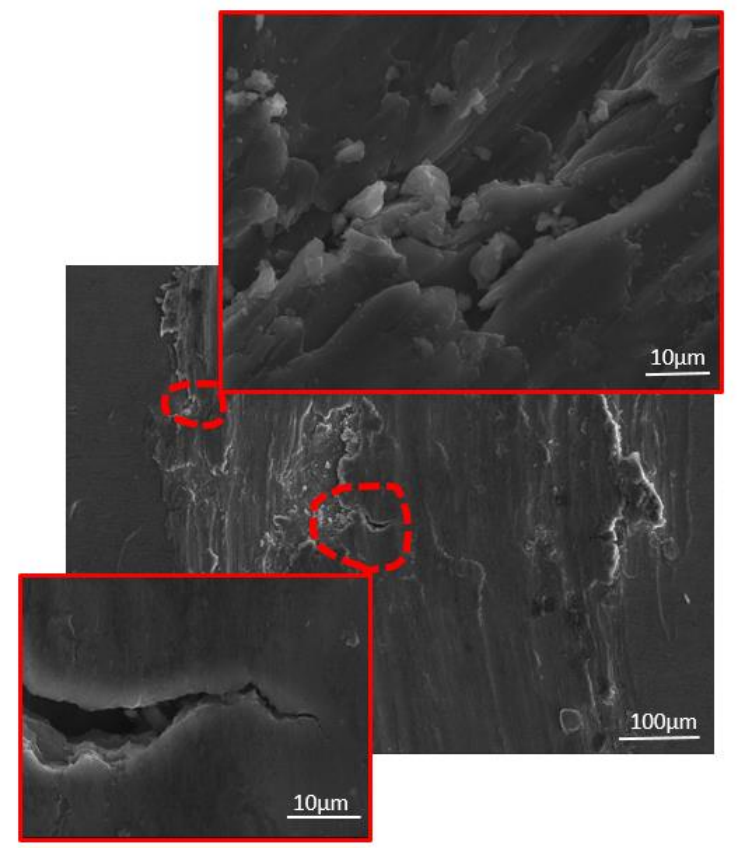

Figure 4. 37 SEM of worn surface of $1 \mathrm{wt} . \%$. $\mathrm{WS}_{2}$ samples with UST. 


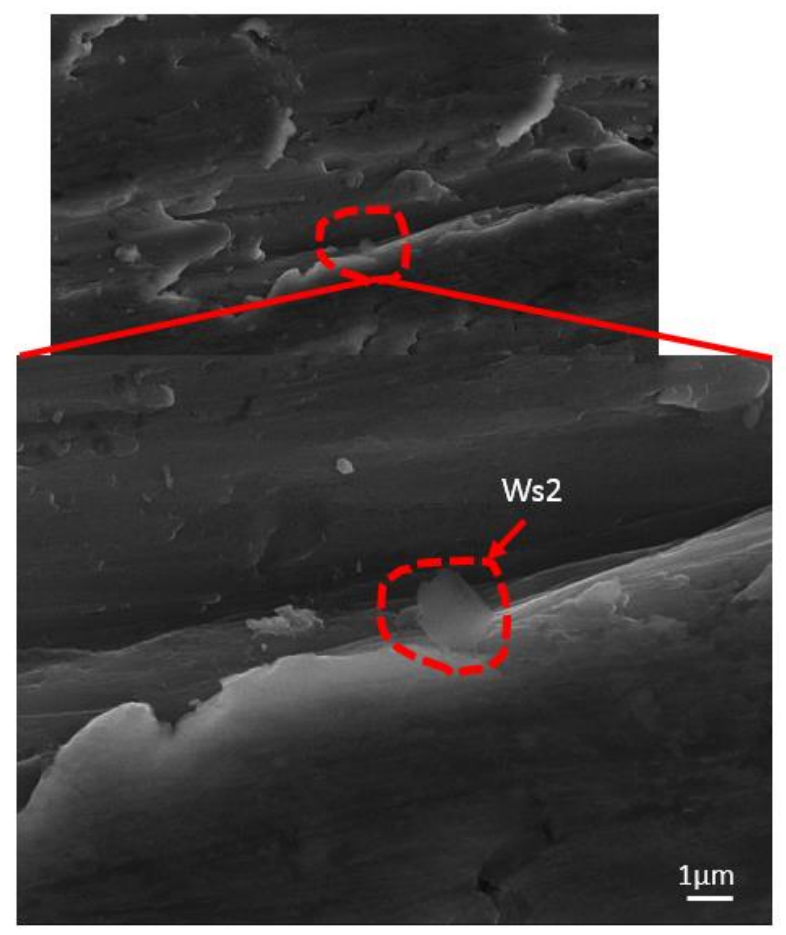

Figure 4. $38 \mathrm{SEM}$ of worn surface of $1 \mathrm{wt} . \%$. $\mathrm{WS}_{2}$ samples with UST.

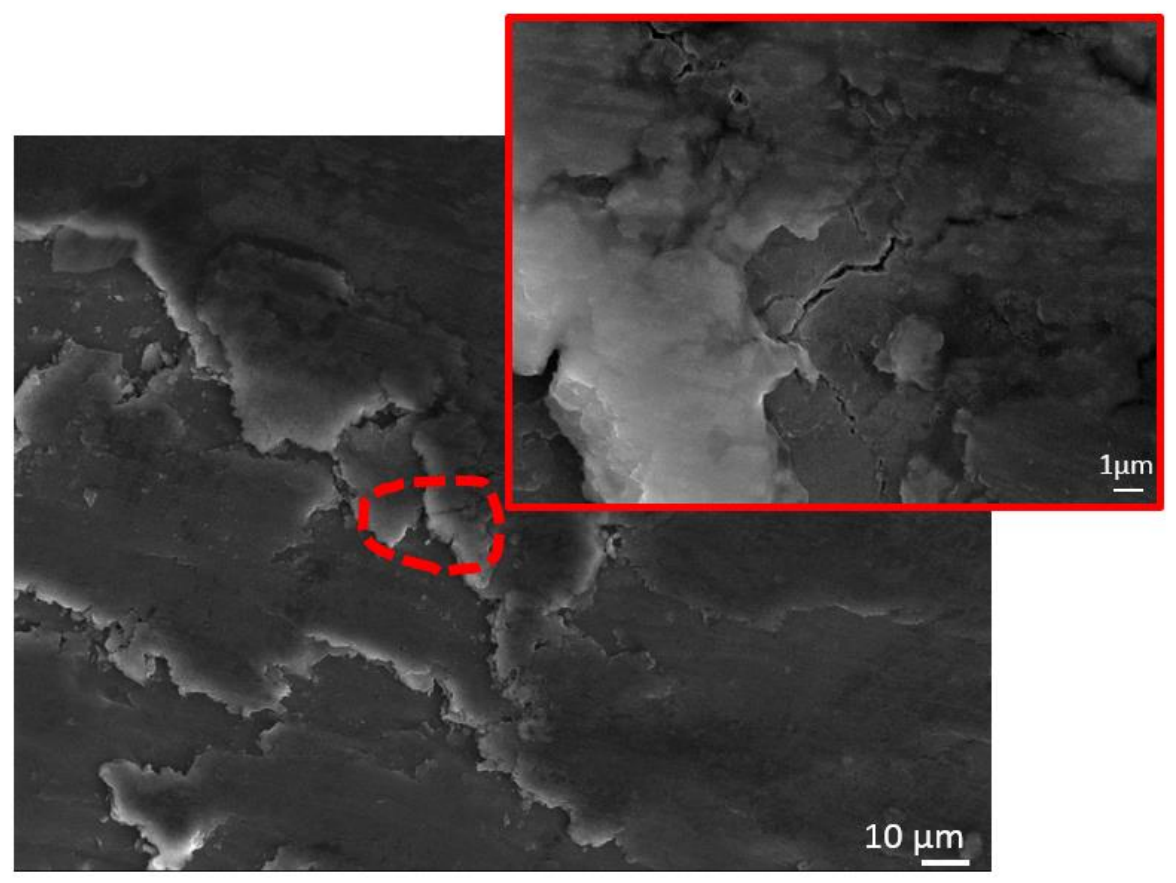

Figure 4. 39 SEM of worn surface of $1 \mathrm{wt} . \%$. $\mathrm{WS}_{2}$ samples without UST. 


\subsection{Characterization of Al-0.15wt. \% CNT MMC manufactured using UST as a}

\section{dispersion technique.}

\subsubsection{Densification measurements of Al-0.15wt. \% CNT MMC as a function of}

$\underline{\text { UST }}$

Following the same procedure as the previous composite, Theoretical density for Al-0.15 wt. \% CNT MMC was calculated using rule of mixtures, resulting in a density of $2.697 \mathrm{~g} / \mathrm{cm}^{3}$ (CNT theoretical density $1.7 \mathrm{~g} / \mathrm{cm}^{3}$ ). Density of the composites by Archimedes' density in samples with and without UST results in values of $2.689 \mathrm{~g} / \mathrm{cm}^{3}$ and $2.678 \mathrm{~g} / \mathrm{cm}^{3}$ respectively.

Reduction of porosity from $0.7 \%$ to $0.3 \%$ was observed with the addition of UST as can be seen on Table 4.8 .

Table 4. 8 Porosity measurements of Al- $0.15 \mathrm{wt} . \% \mathrm{CNT}$ as a function of ultrasonic treatment

\begin{tabular}{cc}
\hline Al-0.15wt. \%CNT & Porosity (\%) \\
\hline No UST & 0.7 \\
UST & 0.3 \\
\hline
\end{tabular}

\subsubsection{Microstructural analysis of Al-0.15wt. \% CNT MMC as a function of UST}

Figure 4.40 shows optical images of the microstructure of cast Al6061 with UST and Al-0.15wt. \% CNT with and without UST. Al6061 with UST (Figure 4.40A) and Al0.15wt. \% CNT with UST (Figure 4.40C) show globular grains (non-dendritic) due to the UST. Al-0.15 wt. \% CNT without UST (Figure 4.40B) presents refinement in the microstructure. However, Al-0.15wt. \% CNT with UST exhibits a more refined microstructure as compare with cast A16061 with UST and Al-0.15wt. \% CNT without UST, reporting an average grain size of $97 \mu \mathrm{m}$ (Table 4.9). The refinement observed 
represents approximately a $30 \%$ of reduction in grain size as compared with the base alloy (Al6061 with UST).

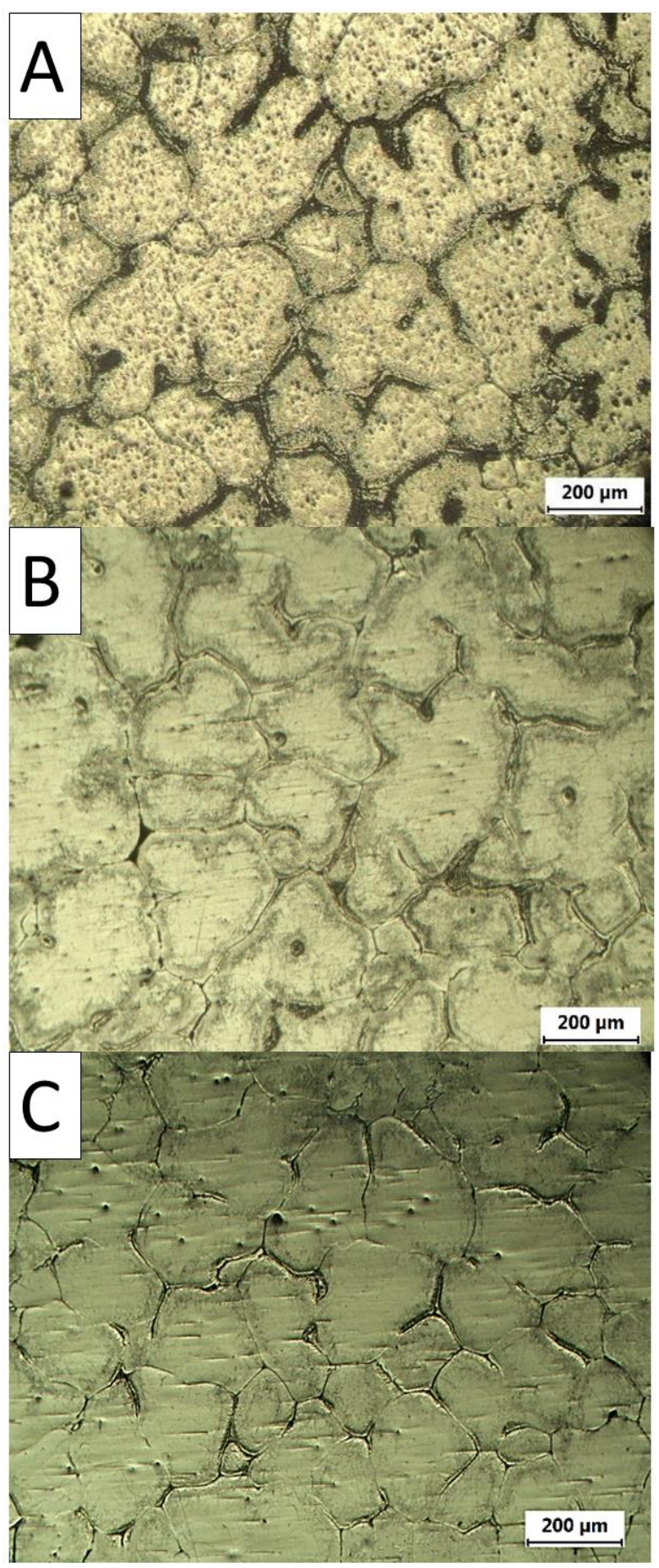

Figure 4. 40 Optical microstructure, (A) Al6061 with UST, (b) Al-015wt. \% CNT without UST, (C) Al-0.15wt. \%CNT with UST. 
Table 4. 9 Grain size measurements of Al- $0.15 \mathrm{wt}$. \% CNT as a function of ultrasonic treatment

\section{Grain size $(\mu \mathrm{m})$}

\begin{tabular}{|c|c|c|c|}
\hline \multicolumn{2}{|c|}{ Temperature $\left({ }^{\circ} \mathrm{C}\right)$} & \multicolumn{2}{|r|}{700} \\
\hline \multicolumn{2}{|c|}{ Amplitude $(\mu \mathrm{m})$} & \multicolumn{2}{|r|}{20} \\
\hline \multicolumn{2}{|c|}{ Time (s) } & \multicolumn{2}{|r|}{45} \\
\hline \multirow{2}{*}{ Al6061 } & UST & 0.15 wt. $\%$ CNT & 0.15 wt. $\%$ CNT-UST \\
\hline & $138 \pm 32.04$ & $110 \pm 27.59$ & $97 \pm 19.36$ \\
\hline
\end{tabular}

Comparison between the grain size measurements of Al 6061 with UST and Al0.15wt. \% CNT with and without UST can be seen on Fig 4.41. Grain refinement due to the addition of CNT particles is observed in sample without UST reporting an average grain size of $110 \mu \mathrm{m}$ as compare with cast Al6061 with UST $(138 \mu \mathrm{m})$. However, this reduction is lower than the one reported by the Al-0.15wt. \% CNT with UST $(97 \mu \mathrm{m})$. The differences in grain refinement can be attributed in the same way to the agglomeration of the reinforcing particles and poor wettability in samples without UST. Samples without UST experience non-uniform distribution on the microstructure and reduced survivable of CNT during the casting process. In addition, knowing that CNTs added to melt can act as barriers to the growth of grains the survivable of these to the casting process will also influence the refinement of the microstructure. Damaging of CNTs during the casting process resulting in fewer particles blocking the path of growing of the grains. 


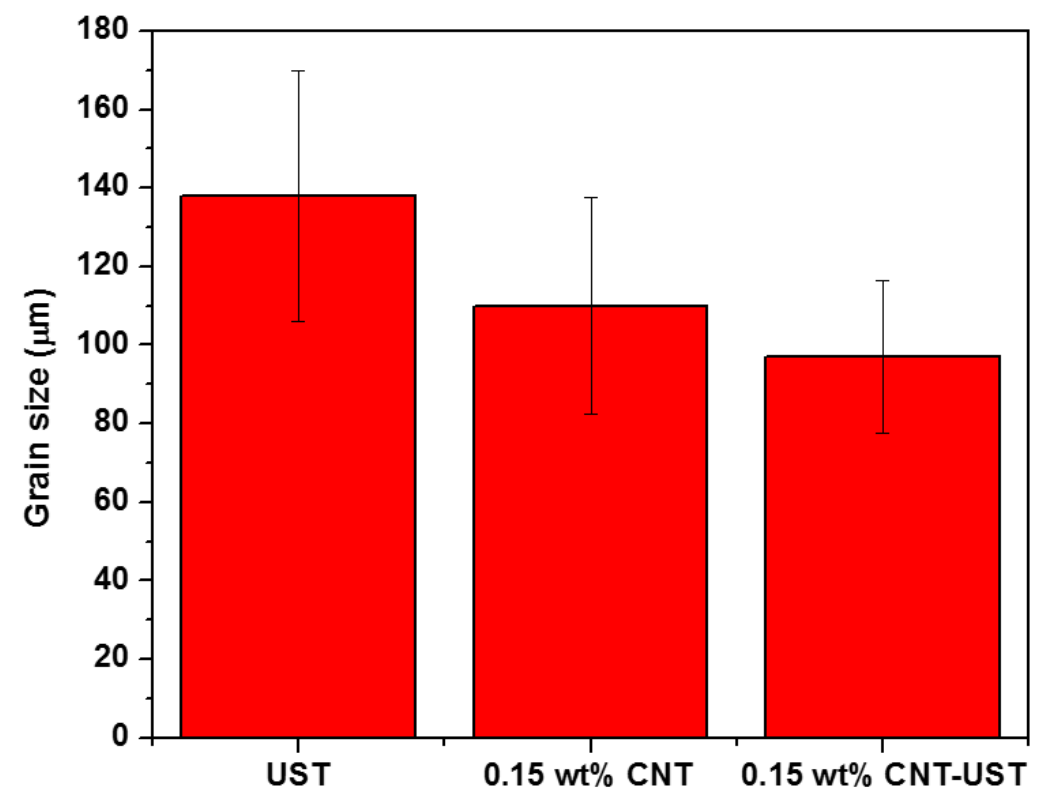

Figure 4. 41 Comparison of grain size measurements of Al 6061 with UST and Al-0.15wt. \% CNT with and without UST.

In the same manner statistical analysis was performed in order to demonstrate that there is significant differences in grain size measurements with the addition of UST.

The values obtained from the test were $Z$ value 3.2920 and $Z$ critical 1.9599. The rejection region for the hypothesis is $(-\infty,-1.9599 ; 1.9599,+\infty), \mathrm{Z}$ critical values falls inside of the rejection region demonstrating that there is significant differences between grain size measurement of Al-0.15 wt. \% CNT with and without UST.

\subsubsection{Morphological studies on fracture surface of Al-0.15wt. \% CNT MMC as a}

\section{function of UST}

In order to study the dispersion of the CNT particles on the MMC, SEM on backscattering mode was performed on the fracture surface of Al-015 wt. \% CNT with and without UST (Figure 4.42, 4.45). Dark areas in backscattering mode correspond to areas with CNTs. 
Few dark areas were found in the fracture surface of the Al-0.15wt. \% CNT without UST sample, suggesting that the CNT particles added remain as agglomerates during the casting process. These agglomerations are a result of high differences in surface energy between CNT $\left(100 \mathrm{~mJ} / \mathrm{m}^{2}\right)$ [92] and Aluminum $(870 \mathrm{mN} / \mathrm{m})$. As expressed on Eq. 12 higher differences in surface energies results in high contact angles. Contact angle between $\mathrm{Al}$ and $\mathrm{CNT}$ has been reported in literature as $160^{\circ}$ [93], which results in poor wettability.

SEM and EDS were performed to study the dark areas, no visible CNTs were found on the fracture surface. However, EDS mapping was performed to confirm the presence of carbon in darks areas. As a result EDS mapping and spectrum of Al-0.15wt. \% without UST (Figure 4.43 and 4.44) detect the presence of aluminum (Al) and Carbon (C) corresponding to the formation of $\mathrm{Al}_{4} \mathrm{C}_{3}$ due to the reaction of $\mathrm{CNT}$ during the casting process.

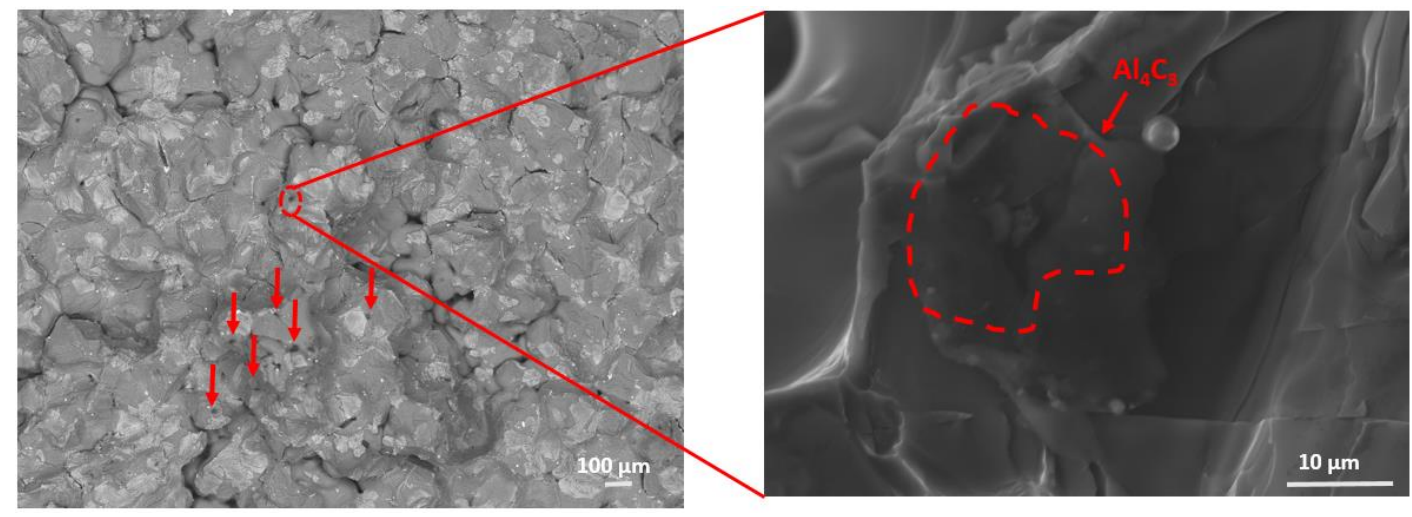

Figure 4. 42 Backscattering and SEM of Al-0.15wt. \% CNT fracture surface without UST 


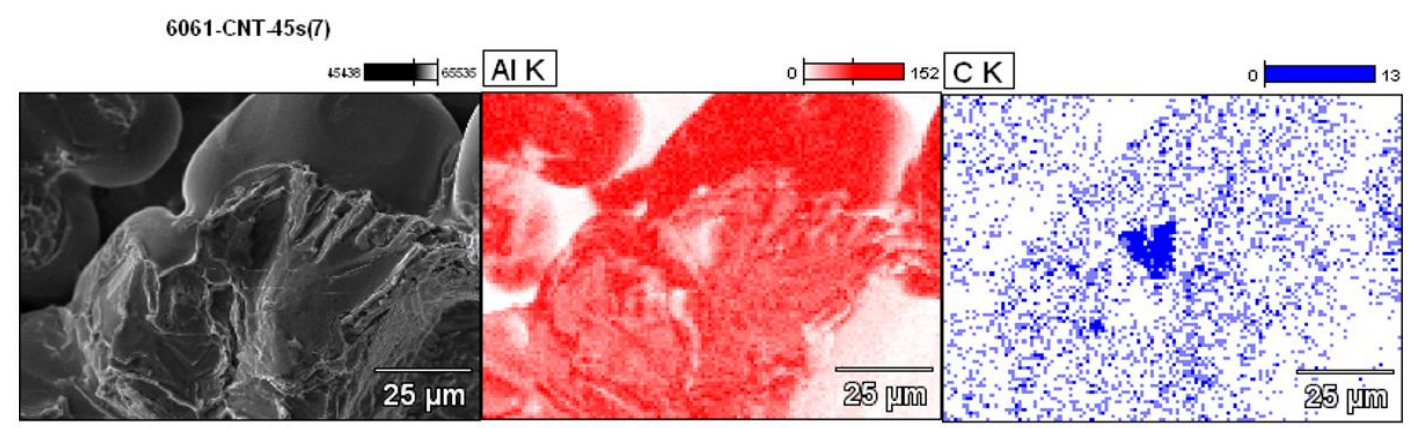

Figure 4. 43 EDS mapping of fracture surface Al-0.15wt. \% CNT without UST Full scale counts: $74965 \quad 6061-C N T-45 s(7)$

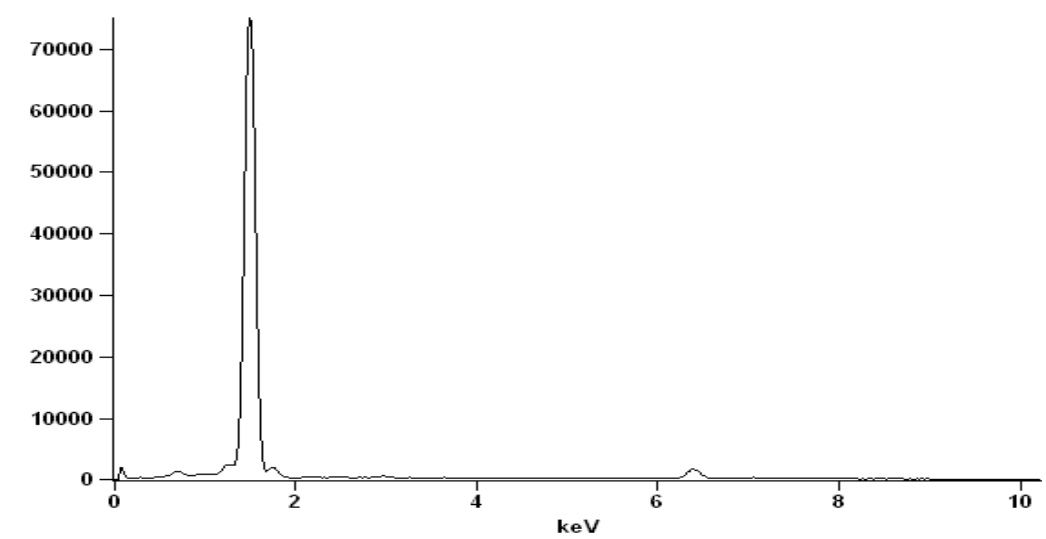

Figure 4. 44 EDS spectrum of Al-0.15wt. \% CNT without UST

In addition, backscattering and SEM of Al-0.15wt. \% CNT fracture surface with UST, clearly show well dispersion of CNT particles in the fracture surface. Dark spots correspond to areas rich in carbon concentration (Figure 4.45). In two dark spots of the fracture surface, particles with the characteristic morphology of CNT were visible. These findings confirm that dark areas consisted in dispersed CNTs (Figure 4.45). Therefore, the $\mathrm{Al} / \mathrm{CNT}$ interface was clear (Figure 4.45), as reported by Li and Zhou, the addition of UST to the casting process drops the wetting angle between carbon and aluminum to $15^{\circ}$ allowing them to have a well bonded interface with the metal matrix. UST improves the interfacial bonding between aluminum and CNT, suppressing the formation of aluminum oxide [22]. 

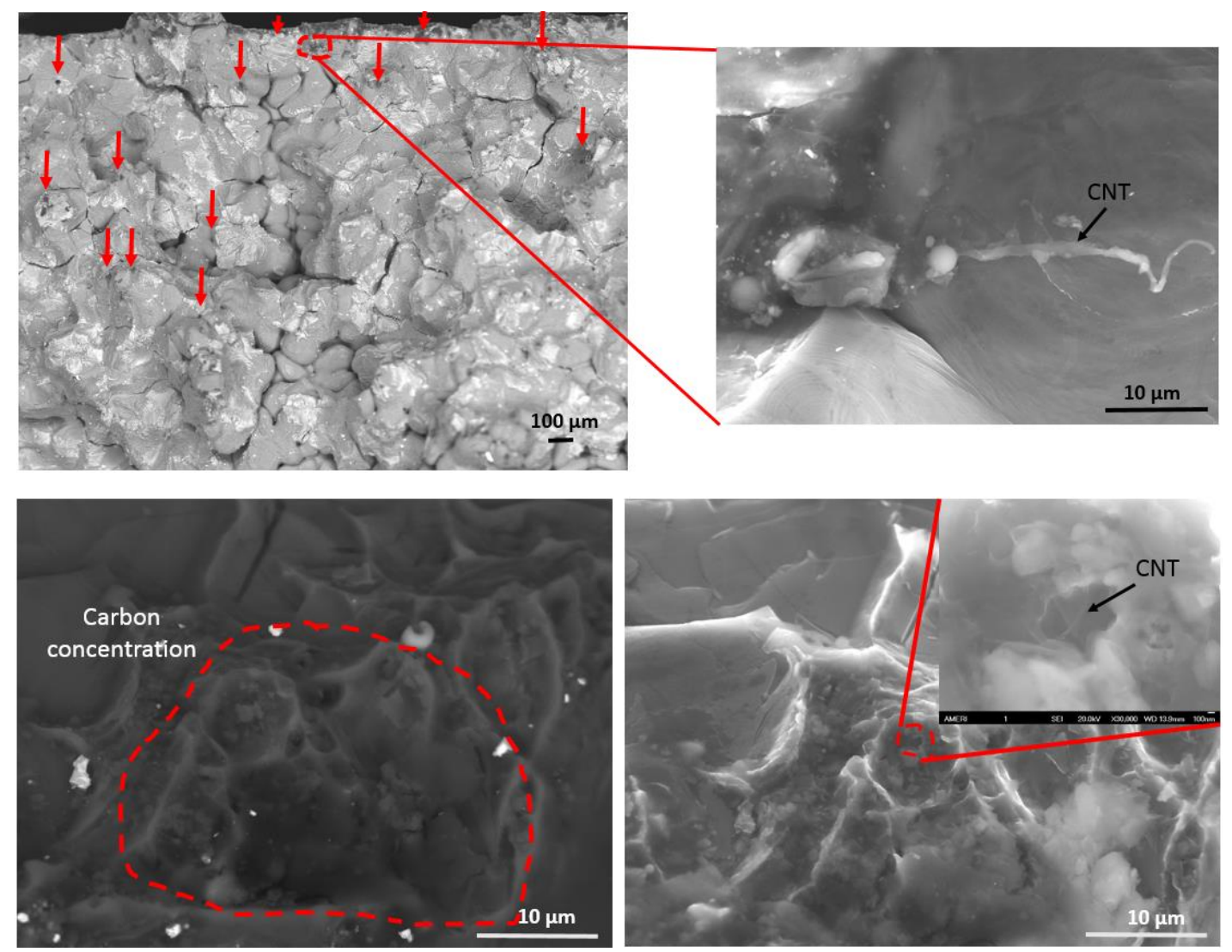

Figure 4. 45 Backscattering and SEM of Al-0.15wt. \% CNT fracture surface with UST

\subsubsection{Influence of reinforcements particles on microhardness of Al-0.15wt. \% CNT MMC as a function of UST}

The addition of CNT particles to the melt enhanced the refinement of the microstructure for specimens with and without UST. Due to the inverse relationship between grain size and micro hardness, increase in micro hardness was observed with the addition of CNT and UST to the casting process. Table 4.10 shows an overall increase in micro hardness of $12 \%$ for the sample with CNT and UST as compared with the base alloy (A16061 with UST). 
Table 4. 10 Micro hardness of Al- $0.15 \mathrm{wt}$ \% CNT as a function of ultrasonic treatment

\section{Micro hardness (MPa)}

Temperature $\left({ }^{\circ} \mathrm{C}\right)$

Amplitude $(\mu \mathrm{m})$

Time (s)
700

20

45

\begin{tabular}{lccc}
\hline & UST & 0.15wt. \% CNT & 0.15wt. \% CNT- \\
Al6061 & & UST \\
\cline { 2 - 4 } & & $757 \pm 61.98$ & $794 \pm 86.79$ \\
\hline
\end{tabular}

In addition, for samples with CNT and no UST, an increases in the micro hardness is reported (Figure 4.46) as compared with the base alloy (696MPa). However, due to the decreased survivable of CNT and the agglomeration of aluminum carbide particles formed from the reaction of $\mathrm{CNT}$ with aluminum, the improvement in microhardness for the sample without UST $(757 \mathrm{MPa})$ is not as good as the one obtained with the combination of CNT and UST (794MPa). 


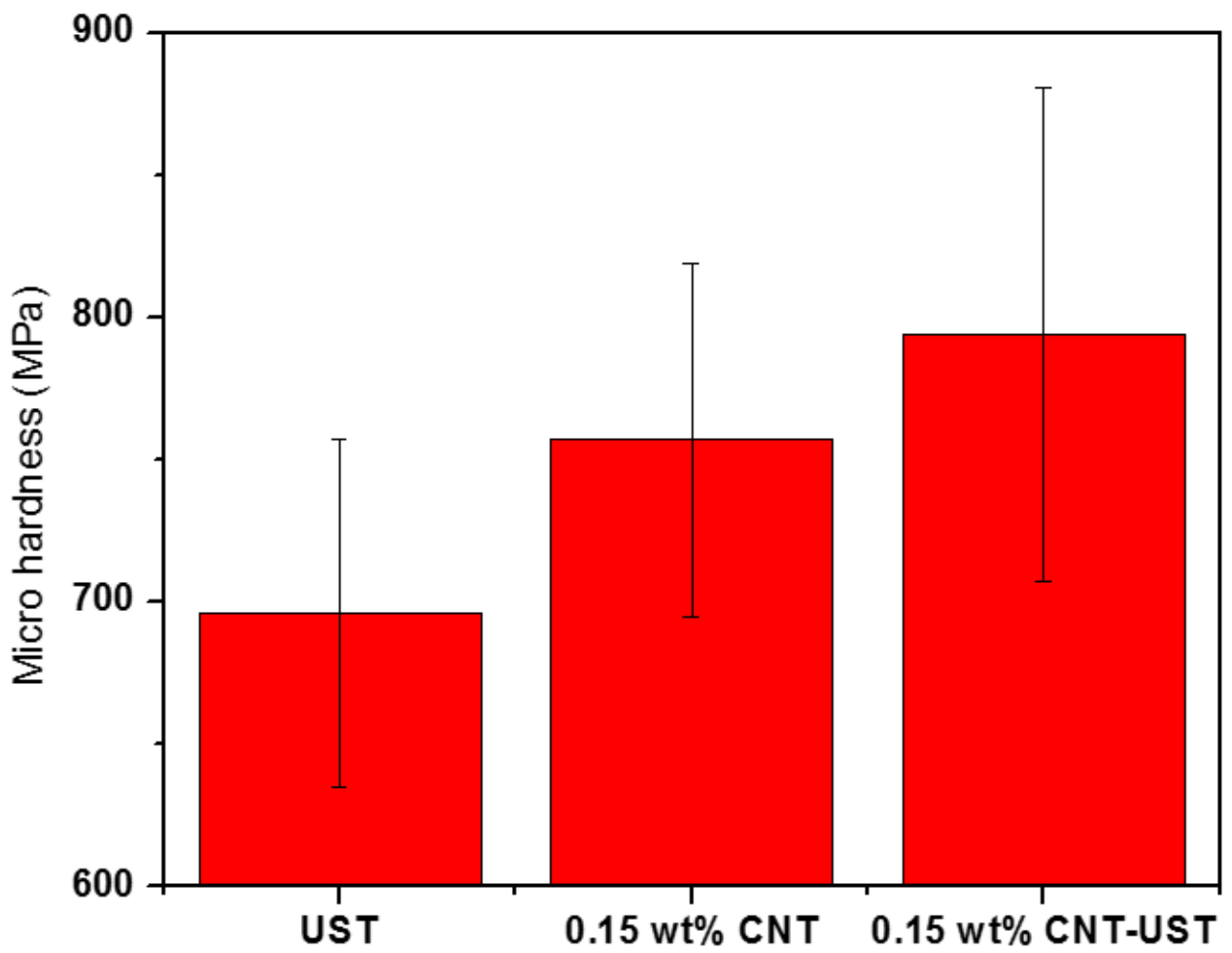

Figure 4. 46 Comparison of microhardness of Al 6061 with UST and Al-0.15wt. \% CNT with and without UST.

\subsubsection{Influence of reinforcements particles on wear behavior of Al-0.15wt. \% CNT $\underline{\text { MMC as a function of UST }}$}

In the same manner that was calculated for previous samples wear volume and COF of Al-0.15wt. \% CNT with and without UST was evaluated. As can been seen in Figure 4.45, the wear volume loss for Al-0.15wt. \% CNT with UST specimen is $0.07 \mathrm{~mm}^{3}$ and Al-0.15 wt. \%. CNT without UST is $0.08 \mathrm{~mm}^{3}$. Improvement of $13 \%$ in wear resistance was reported with the addition of UST due to the increase of microhardness on specimen treated with UST. 


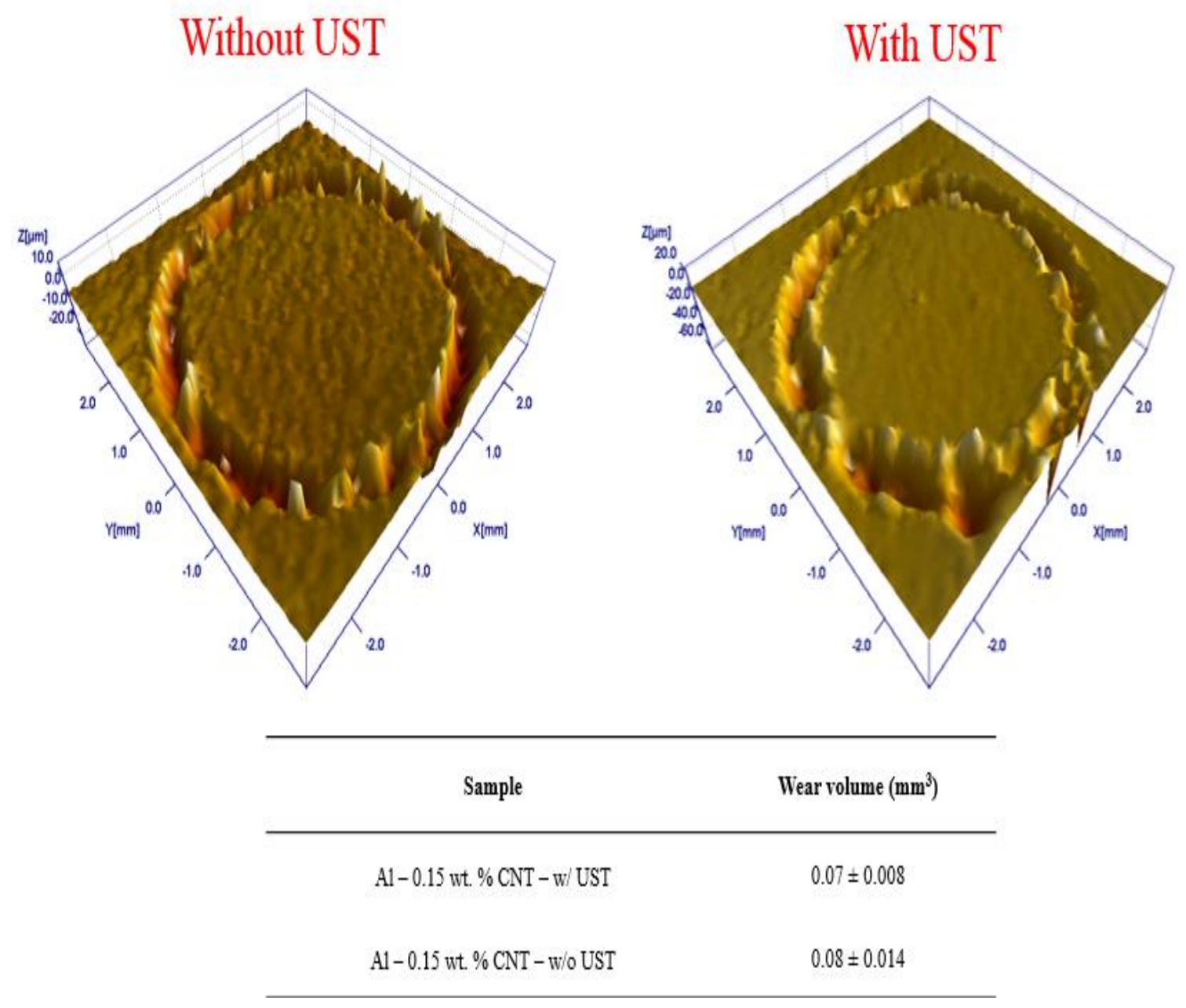

Figure 4. 47 3D optical profiles of wear tracks of Al-.015wt. \% CNT with and without UST

The coefficient of friction was computed for specimen with and without UST, the results present for both specimens a COF of 0.43 . By considering the standard deviation of the COF both samples are considered to have an almost similar lubricious effect (Figure 4.48). In addition, COF of Al6061 with UST also have the same value. Therefore, no lubricious effect is shown in COF. It is important to note that the addition of UST to the casting of CNT composite resulted in the enhancement of its wear resistance without affecting its lubricious properties. 


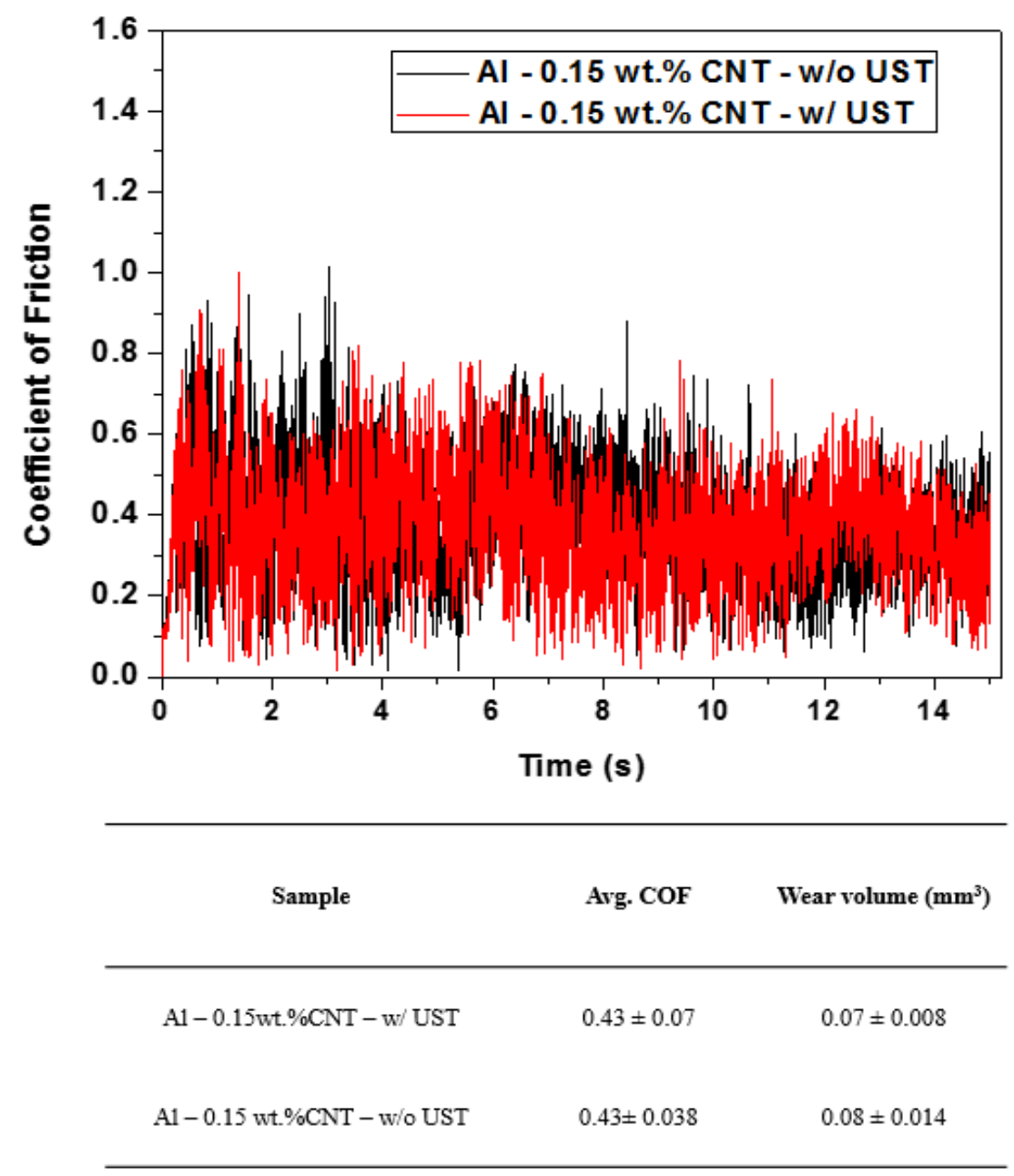

Figure 4. 48 Coefficient of friction for Al-0.15wt. \% CNT with and without UST

\subsubsection{SEM of the worn surface of Al-0.15wt. \% CNT MMC with and without UST}

To understand the wear mechanism, worn surfaces of specimens with and without UST were observed under SEM (Figure 4.49). The surfaces of both worn tracks have a rough appearance. Also, piled up of material was visible on the edge of the worn surface of specimen with and without UST. During the wear test the formation of cracks was visible in specimen without UST (Figure 4.49B) showing a brittle behavior of the composite. 
Crack formation are related to the large temperature differences between the heat generated from the high normal stress of the test and the sample surface.

The addition of UST to the casting process of Al-CNT composites resulted beneficial in the wear resistance of the material without affecting the lubricious properties of the composite. Therefore, the dominant wear mechanism in the Al- 0.15 wt. \% CNT with UST associated with volume loss is attributed to the increase in hardness of the composite.

SEM of the worn surface did not show evidence of CNT particles; this could be related to the low concentration on CNT added to the composite.
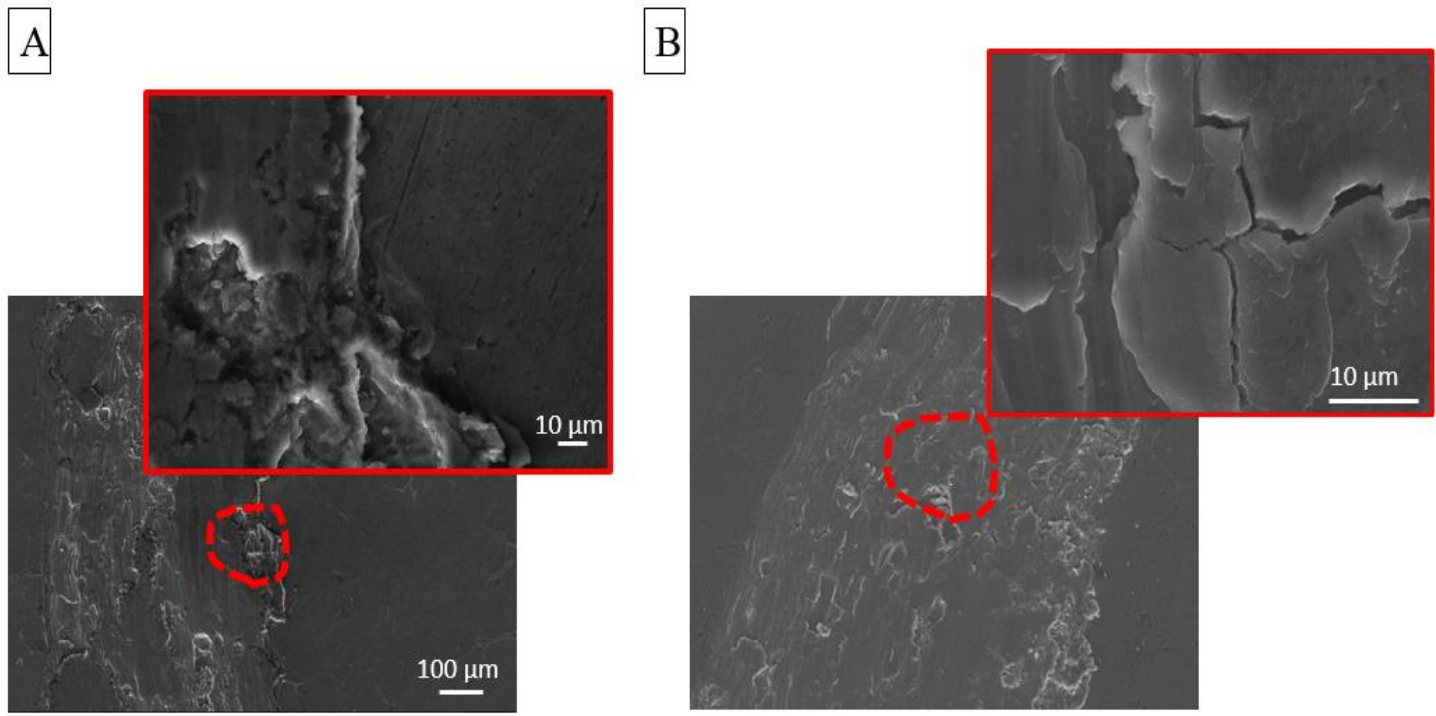

Figure 4. 49 SEM of worn surface of Al-0.15 wt. \% CNT (A) with UST, (B) without UST. From the parametric studies, the development of cavitation due to UST was mathematically and experimentally demonstrated. In addition, the effect of UST parameters on the degassing of the melt, grain refinement and microhardness was evidenced. Mayor improvement was obtained with the following ultrasonic processing conditions: 45 seconds of sonication time, 20 microns amplitude, and a melting 
temperature of $700{ }^{\circ} \mathrm{C}$. As a result, a reduction of porosity from $2.66 \%$ to $1 \%$ was obtained, $32 \%$ reduction on grain size and increase of $8 \%$ on hardness as compare with cast sample without UST.

MMCs were successfully manufactured, showing dispersion and wetting of the reinforcement particles. Agglomeration and poor wettability are the principal barriers for the incorporation of reinforcements to the metal matrix in the manufacturing of MMCs. The differences in surface tension between molten aluminum and reinforcement particles lead to high contact angles, making difficult the wetting of the particles with the matrix.

For better wetting between $\mathrm{Al}$ and reinforcement particles, higher values of surface energy are required. Usually substrates with higher surface energy held together by bonds, while substrate with lower surface energy are held together by forces. In comparison $\mathrm{WS}_{2}$ surface energy $(40 \mathrm{~mJ} / \mathrm{m} 2)$ is much lower than CNT $(100 \mathrm{mj} / \mathrm{m} 2)$ due to the fact that CNTs are held together by the covalent bound of its carbon atoms making these particles high energy substrates, while $\mathrm{WS}_{2}$ are held together by van der Waals forces which make them low energy substrates.

Based on Eq. 12, substrates with higher surface energy will reduce the contact angle between them and aluminum resulting on getting wet easily. Therefore, CNTs particles has better wetting with aluminum that $\mathrm{WS}_{2}$

In addition, for both MMCs (Al - 1 wt. $\% \mathrm{WS}_{2} \& \mathrm{Al}-0.15$ wt. \% CNT) wear resistance was improved without affecting the lubricious properties, this improvement is attributed to the increase of hardness in the UST treated samples. 


\section{CHAPTER V: CONCLUSIONS}

In this study, the addition of UST to the casting process to improve the mechanical properties of Al6061 and manufacture MMC was successfully accomplished. This work also studied the parameters of UST in order to optimize the process. The resulting microstructure and mechanical properties were also studied. The optimum conditions for UST with a maximum grain size reduction and increase in micro hardness was found for the following processing conditions: 45 second of sonication time, 20 micron of sonication amplitude and $700^{\circ} \mathrm{C}$ melting temperature. Also, MMC such as $\mathrm{Al}-1 \mathrm{wt} . \% \mathrm{WS}_{2}$ and $\mathrm{Al}-$ 0.15wt. \% CNT were successfully manufactured using UST as a dispersion technique for the reinforcement. The major findings of this study are:

- Grain refinement was observed with the addition of UST to the casting process. The average grain size at the ideal UST conditions decreases from $203 \mu \mathrm{m}$ to 138 $\mu \mathrm{m}$, representing a reduction of $32 \%$ in comparison with the sample cast at the same temperature without UST.

- Increase in sonication time, and amplitude resulted in more uniform microstructure. Samples with UST exhibited a microstructure with equiaxed dendritic structures and globular grains (non-dendritic). The refined microstructure results from the formation of excessive solidification sites restricting the growth of dendritic branches.

- Porosity was reduced until 1\% for the cast Al6061 with UST at ideal condition, as compare with the cast Al6061 without UST. 
- An increase of $8 \%$ in microhardness from $647 \mathrm{MPa}$ to $699 \mathrm{MPa}$, for the simple treated at optimum conditions of UST in comparison with the sample without UST.

- The cast Al6061 process with the addition of UST follows Hall-Petch relationship and is reported for the first time in the literature

- SEM showed superior dispersion of $\mathrm{WS}_{2}$ and CNT particles on the fracture surface with the addition of UST. Big clusters of particles were broke and particles were homogenously dispersed throughout the microstructure.

- Combination of UST and the addition of reinforcements such as $\mathrm{WS}_{2}$ and CNT results in the reduction of grain size and increases of microhardness. For Al -1wt. $\% \mathrm{WS}_{2}$, grain size deceases from $101 \mu \mathrm{m}$ to $98 \mu \mathrm{m}$ and micro hardness increases from $771 \mathrm{MPa}$ to $817 \mathrm{MPa}$. For Al-0.15 wt. \% CNT grain size deceases from 110 $\mu \mathrm{m}$ to $97 \mu \mathrm{m}$ and micro hardness increases from $757 \mathrm{MPa}$ to $794 \mathrm{MPa}$, as compared to its respective control sample without UST.

- The wear volume loss for Al-1wt. \% $\mathrm{WS}_{2}$ with UST specimen is of $0.069 \mathrm{~mm}^{3}$ and Al-1 wt. \% $\mathrm{WS}_{2}$ without UST is $0.072 \mathrm{~mm}^{3}$. The specimen with UST reports an improvement of $4.2 \%$ in wear resistance as compared with the one without UST. The coefficient of friction was 0.048 for the sample with UST and 0.042 for the one without UST.

- The wear volume loss for Al-0.15wt. \% CNT with UST sample is $0.07 \mathrm{~mm}^{3}$ and Al- 0.15 wt. \%. CNT without UST is $0.08 \mathrm{~mm}^{3}$. The specimen with UST reports an improvement of $13 \%$ in wear resistance as compared with the one without UST. The coefficient of friction was for both samples 0.043 . 


\section{CHAPTER VI: RECOMMENDATIONS AND FUTURE WORK}

The objective of this thesis was to study the effect of ultrasonic treatment parameters (amplitude, time and temperature) to the casting process of A16061 in order to determine the ideal conditions of UST. Also, these UST conditions were implemented for the manufacturing of $\mathrm{MMC}$ using $\mathrm{WS}_{2}$ and $\mathrm{CNT}$ as reinforcement particles. Based on the conclusion of this thesis, recommendations for future work are made as follow:

- Study longer periods of time and higher amplitudes to determinate if there is a limit where UST is no longer beneficial for the mechanical properties of the material.

- Carry out the casting process with UST in a protected atmosphere like Helium in order to prevent oxide formation.

- Evaluate the UST effect on the dispersion of larger quantities of reinforcement particles.

- Evaluate the UST effect on the dispersion of reinforcement particles with different morphology. 


\section{REFERENCES}

[1] Noboru Nakayama, Shota Sakagami, Masaomi Horita1, Hiroyuki Miki, Ayaka Takahashi, and Keizo Hashimoto, Fabrication of $\mathrm{WS}_{2}$ dispersed Al Composite Material by Compression Shearing Method at Room Temperature, Key Engineering Materials Vols. 622-623 (2014)

[2] Z.Y. Ma, S.C. Tjong, In situ ceramic particle-reinforced aluminum matrix composites fabricated by reaction pressing in the TiO2 (Ti)-Al-B (B2O3), Syst. Metall. Mater. Trans. A 28 (1997) 1931e1942.

[3] J.F. Jiang, Y. Wang, Microstructure and mechanical properties of the semisolid slurries and rheoformed component of nano-sized $\mathrm{SiC} / 7075$ aluminum matrix composite prepared by ultrasonic-assisted semisolid stirring, Mater. Sci. Eng. A 639 (2015) 350e358.

[4] B. Su, H.G. Yan, G. Chen, J.L. Shi, J.H. Chen, and P.L. Zeng, Study on the Preparation of the SiCp/Al-20Si-3Cu Functionally Graded Material Using Spray Deposition, Mater. Sci. Eng. A, 2010, 527(24), p 6660-6665

[5] S.M. Seyed Reihani, Processing of Squeeze Cast Al 6061-30 vol\% SiC Composites and Their Characterization, J. Mater. Des., 2004, 27(3), p 216-222

[6] D. Bozic, B. Dimcic, O. Dimcic, J. Stasic, and V. Rajkovic, Influence of SiC Particles Distribution on Mechanical Properties and Fracture of DRA Alloys, Mater. Des., 2010, 31(1), p 134-141

[7]P.M. De Cicco, X.C. Li, and L.S. Turng, Semi-solid Casting (SSC) of Zinc Alloy Nanocomposites, J. Mater. Process. Technol., 2009, 209(18-19), p 5881-5885

[8] N.J. Petch J. Iron Steel Inst., 174 (1653), p. 25

[9] Murty BS, Kori SA, Chakraborty M (2002) Int Mater Rev 47:3

[10] Davis JR (1993) Aluminum and aluminum alloys. ASM specialty handbook. ASM International, Metals Park

[11] Abramov OV (1994), Ultrasound in liquid and solid metals. CRC Press, Boca Raton

[12] Eskin GI (1998) Ultrasonic treatment of light alloy melts. Gordon and Breach Science Publishers, Amsterdam

[13] Campbell, John, ed. 2003. Castings. second edition ed: Butterworth Heinemann: London,Elsevier. 
[14] Chalmers, B., ed. 1964. Principles of Solidification. Vol. 319. New York: John Wiley and Sons.

[15] Czerwinski, F. 2005. Near-liquidus molding of $\mathrm{Mg}-\mathrm{Al}$ and $\mathrm{Mg}-\mathrm{Al}-\mathrm{Zn}$ alloys. Acta Materialia 53:1973-1984.

[16] D. Zhang, S. Jia, P. Allison, and L. Nastac, Numerical Modeling of the Dispersion of Ceramic Nanoparticles during Ultrasonic Processing of 6061-based Nanocomposites, Proceedings of the "Advanced Metal Casting Technologies" Symposium, MS\&T2014 Conference, A. Druschitz, L. Nastac, and P. Sanders, Ed., Pittsburgh, PA, October 12-16, 2014

[17] J.B. Ferguson, B.F. Schultz, P.K. Rohatgi and C.-S. Kim, Brownian Motion Effects on the Particle Settling and Its Application to Solidification Front in Metal Matrix Composites, Light Metals 2014, J. Grandfield, Ed., John Wiley \& Sons, Inc., 2014, p $1383-1388$

[18] B. Vijaya Ramnath 1 , C. Elanchezhian 1, RM. Annamalai1 , S.Aravind 1, T. Sri Ananda Atreya 1, V. Vignesh 1 and C.Subramanian 2, aluminium metal matrix composites - a review, Aluminium metal matrix composites - a review .Adv. Mater. Sci. 38 (2014) 5560

[19] Shian Jia, Daojie Zhang, Laurentiu Nastac, Experimental and Numerical Analysis of the 6061-Based Nanocomposites Fabricated via Ultrasonic Processing, Journal of Materials Engineering and Performance, June 2015, Volume 24, pp 2225-2233

[20] R. S. Rana, Rajesh Purohit, and S.Das, Review of recent Studies in Al matrix composites, International Journal of Scientific \& Engineering Research Volume 3, June2012

[21] Donthamsetty S., Damera N. R. Professor, Jain P.K., Ultrasonic Cavitation Assisted Fabrication and Characterization of A356 Metal Matrix Nanocomposite Reiforced with Sic, B4C, CNTs, AIJSTPME (2009), Volume 2, pages 27-34

[22] Hong Yan, Zhi-Xiang Huang, Hong-Xu Qiu, Microstructure and Mechanical Properties of CNTs/A356 Nanocomposites Fabricated by High-Intensity Ultrasonic Processing, Metallurgical and Materials Transactions A, February 2017, Volume 48, pp 910-918

[23] Y. Yang, J. Lan, and X.C. Li, Study on Bulk Aluminum Matrix Nano-composite Fabricated by Ultrasonic Dispersion of Nano-sized SiC Particles in Molten Aluminum Alloy, Mater. Sci. Eng. A, 2004, 380, p 373-378

[24] J.C. Yan, Z.W. Xu, L. Shi, X. Ma, and S.Q. Yang, Ultrasonic Assisted Fabrication of Particle Reinforced Bonds Joining Aluminum Metal Matrix Composites, Mater. Des., 2011, 2011, p 343-347 
[25] Sara Rengifo, Cheng Zhang, Sandip Harimkar, Benjamin Boesl, Arvind Agarwal, Effect of $\mathrm{WS}_{2}$ Addition on Tribological Behavior of Aluminum at Room and Elevated Temperatures, Tribol Lett (2017) Pages, 65-76

[26] Bhaskar Raju S A, A R K Swamy and A Ramesh, Mechanical and tribological behavior of metal aluminum metal matrix composites using powder metallurgy technique, Int. J. Mech. Eng. \& Rob. Res. 2014, Vol 3, 551-563.

[27] Dr. G. Mallesh, Manjunatha H. S , Pradeep Kumar V. G, Rakesh D. R, Mechanical and Tribological Properties of Aluminum Al6061 alloy Reinforced with SiCp, International Journal of Emerging Technology and Advanced Engineering, March 2015, Volume 5, pages 111-117

[28] Chernov, D.K. 1879. Zapiski Imperat. Russ. Teckhnich. Obshch., no. 1:1-24.

[29] Southin, R.T. 1966. J. Inst. Met. 94:401-7.

[30]Flemings MC (1974) Solidification processing. McGraw-Hill,New York

[31] L. Ma, F. Chen, G. Shu, J. Mater. Sci. Lett. 14 (1995) 649-650.

[32]G.I. Ėskin, D.G. Eskin, Ultrasonic Treatment of Light Alloy Melts, CRC Press, Boca Raton, Florida, 2015.

[33] Y. Tsunekawa, H. Nakanishi, M. Okumiya N. Mohi, Key Eng. Mater. 104-107 (1955) 215-224

[34]O.V. Abramov, High-intensity Ultrasonics: Theory and Industrial Applications, Gordon and Breach Science Publishers, Amsterdam, TheNetherlands,1998.

[35] J.C. Yan, Z.W. Xu, L. Shi, X. Ma, and S.Q. Yang, Ultrasonic Assisted Fabrication of Particle Reinforced Bonds Joining Aluminum Metal Matrix Composites, Mater. Des., 2011, 2011, p 343-347

[36] I.Tzanakis, G.S.B.Lebon, .D.G.Eskin, .K.A.Pericleous. Characterizing the cavitation development and acoustic spectrum in various liquids. Ultrasonics Sonochemistry Volume 34, January 2017, Pages 651-662

[37] I.Tzanakis, G.S.B.Lebon, .D.G.Eskin, .K.A.Pericleous, Characterization of the ultrasonic acoustic spectrum and pressure field in aluminum melt with an advanced cavitometer. Journal of Materials Processing Technology, Volume 229, March 2016, Pages $582-586$ 
[38] D.G. Eskin, K. Al-Helal, I. Tzanakis. Application of a plate sonotrode to ultrasonic degassing of aluminum melt: acoustic measurements and feasibility study. J. Mater. Process. Technol., 222 (2015), pp. 148-154

[39] D. Xu, W.K. Jones, J.W. EvansThe use of particle image velocimetry in the physical modeling of flow in electromagnetic or direct-chill casting of aluminum: part I. Development of the physical model. Metall. Mater. Trans. B, 29B (1998), pp. 1281-1288

[40] H. Xu, X. Jian, T.T. Meek, Q. Han, Degassing of molten aluminum A356 alloy using ultrasonic vibration, Materials Letters 58 (29) (2004) 3669.

[41] I. Gonçalves, C.Silva, A. Cavaco-Paulo, ChemInform Abstract: Ultrasound Enhanced Laccase Applications, Green Chem., 2015, 17, 1362

[42] H. Xu, T. Meek, Q. Han, Effect of ultrasonic field and vacuum on degassing of molten aluminum alloy. Materials Letters, Volume 61, Issues 4-5, February 2007, Pages 1246-1250.

[43]G.I. Eskin, Yu.P. Pimenov, G.S. Makarov, Mater. Sci. Forum. 242 (1997) 65.

[44] Y.Chen, W.Hsu, J.Shih, The Effect of Ultrasonic Treatment on Microstructural and Mechanical Properties of Cast Magnesium Alloys, Materials Transactions, Vol. 50, No. 2 (2009) pp. 401 to 408

[45] G.I. Eskin, Influence of cavitation treatment of melts on the processes of nucleation and growth of crystals during solidification of ingots and castings from light alloys, Ultrason. Sonochem., 1994, vol. 1, pp. 59-63.

[46] ..X.Jian. H.Xu, T.T.Meek, Q.Han, Effect of power ultrasound on solidification of aluminum A356 alloy, Materials Letters Volume 59, Issues 2-3, February 2005, Pages 190-193

[47] W. Khalifa, Y. Tsunekawa, and M. Okumiya: Int. J. Cast Metal. Res., 2008, vol. 21, pp. 129-34.

[48] G. Cho, H. Jang, K. Choe, W. Kim, Effect of Ultrasonic Treatment on the Microstructures and Mechanical Properties of Die Casting Aluminum Alloys, 2010, The Japan Institute of Light Metalspp. 1735-1739

[49] Trans. Nonferrous Met. Soc. China 24(2014) 2414-2419

[50] H.Puga et al./ Journal of Materials Processing Technology 211 (2011) 1729- 1735

[51] J.-G. Jung et al. / Materials Science \& Engineering A 669 (2016) 187-195 
[52] X. Jian et al. / Materials Letters 59 (2005) 190-193

[53] J.-G. Jung et al. / Journal of Alloys and Compounds 693 (2017) 201e21

[54] F. Wang, D. Eskin, J. Mi, T. Connolley, J.Lindsay, M. Mounib, A refining mechanism of primary Al3Ti intermetallic particles by ultrasonic treatment in the liquid state, Acta Materialia 116 (2016) 354-363

[55] F. Wang et al. / Journal of Crystal Growth 435 (2016) 24-30

[56] J. Lin et al. / Materials Chemistry and Physics, 178 (2016) 112-118

[57] Met. Mater. Int., Vol. 21, No. 1 (2015), pp. 72 78 doi: 10.1007/s12540-015-1008-6

[58] Trans. Nonferrous Met. Soc. China 24(2014) 76-81(Lashtabeg, Smart et al. 2013)

[59] Trans. Nonferrous Met. Soc. China 26(2016) 1826-1834

[60] Rare Metal Materials and Engineering, 2016, 45(6): 1401-1405

[61] Sonics, sonics \& materials, VCX-750 user's guide.

[62] A. Font, M. da Silva, M. Baile, J, Picas, Effect of ultrasound during the solidification process of the A357 aluminum alloy.

[63] G.I.Eskin Broad prospects for commercial application of the ultrasonic (cavitation) melt treatment of light alloys, Volume 8, Issue 3, July 2001, Pages 319-325

[64] X.Jian. H.Xua , T.Meek, Q.Han, Effect of power ultrasound on solidification of aluminum A356 alloy, Volume 59, Issues 2-3, February 2005, Pages 190-193

[65] T.V. Atamanenko, D.G. Eskin, L. Zhang, L. Katgerman, Criteria of Grain Refinement Induced by Ultrasonic Melt Treatment of Aluminum Alloys Containing $\mathrm{Zr}$ and Ti, August 2010, Volume 41, Issue 8, pp 2056-2066

[66] G.I. Eskin: Ultrason. Sonochem., 1994, vol. 1, pp. 59-63.

[67] M. Faraji, D.G. Eskin, and L. Katgerman: Giessereiforschung, 2010, vol. 62, pp. 205.

[68] L. Xin-Tao, L. Ting-Ju, L. Xi-Meng, and J. Jun-Ze: Ultrason. Sonochem., 2006, vol. 13, pp. 121-5.

[69] L. Zhang, D.G. Eskin, A. Miroux, and L. Katgerman: Light Metals, 2012, pp. 9991004. 
[70] L. Francis, A Unified Approach to Processing of Metals, Ceramics and Polymers, Materials Processing, Page 251-242

[71] N.J. Petch J. Iron Steel Inst., 174 (1653), p. 25

[72] T.G. Nieh, J. Wadsworth, Hall Petch relation in nanocrystaline solids, Vol. 25, pp. 955-958, 1991

[73] Razavi Tousi SS, Yazdani Rad R, Salahi E, Mobasherpour I, Razavi M. Production of Al-20 wt.\% Al2O3 composite powder using high energy milling. Powder Technol., 192, (2009), 346-351.

[74] Habibnejad-Korayem M, Mahmudi R, Ghasemi HM, Poole WJ. Tribological behavior of pure $\mathrm{Mg}$ and AZ31 magnesium alloy strengthened by A12O3 nanoparticles. Wear, 268, (2010), 405-412.

[75] Radi Y, Mahmudi R. Effect of Al2O3 nano-particles on the microstructural stability of AZ31 Mg alloy after equal channel angular pressing. Mater Sci Eng A, 527, (2010), 2764-2771.

[76] Wang HY, Jiang QC, Zhao YQ, Zhao F, Ma BX, Wang Y. Fabrication of TiB2 and TiB2-TiC particulates reinforced magnesium matrix composites. Mater Sci Eng A 372, (2004), 109-114.

[77] Guozhong Cao, Nanostructures \& nanomaterials: synthesis, properties \& applications, Imperial College Press, (2004).

[78] J D Fast, Interaction of Metals and Gases, Academic Press, (1965).

[79] J. Hashim, L. Looney, M.S.J. Hashmi, Metal matrix composites: production by the stir casting method, J. Mater. Process. Technol. 92-93, (1999) 1-7.

[80] J.A. Garcia-Hinojosa, R.C. González, I.J.A. Juárez, M.K. Surrapa, Effect of grain refinement treatment on the microstructure of cast Al-7Si-SiCp composites, Mater. Sci. Eng. A386, (2004), 54-60.

[81] S.Nimityongskul, N. Alba-Baena, H. Choi, M. Jones, T. Wood, M. Sahoo, R. Lakes, S. Kou, X. Li. Characterization of Hot Extruded $\mathrm{Mg} / \mathrm{SiC}$ Nanocomposites Fabricated by Ultrasonic Dispersion Casting, 2011, Volume 46, Issue 9, pp 2991-2997.

[82] N. Srivastava, G.P.Chaudhari, Strengthening in Al alloy nano composites fabricated by ultrasound assisted solidification technique, Materials Science and Engineering, Volume 651, 10 January 2016, Pages 241-247 
[83] H. Choi, N. Alba-Baena, S.Nimityongskul, M. Jones, T. Wood, M. Sahoo, R. Lakes, $\mathrm{S}$. Kou, X. Li, Characterization of hot extruded $\mathrm{Mg} / \mathrm{SiC}$ nanocomposites fabricated by casting, J Mater Sci (2011) 46:2991-2997

[84] G. Cao, H Konishi, X.Li, Mechanical properties and microstructure of SiC-reinforced Mg-(2.4)Al-1Si nanocomposites fabricated by ultrasonic cavitation based solidification processing, 2008, Materials science and engineering, volume 486, pages 357-362

[85] Y.Yang, J. Lan, X.Li, Study on bulk aluminum matrix nano-composite fabricated by ultrasonic dispersion of nano-sized $\mathrm{SiC}$ particles in molten aluminum alloy, 2004, Materials Sciences and Engineering, Vol 380, Pages 378-383.

[86] L.Poovazhagan, K.Kalaichelvan, A.Rajadurai, V.Senthilvelan, Characterization of Hybrid Silicon Carbide and Boron Carbide Nanoparticles-Reinforced Aluminum Alloy Composites, Volume 64, 2013, Pages 681-689

[87] W. W. Smeltzer, Oxidation of Aluminum in the Temperature Range $400^{\circ}-600^{\circ} \mathrm{C}$, Journal of the electrochemical society, 1955

[88] S. G. Srinivasan, X. Z. Liao, M. I. Baskes, R. J. McCabe, Y. H. Zhao, and Y. T. Zhu, Compact and Dissociated Dislocations in Aluminum: Implications for Deformation, Physical review letters - 94, 2005.

[89] A. Agarwal, R. Balasubramaniam, Hall-Petch behavior of stoichiometric $\mathrm{Fe}_{3} \mathrm{Al}$, Journal of materials sciences letters 16, 1997, pages 469-470

[90] P. Nautiyal, A. Gupta, S. Seal, B. Boesl, A. Agarwal, Reactive wetting and filling of boron nitride nanotubes by molten aluminum during equilibrium solidification, Acta Materialia, Volume 126, March 2017, Pages 124-131.

[91]A. Ghorai, A. Midya, R. Maiti, S. K Ray, Exfoliation of $\mathrm{WS}_{2}$ in Semiconducting Phase using a Group of Lithium Halides: a New Method of Li Intercalation, The Royal Society of Chemistry 2016

[92] Yu Huang, Qiubao Ouyang, Di Zhang, Jing Zhu, Ruixiang Li, Hong Yu. Carbon Materials Reinforced Aluminum Composites: A Review. Acta Metallurgica Sinica (English Letters), 2014, 27(5): 775-786 